Relationship of plankton and marine snow to hydrography and currents on the southwest portion of Georges Bank during June 1997

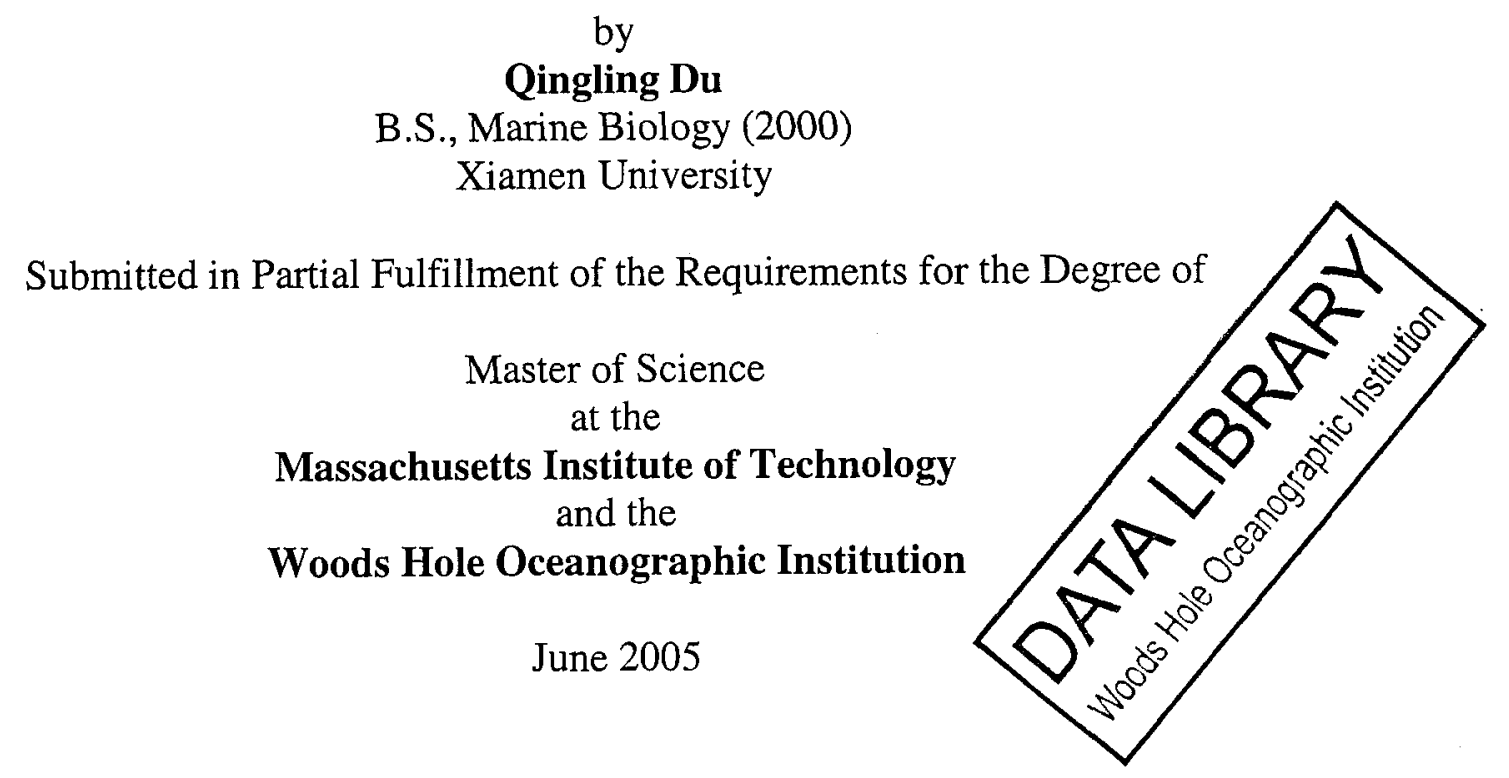

(C2005 Qingling Du

All Rights Reserved.

The author hereby grants to MIT and WHOI permission to reproduce paper and electronic copies of this thesis in whole or in part and to distribute them publicly.

Signature of Author

a

WHOI-MIT Joint Program/Biological Oceanography

MIT and WHOI

June, 2005

Certified by

Cabell Davis

Thesis Supervisor

Senior Scientist, Biology Department, WHOI

Accepted by

John B. Waterbury

Chair

Joint Committee for BiologicallOceanography, WHOI 
$-2-$ 


\title{
Relationship of plankton and marine snow to hydrography and currents on the southwest portion of Georges Bank during June 1997
}

\author{
by \\ Qingling Du
Submitted to the WHOI Academic Programs Office and to the Biology Department at MIT \\ Master of Science in Biological Oceanography
}

\begin{abstract}
A key question in biological oceanography is how plankton populations maintain themselves in regions of favorable growth and survival in the face of horizontal transport by ocean currents. Plankton are thought to be retained on the highly productive Georges Bank by the clockwise flow, which intensifies with vernal warming. The extent to which plankton are transported off the bank to the southwest or transported northward and retained on the bank remains poorly understood. This thesis examined the relationship between plankton and physical properties in the southwest corner of the bank, the retention-loss region (RLR). Analysis of field data (Video Plankton Recorder, Acoustic Doppler Current Profiler, and satellite-tracked drifters) and modeling results was performed to quantify the relationships between plankton, hydrography, and currents and the fluxes through the RLR. Temperature-salinity-plankton diagrams and factor analysis revealed that most plankton taxa had characteristic relationships to the hydrography, with the exception of copepods which were everywhere abundant. The flux of plankton during a complete tidal cycle and in the de-tided current data indicated this region was not retentive to plankton, since the bulk of the flow remained to the southwest, despite the presence of a vernally warmed surface layer. A Lagrangian particle trajectory model was used to further examine transport of plankton through the RLR during late spring /early summer (June) when vernal stratification was established. Passive particles were used, since no diel vertical migration by plankton was found in the data. The model revealed that the bulk of the plankton was carried out of the RLR through the southern and western boundaries. The modeling and data analysis show clearly that the plankton were lost from the bank to the southwest rather than being re-circulated to the north. These results have important implications for the plankton populations on Georges Bank and can be used in future modeling efforts that examine the factors controlling plankton populations in this region.
\end{abstract}

Thesis Supervisor: Cabell Davis Title: Senior Scientist 


\section{Contents}

Abstract

1.Introduction

2.Methods

2.1 Field surveys

2.2 Video Plankton Recorder System

2.3 ADCP and flux estimates

2.4 Satellite-tracked Drifters

2.5 Diel migration

2.6 Temperature-salinity diagram

2.7 Data display

2.8 Kriging

2.9 Temperature-Salinity-Plankton (T-S-P) plots

2.10 Factor analysis

2.11 Lagrangian particle trajectory modeling

2.12 Spectral Analysis

3.Results

3.1 T-S Properties, water masses and hydrographic features

3.2 Satellite SST imagery

3.3 Flow field: GPS-Model Drifters and ADCP

3.4 Diel Migration

3.5 Distributional patterns of plankton taxa

3.5.1 General abundance levels

3.5.2 The distribution of copepods

3.5.3 The distribution of Chaetoceros socialis

3.5.4 The distribution of rod-shaped diatom chains

3.5.5 The distribution of medusae

3.5.6 The distribution of marine snow

3.6 Fluxes of plankton taxa through the retention/loss region

3.7 Model predicted retention/loss of $C$. socialis

3.8 Power spectra of dominant variables.

3.9 Factor analysis

4.Dissussion

4.1 New technology

4.2 Plankton Distributions

4.3 Diel Vertical Migration

4.4 Water masses and plankton

4.5 Spectral Analysis

4.6 Retention-loss 


\subsection{Significance of results}

\section{References}

\section{List of figures}

Fig 1. Map of Georges Bank, defined by the $100 \mathrm{~m}$ isobath and the Great South Channel Fig 2. Map of the Retention Loss Region (RLR) on the southwest corner of Georges Bank Fig 3. T-S diagram for VPR 5-6, VPR 2-3 and VPR 7

Fig.4. VPR 2-3, twelve N-S sections for: A. temperature, B. salinity, C. density, and D. fluorescence

Fig.5 VPR 5-6, A. temperature, B. salinity, C. density, and D. fluorescence .

Fig. 6. VPR5-6, 3D-kriged distributions of temperature, fluorescence,density, and salinity Fig.7. VPR 7, twelve N-S sections for: A. temperature, B. salinity, C. density, and D. fluorescence

Fig. 8. Satellite image of sea surface temperature (SST) on June 11, 1997

Fig. 9. Satellite SST image sequence showing SW transport at $S$ boundary of the RLR.

Fig. 10A. GPS (red) and model (blue) drifter tracks, June 13-17.

Fig. 10B. Detided ADCP data from VPR5-6 survey (16 and $30 \mathrm{~m}), 14-16$ June

Fig.11A. Copepod vertical distribution (\#/liter, top panel) and normalized weighted mean depth (NWMD) (bottom panel) versus time for VPR4

Fig.11B. Medusae vertical distribution $(\log [\# /$ liter +1$]$, top panel) and normalized weighted mean depth (NWMD) (bottom panel) versus time for VPR4

Fig.12A. Copepods, along-track abundance, $\log 10(\# /$ liter +1$)$, and T-S-P plots from the three VPR surveys.

Fig. 12B. Copepod abundance, $\log 10(\# /$ liter +1$)$, in the twelve 2 -h sections of VPR2-3.

Fig. 12C. Copepod abundance, $\log 10(\# /$ liter +1$)$, in the twelve 2 -h sections of VPR7

Fig.13A. C. socialis, along-track abundance, $\log 10(\# /$ liter +1$)$, and T-S-P plots from the three VPR surveys

Fig.13B. C. socialis abundance, $\log 10(\# /$ liter +1$)$, in 2 -h sections for VPR $2-3$ and VPR7

Fig. 13C. VPR 5 (top 4 panels) and VPR 6 (bottom 4 panels), C. socialis abundance, $\log 10(\# /$ liter +1$)$, before (left) and after (right) model-correction for $3 \mathrm{D}$ advection during the tow. Fig. 14A. Rod-shaped diatom chains, along-track abundance, $\log 10(\# /$ liter +1$)$, and T-S-P plots from the three VPR surveys.

Fig. 14B. Rod-shaped diatom chains, abundance, $\log 10(\# /$ liter +1$)$, in the twelve 2 -h sections for VPR 2-3 (left panels) and VPR7

Fig. 14C. Rod-shaped diatom chains, abundance, log10(\#/liter+1), in VPR5 (top panels) and VPR6 (bottom panels) in the twelve 2-h sections for VPR 2-3 (left panels) and VPR7

Fig.15A. Medusae, along-track abundance, $\log 10(\# /$ liter +1$)$, and T-S-P plots from the three VPR surveys

Fig. 15B. Medusae abundance, $\log 10(\# /$ liter +1$)$, in 2-h sections for VPR 2-3 and VPR7.

Fig. 15C. Medusae abundance, $\log 10(\# /$ liter+1), in VPR5 (top panels) and VPR6 (bottom panels)

Fig.16A. Marine snow, along-track abundance, $\log 10(\# /$ liter +1$)$, and T-S-P plots from the three VPR surveys 
Fig. 16B. Marine Snow abundance, $\log 10(\# /$ liter+1), in VPR5 (top panels) and VPR6 (bottom panels)

Fig. 17. VPR2-3, A. Eastward ADCP current, and B. eastward flux of C. socialis (in 1000s of colonies $\mathrm{m}-2 \mathrm{~s}-1)$.

Fig.18. Total flux of $C$. socialis during the first 12-h tidal cycle of VPR 2-3

Fig 19A. Velocity vectors for kriged detided ADCP currents in VPR 5-6 at four different depths.

Fig 19B. Flux of copepods

Fig 19C. Flux of C. socialis

Fig. 19D. Flux of diatom rods

Fig 19E. Flux of medusa

Fig. 20.A Initial (black) and final (blue) C. socialis distributions from a $20 \mathrm{~d}$ model run.

Fig. 20.B The drifter tracks (Red) vs Model run (Black)

Fig. 21A. Power spectra for pressure, temperature, salinity, density, fluorescence and copepod abundances for the first two hours' section in VPR 7.

Fig. 21B. Same as Fig. 21A except for tow VPR 5-6

Fig. 21C. same as Fig. 21A except for tow VPR 7

\section{List of tables}

Table 1. Abundance (number per liter) of plankton observed during 5-s time bins. (VPR5-6).

Table 2. The mean flux of plankton taxa in the RLR from the VPR 5-6 survey

Table 3. Model-estimated retention and loss of $C$. socialis

Table 4. Eigenvalues from the principle component analysis for VPR 2-3

Table 5. Factor loading matrix for VPR 2-3

Table 6. Eigenvalues from the principle component analysis for VPR 5-6

Table 7. Factor loading matrix for VPR 5-6

Table 8. Eigenvalues from the principle component analysis for VPR 7

Table 9. Factor loading matrix for VPR 5-6

Table 10. Correlation coefficients table 


\section{Acknowledgements}

At this time, I would like to thank these specific individuals for their valuable contributions.

Firstly, I am very grateful for the advice and support of my advisor, Cabell Davis, for his guidance, insight, and patience throughout this endeavor without which this thesis would never have come to fruition.

Thanks to Dennis McGillicuddy for his support in providing the flow fields output from Quoddy Model(Dartmouth college Fininte Element Coast Ocean Model) and for his faith and trust in me to finish the thesis.

Thanks to Carin Ashjian, for her helpful discussion on research methods and also for her advice on writing the thesis.

Thanks to Glenn Flierl, for his comments and time that have greatly improved and clarified this work.

Thanks to Rubao $\mathrm{Ji}$, for his kind help in running the Lagrangian particle trajectory program and for sharing his modeling techniques.

Thanks to Qiao $\mathrm{Hu}$, for his advice on programming and mathematical methods.

Thanks to Fen, Yan, Jonathan, Hai and Gareth, for their support throughout my years at MIT and WHOI and always encouraging me to rise to the challenge.

Thanks for Ning's endless assistance and giving me the strength to carry on.

Thanks for Yang's standing by my side even when the hopes seemed to be gone.

Thanks to my brother, Sheng, for his support and encouragement, and for the countless number of phone calls which helped me relieve a great deal of stress.

Thanks to my parents, for bringing me into this world and for their love and faith in me.

Thanks for Woods Hole Oceanographic Institution Academic Program for providing the research funding. 


\section{Relationship of plankton and marine snow to hydrography and currents on the southwest portion of Georges Bank during June 1997.}

\section{Introduction}

A fundamental objective of biological oceanography is to understand the processes regulating the distribution and abundance of living organisms in the sea. Characterization of the distribution and abundance of zooplankton is particularly complex because these organisms inhabit a three-dimensional fluid environment. Abundance of marine zooplankton is controlled by a combination of physical and biological processes. Plankton are by definition passive drifters, with the term plankton coined by Victor Henson at the University of Kiel in 1887 from the Greek word "planktos", meaning "drifter" or "wanderer". Physical advection through wind, buoyancy, and tidally driven flows, is a dominant factor controlling plankton distributional patterns. Although plankton cannot swim effectively against horizontal currents, they can swim against the much weaker vertical currents in the sea and are well known to undergo seasonal and diel vertical migrations over distances of meters to 100 s of meters. This vertical swimming behavior can interact with physical transport to generate uneven distributions of plankton (Hardy, 1936; Evans, 1978; Lough and Trites, 1989) that combined with physical convergence can lead to dense aggregations of plankton in frontal regions. Dominant biological processes controlling plankton abundance include feeding, growth, reproduction and mortality. These biological processes in turn are impacted by water temperature, turbulence, and predator/prey interactions.

Changes in the recruitment of zooplankton and fish are determined during their early planktonic life stages (Hjort, 1914; Davis et al., 1987a; GLOBEC, 1991a,b, 1992). Hence, the investigation of physical and biological processes affecting those early stages will shed light on the factors controlling recruitment and the potential impact of climatic change. The US GLOBEC (GLOBal ocean ECosystems dynamics) Georges Bank Program was designed to investigate how these processes control the population 
dynamics of the target taxa including pelagic stages of cod (Gadus morhua) and haddock (Melanogrammus aeglefinus) as well as the dominant copepods, Calanus finmanchicus and Pseudocalanus spp., which are primary prey for early life stages of the fish larvae (GLOBEC, 1991a,b, 1992). The overall goal of the GLOBEC Georges Bank Program is to determine the processes controlling the abundance of these species on the bank.

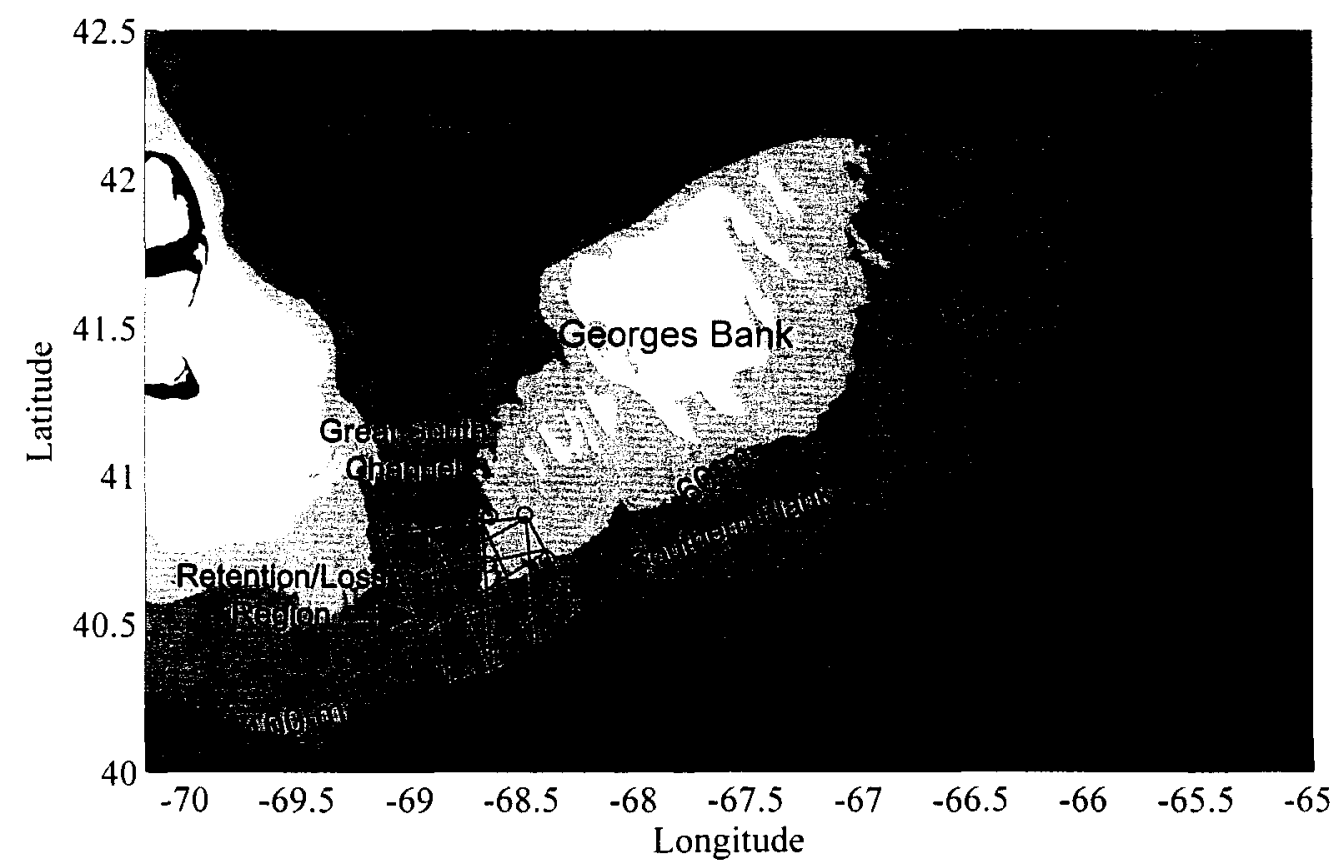

Figure 1. Map of Georges Bank, defined by the $100 \mathrm{~m}$ isobath and the Great South Channel (i.e., $-69^{\circ}$ longitude). The study area in the Retention Loss Region (RLR) is demarcated by sampling tracks for VPR5 and 6 (black lines). Open circles denote locations of moored current meters.

Georges Bank is a shallow submarine bank on the southern edge of the Gulf of Maine (Fig. 1). It is marked by clockwise residual circulation gyre (Butman, 1987) which is sensitive to climatic change (Green et al., 2003). This physical recirculation pattern enables distinct populations to develop and persist for long periods, and allows for timeseries studies such as to investigate the seasonal changes in distribution and abundance of plankton (GLOBEC, 1991b, 1992). The partially closed circulation pattern together with tidal mixing and cross-frontal exchange of nutrients makes Georges Bank one of the most productive shelf ecosystems in the world (Wiebe et al., 1996). The circulating gyre is 
only partially closed during late spring and summer, with recirculation occurring from the southern flank to the northern edge along the western end of the bank (Butman et al., 1987) while some parcels of water continue flowing southwestward to the Mid-Atlantic Bight along the southern flank (GLOBEC, 1992).

It is believed that copepod populations on the bank originate mainly in the Gulf of Maine to the north. Populations may be partly advected onto the bank along the northern edge (Davis, 1982, 1987b; Meise and et al., 1996). Advection subsequently spreads populations around the bank onto the southern flank and into the southwestern corner of the bank. Some retention on the bank occurs by recirculation along the southwestern edge (Limeburner and et al., 1996; Manning and et al., 1996), but the extent of retention of plankton on the bank in this region has not been directly measured. The bank is divided into several distinct regions, defined by hydrographic characteristics and structure. A tidal mixing front separates the shallow well-mixed region on the bank crest from the deeper stratified regions of the bank on the flanks. The strength of this tidal front increases with seasonal stratification as does the intensity of the around-bank advective flow. A permanent shelf-slope front along the southern edge of the Georges Bank separates the southern flank water from the Slope Water to the south (Flagg, 1987; GLOBEC, 1992). A certain amount of water flowing to the southwest along the southern flank of the bank continues to flow westward into the Mid -Atlantic Bight (GLOBEC, 1992). Thus, this southwestern corner of Georges Bank is likely to be a key region where plankton and particles are either loss or retained. Quantifying the abundance and distribution of the dominant plankton in this region in relation to the hydrographic structure and currents will shed new light on the processes controlling plankton in this area and the extent to which this region serves to retain plankton on Georges Bank.

Georges Bank zooplankton is dominated during winter/spring by the boreal copepods Calanus and Pseudocalanus and during summer/fall by the warm-water copepods 
Centropages, and Paracalanus, with Oithona abundant year around (Davis, 1987b; Sherman et al, 1987). Dominant planktonic predators include jellies, chaetognaths, predatory copepods, mysids, and decapods (Davis, 1987b). Pteropods, larvaceans, and polychaetes also can be very abundant (Gallager et al., 1996; Norrbin et al., 1996). During spring, the phytoplankton community is dominated by diatoms, including: Chaetoceros chains (e.g. C. decepians), coils (C. debilis), and colonies (C. socialis), and various rod-shaped chain diatoms (Cura, 1987). In addition to plankton, marine snow is widespread and very abundant on the bank (e.g. Ashjian et al., 2001). Marine snow particles can be formed from large gelatinous sources such as cast larvacean houses and decaying $C$. socialis colonies, or can form as aggregates of smaller particles, including phytoplankton cells, zooplankton fecal material and other detritus. Most organic components of marine snow are consumed by microbes, zooplankton and other filterfeeding animals (Kiorboe, 2001). Studying these plankton population fluxes will help us better understand the mechanisms of how plankton are dispersed and recruited in the Bank system as well as the controlling processes that impact on the food availability to the early life stages of cod and haddock.

The major focus of the GLOBEC Georges Bank Program in 1997 was to determine how the large scale circulation in the Georges Bank/Gulf of Maine region affects the source, retention, and loss of plankton from the bank (GLOBEC, 1992). In this thesis, data analysis and modeling results are used to determine the relationship of plankton and associated environmental variables in the southwest corner of Georges Bank and the extent to which this region retained plankton on the bank during the spring/summer period.

\section{Methods}


As part of the overall GLOBEC effort to study source-retention-loss of plankton on Georges Bank, an intensive process-oriented field study was conducted in the "retentionloss region" RLR (southwest corner) of the bank to measure the association of plankton, hydrography, and currents in this region and determine the extent to which this area retains plankton populations on the bank (Ashjian and Davis, 1997). The study was conducted aboard the $R / V$ Endeavor (cruise EN302, June 9-22, 1997). This study used a combination of sampling methods including the Video Plankton Recorder (VPR), Acoustic Doppler Current Profiler (ADCP), and satellite tracked drifters.

\subsection{Field Surveys}

Five consecutive VPR surveys were carried out during the cruise (Fig. 2) (Ashjian and Davis, 1997) including:

1) VPR2_3, a 24-hour towyo section along the eastern side of the RLR (Fig. 2, red line). This $\mathrm{N}-\mathrm{S}$ section took 2 hours to complete and was repeated 12 times during the 24-h period. The purpose of this survey was to quantify the flux of plankton into the RLR from the Southern Flank of the bank.

2) VPR4, a 24-hour towyo around a drifter within the RLR to measure the diel vertical migration of plankton (Fig. 2, green line),

3) VPR5, a N-S oriented zigzag survey mapping the interior of the RLR (Fig. 2, black line),

4) VPR6, an E-W oriented zigzag survey mapping the interior of the RLR (Fig. 2, black line), and

5) VPR7, a 24-h E-W towyo along the northern side of the RLR (Fig. 2, blue line), designed to measure the northward flux out of the RLR. 


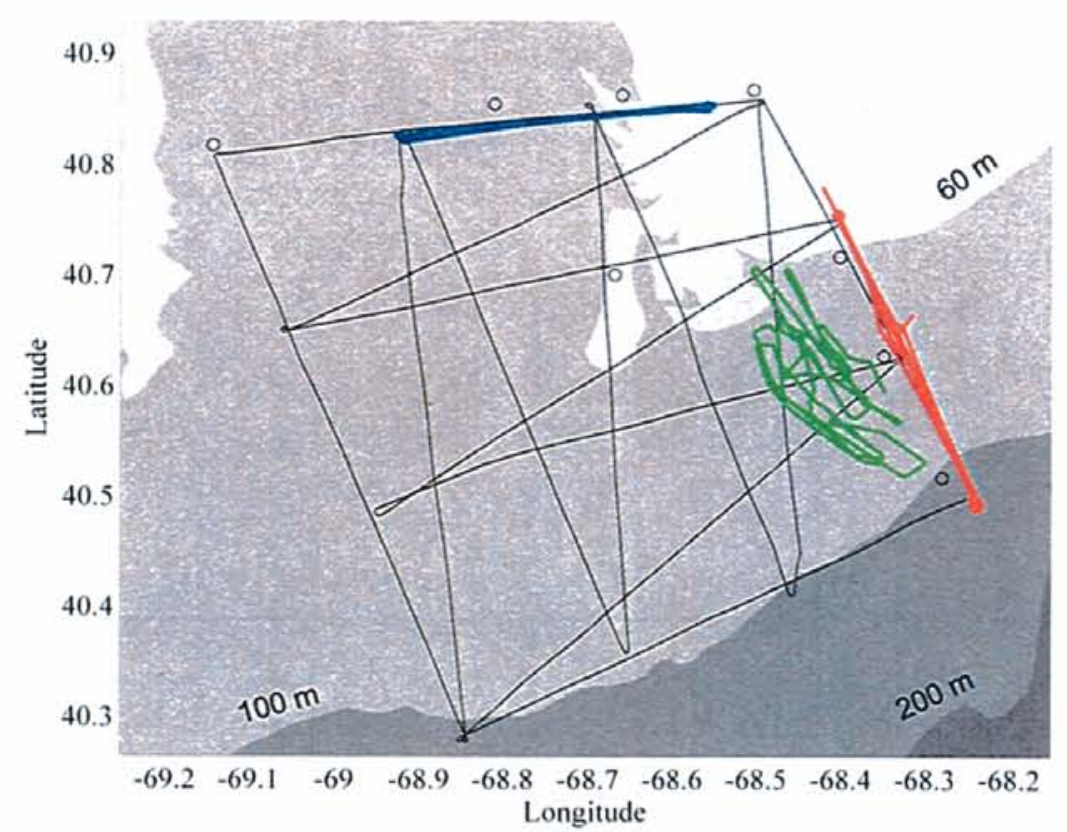

Figure 2. Map of the Retention Loss Region (RLR) on the southwest corner of Georges Bank. Sampling tracks for VPR2_3, VPR4, VPR5_6, and VPR7 are represented by red, green, black, and blue lines, respectively. VPR5 is the N-S zigzag survey, and VPR6 is the E-W zigzag survey. Open circles denote locations of moored current meters.

\subsection{Video Plankton Recorder System}

The VPR quantifies the abundance of major planktonic taxa and associated environmental variables (CTD, fluorescence, turbidity, and PAR) with high-resolution over a broad range of spatial scales $\left(10^{-1}-10^{6} \mathrm{~m}\right.$ ) (Davis et al., 1992a, b, 1996, 2004, 2005). The VPR represents a powerful tool for rapid surveys of the micro- to mega-scale structure of zooplankton assemblages either alone, or in conjunction with other sampling techniques (Davis et al., 2005). Plankton abundances obtained using the VPR are similar to those observed using conventional net systems (Benfield et al., 1996; Broughton and Lough, submitted). For example the VPR has been found to yield data on the taxonomic composition of plankton dominated by copepods (Calanus, Pseudocalanus, Oithona), pteropods (Limacina) and larvaceans (Oikopleura) (Benfield et al., 1996). Although the VPR may not differentiate different species or different life stages within a species 
(Benfield et al., 1996; Davis et al., 2004), the instrument is able to differentiate between major planktonic taxa (e.g., copepods, medusae, diatoms etc.) and can distinguish species in some cases. The VPR works much more effectively than traditional net systems to describe the abundances and distributions of fragile or gelatinous taxa, because the instrument samples non-invasively (Norrbin et al., 1996). Full description of the VPR data acquisition, analysis, and display systems used during the 1997 surveys is given elsewhere (Davis et al., 2004).

Video tapes were analyzed for plankton abundances using the Visual Plankton software to obtain automatic classification. For VPR7 all the images in the tow had been previously manually sorted (Davis et al., 2004; $\mathrm{Hu}$ and Davis, in press). For other tows, the automatic identification system was used. In addition to taxonomic identification, the size measurement of each organism was obtained in three steps: 1) convert the particle image pixels to particle area $\left.\left(\mathrm{mm}^{2}\right), 2\right)$ assume the organism has a spherical shape, so its radius is determined by the square root of the bug area divided by $\pi, 3$ ) estimate equivalent spherical volume in cubic millimeters: bug volume $=$ particle area $*$ particle radius $* 4 / 3$. For biomass, the density of plankton is assumed to be near unity for the wet mass conversion so that organism volume times $10^{6}$ gives microliters or micrograms wet weight. Carbon then is estimated as $10 \%$ of wet weight since dry weight is about $30 \%$ of wet weight and carbon is about $30 \%$ of dry weight (Davis et al., 1985). Plankton and particle observations were merged with environmental and navigational data by binning the observations for each category into the time intervals. For plankton, the number or mass of individuals in a given taxon observed during each 10-s interval was divided by the volume imaged during the interval in liters to obtain abundance in number/liter or biomass in $\mu \mathrm{gC} /$ liter. Since video fields were acquired at $60 \mathrm{~Hz}$ and the image volume per field was $0.5 \mathrm{ml}$, the volume imaged per $10 \mathrm{~s}$ was 0.3 liters.

Although the sampling volume of the VPR is much smaller than that of plankton nets, the VPR can still provide a good estimate of plankton abundances (Davis et al., 2005). VPR sampling is like a subsample taken along the towyo track of a plankton net. Plankton net 
tows spaced 2-km apart. The 2-km tows by plankton net are to estimate plankton abundance over the scale of the station spacing (e.g. $20 \mathrm{~km}$ ), while the VPR tows along the same survey line $(20 \mathrm{~km})$ could count 1,000 to 10,000 organisms. We can see that VPR provide a better estimate in particle abundance in the scale of the station spacing whether for total numbers of particles counted or for length of tow (Davis et al., 2005).

\subsection{ADCP and flux estimates}

An ADCP was used to obtain the required vertical profiles of the velocity field as a function of ship position. The ADCP is a current measuring instrument employing the transmission of high frequency acoustic signals in the water. The current is determined by a Doppler shift in the backscatter echo from plankton, suspended sediment, and bubbles, all assumed to be moving with the mean speed of the water. The ADCP used in this study was hull-mounted and downward facing with four transducer heads aimed in orthogonal directions.

ADCP data (eastward-westward velocity $u$ and northward-southward velocity $v$ ) were collected every five minutes at 4-m depth intervals from $16 \mathrm{~m}$ down to near bottom or a maximum of $216 \mathrm{~m}$ (50 bins). The Video Plankton Recorder (VPR) was used together with the ADCP data to quantify the flux of the plankton and marine snow through the RLR. The flux of plankton is given by the product of their concentration and the current magnitude and direction. In this application, the VPR serves as tool for measuring the concentrations of plankton with high resolution. The ADCP data collected during the VPR2_3 deployment were analyzed as separate 2-hour sections, corresponding to the repeated sections across the south flank from the mixed area to the slope water (Fig. 2). Each 2-hour section of ADCP data was mapped to a regular grid using the kriging program EZKrig developed by D. Chu (WHOI AOPE). Likewise, the plankton concentrations determined from the VPR during each section were kriged using the same grid as the ADCP. The eastward flux through each section then was computed as the product of abundance and eastward velocity, negative values indicating a westward flux. 
The net flux over 24-hours was determined by integrating the 2-h fluxes within each grid cell. A similar approach was used for the N-S flux through the E-W section sampled on the north side of the RLR during VPR7. For the VPR5_6 grid, which sampled the interior of the RLR, the ADCP data was detided (using a routine developed by Julio Candela) and used together with the corresponding VPR plankton concentrations to approximate the residual fluxes of the organisms through the region. In the latter case, the ADCP and VPR data first were kriged to a standard regular 3D grid, so that the fluxes could be computed directly as the product of the velocity and abundance. Flux of taxa will vary in magnitude with both abundance and velocity but in direction only from velocity.

\subsection{Satellite-tracked Drifters}

Lagrangian drifters were used to estimate the transport through the RLR. Six GPS/ARGOS drifters were deployed on the N-S transect line of VPR2_3 (the input side of the RLR) at the 65,75 , and $85 \mathrm{~m}$ isobaths. Two drifters were deployed at each of these three locations, with one drifter drogued at $10 \mathrm{~m}$ and the other at $30 \mathrm{~m}$ using holy sock drogues. The drifters were tracked using VHF and ARGOS satellite. These drifters were retrieved after 3-5 days.

\subsection{Diel migration}

VPR 4 was designed to investigate the diel changes in the vertical distribution of taxa in the water column. Such behavior, if found, would affect plankton transport in a vertically sheared flow field. This tow was a 24 hour survey around the 3 drifter pairs. Plankton abundance data first were separated into day and night portions. At this season and latitude, data from 09:00 to 15:00 were selected as the observations in daytime and data from 21:00 to 03:00 as nighttime. Within each of these two 6-h data portions, the data were further subdivided into individual towyos (i.e., individual down-ups) by finding the time when the VPR reached the top of each undulation. The weighted mean depth of the 
vertical distributions of each undulation was obtained for each taxon by the following equation (Ashjian et al., 2001):

Mean depth $=\sum_{i=1}^{J} N_{i} \cdot D_{i} \cdot \mathrm{d} z_{i} / \sum_{i=1}^{J} N_{i} \cdot \mathrm{d} z_{i}$

Where, $J$ is the total number of data points ( $J$ concentrations of organisms at $J$ depths). $N_{i}$ is abundance of organisms corresponding to the $i^{\text {th }}$ data point while $D_{i}$ is the depth of the $i^{\text {th }}$ point and $\mathrm{d} z_{i}$ is the depth interval. $N_{\text {total }}$ is the total number of plankton or particles for that subdivision. The weighted mean depth of the vertical distributions of each subdivision is normalized by dividing by the mean of bottom depth (each data point corresponding to a bottom depth).A t-test was employed to ascertain whether the normalized weighted mean depths within a region were significantly different from 0.5 (Zar, 1974).

\subsection{Temperature-salinity diagram}

Temperature-salinity properties were used to characterize the water in the RLR. T-S diagrams, in which the two properties are plotted against each other, were utilized to classify and analyze the different water masses (Flagg, 1987). Source water types are TS-points representing, to some extent, water masses as they exist in their formation region. But water mass properties are not constant in time because of variations in forcing since the time of water mass formation. Thus, each water mass was differentiated by clustering an area instead of selecting one point in T-S space (one point in T-S diagram represents a water mass in theory).

\subsection{Data display}

The irregularly spaced distributional data from the VPR were mapped to a regular grid using an inversed distance method (NCAR Zgrid routine) and displayed using curtain plots in Matlab. The data also were mapped to regular grids using kriging (see kriging section). The VPR data also were examined using temperature-salinity-plankton (T-S-P) 
plots. The curtain plots were used to show the along-track vertical distribution of the different variables. The curtain plots were generated by first obtaining the values of a given variable at 10 -second intervals along the VPR tow paths (Davis et al., 1996). The corresponding latitude, longitude, and depth of these data points then were found from the navigational and pressure-sensor data.

\subsection{Kriging}

Sectional kriging was performed on data for several environmental variables (temperature, salinity, density, fluorescence). Software developed in Matlab by Denzang Chu (WHOI) was used for kriging, and the results were saved for subsequent customized plotting. Data were saved in depth-specific files with columns for latitude, depth and variable value. Each of these data files for each variable was read into the kriging program at a time. A variogram then was generated and a function fit via least squares to the variogram (inverse of correlogram). Standard kriging then was performed and the kriged data, together with the parameter values and correlogram data were saved as a Matlab binary file for subsequent generation of the particular plots.

\subsection{Temperature-Salinity-Plankton $(T-S-P)$ plots}

To further examine the association of the plankton with the different water mass types in the transects, temperature-salinity-plankton (T-S-P) plots are presented (Michel et al., 1976). These plots were generated directly from the binned data by plotting plankton abundance as a colored dot at each temperature-salinity point. Dot diameter and color was linearly related to abundance.

\subsection{Factor analysis}

Here principal components analysis was utilized as a data dimensionality reduction method, that is, as a method for reducing the number of linearly dependent variables. In order to let the individual variables have equal weight in their influence on the underlying 
variance-covariance structure, the data are normalized before analysis (because the data are in different units). In the resulting correlation matrix, the variances of all variables are equal to 1.0. The total variance of the data set is equal to the trace of the covariance matrix, which is also equal to the sum of the eigenvalues (the trace of the diagonal matrix containing the eigenvalues). Using this method the proportion of the total variance accounted for by the individual principal components is known. The factors were ordered according to the proportion of the variance of the original data that these factors explain. Then factors that account for most variances are extracted. Only a small subset of factors was kept for further consideration and the remaining factors were considered as either measurement error or noise. Only factors with eigenvalues greater than 1 were retained (Kaiser, 1960). In essence unless a factor extracts at least as much as the equivalent of one original variable, it is rejected. The retained factors were rotated by the Varimax method after selecting the most significant factors. Varimax rotation is an orthogonal rotation of the factor axes to maximize the variance of the squared loadings of a factor (column) on all the variables (rows) in a factor matrix, which has the effect of

differentiating the original variables by extracted factor. That is, it minimizes the number of variables that have high loadings on any one given factor. Each factor will tend to have either large or small loadings of particular variables on it. Also the part of variance explained by the total subspace after rotation is the same as it was before rotation although the partition of the variance has changed, since the new axes always explain less variance than the original factors (Davis, J.C., 1986; Reyment et al., 1993).

\subsection{Lagrangian particle trajectory modeling}

Results of numerical modeling runs (done by R. Ji) were analyzed to examine the transport of plankton particles through the RLR. The flow fields were derived using an advanced dat assimilative model described in Lynch's papers (Lynch et al.,1998; 2001). The basic approach is to assimilate the observed ADCP data to invert for a sea level boundary condition that minimizes the difference between observed and predicted 
velocities in the interior. Flow fields output were interpolated to Chen's FVCOM model grid in order to be compatible with existing tracking/dealiasing programs developed for FVCOM output analysis. The Quoddy flow-field data was in binary format (produced in SGI machine) and was changed in word length (from big endian to small endian) using program "swap". The 20 original sigma layers in Quoddy output were interpolated into 50 standard layers ( 2 meters each layer). In order to obtain a preliminary assessment of paths and time scales of water parcel movement, a Lagrangian particle trajectory program was incorporated into FVCOM (Chen et al., 2003). The technique was originally developed by Chen and Beardsley (1998) and coupled with ECOM-si. It was subsequently modified by (Zheng, 1999). In this program, particle trajectories are traced by solving the equation,

$$
\frac{d \vec{x}}{d t}=\vec{v}(\vec{x}(t), t)
$$

where $\vec{x}(t)$ is the particle position at a time $t$, and $\vec{v}$ is the velocity interpolated from the surrounding model grid points. Horizontally the velocity is interpolated using a least squares method based on velocities at four adjacent cell points, while a linear interpolation is used in the vertical. The equation is solved by a classical 4th order 4-stage explicit Runge-Kutta method with a time step of 1 minute and a truncation error of the $\operatorname{order}(\Delta t)^{5}$.

The model was run for twenty days. A box area was constrained by the border of the RLR defined by the boundary of the VPR 5-6 survey (Figs. 1,2). Particles were input into the model at the $x, y, z, t$ points corresponding to the space-time points of individual plankton images observed by the VPR. Separate model runs were made for the inlet (VPR2_3), interior (VPR5, VPR6), and outlet (VPR7) regions of the RLR. Particles remaining in the RLR were defined as undetermined. Particles leaving the RLR to the north were counted as retained on Georges Bank, while those leaving the RLR to the 
south or west were counted as lost from the bank. No vertical migration behavior was used (or observed, see Results).

\subsection{Spectral Analysis}

Power spectra for temperature, salinity, density, fluorescence, pressure and the abundance of plankton and marine snow were computed to determine the dominant scales of variability for these properties. The data were normalized by subtracting the mean and then divided by the standard deviation. The MATLAB routines PSD (Power Spectral Density) and FFT (Fast Fourier Transform) were used for spectral analysis. This analysis was intended to shed light on the dominant factors that influence the distribution of plankton.

\section{Results}

\subsection{T-S Properties, water masses and hydrographic features}
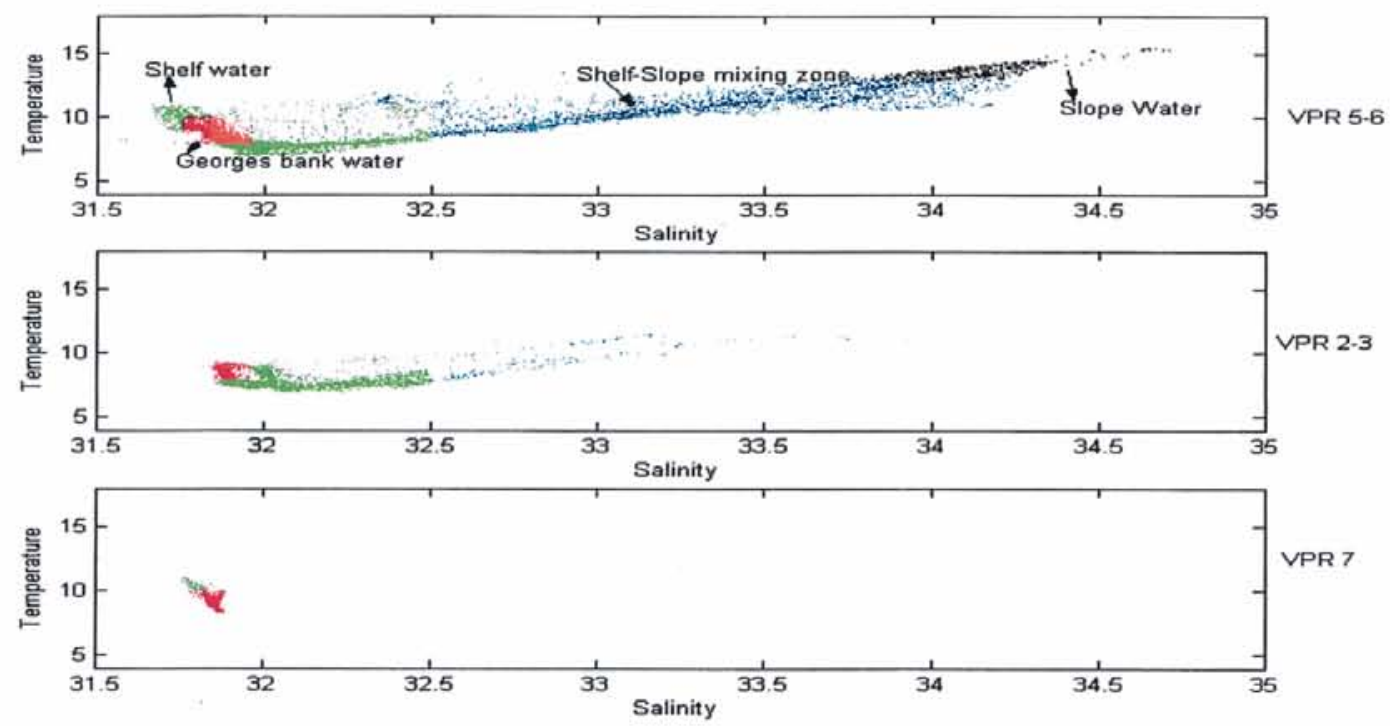

Figure 3. T-S diagram for VPR 5-6, VPR 2-3 and VPR 7.Four water types were identified:Slope water (black points), Georges Bank water (Red points), shelf water (green points) and water along the shelf-slope mixing curve (Blue points). 
A

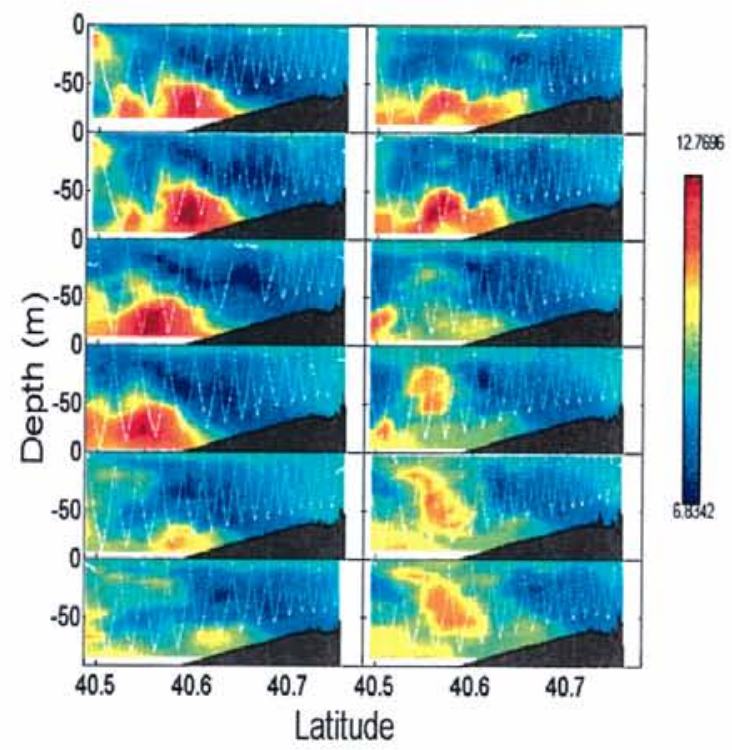

C

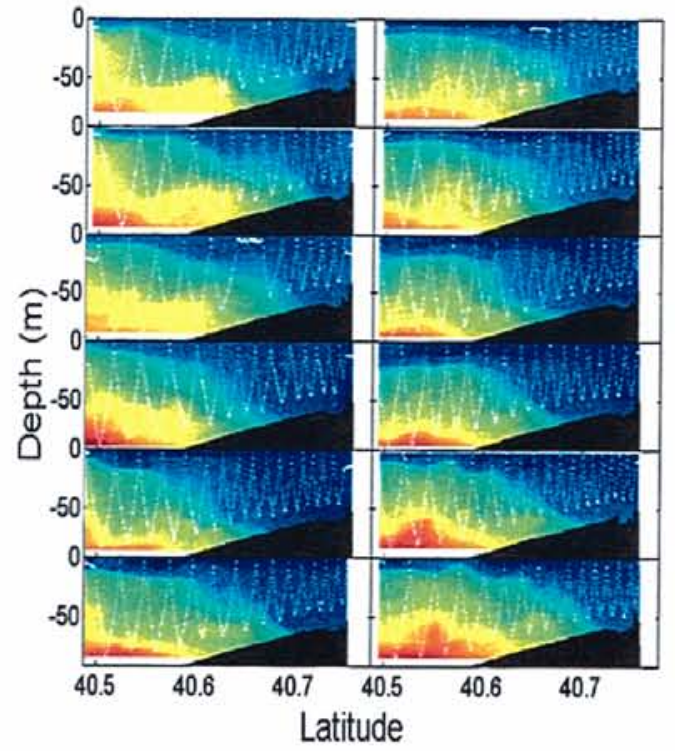

B

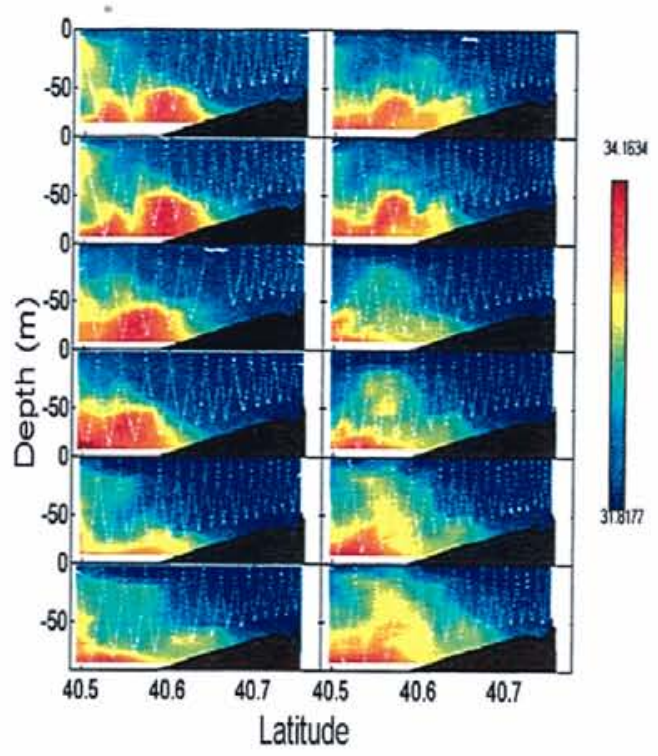

D

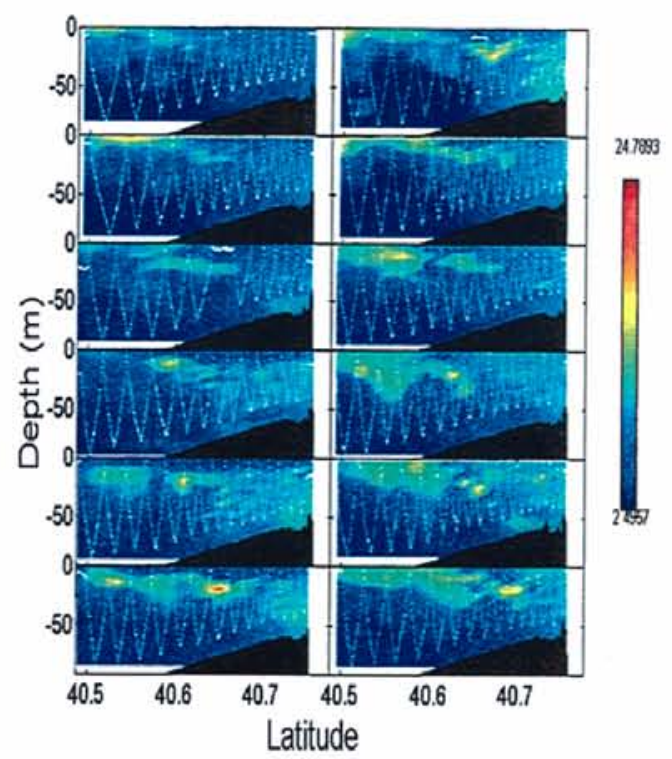

Fig.4. VPR 2-3, twelve N-S sections for: A. temperature $\left({ }^{\circ} \mathrm{C}\right)$, B. salinity, C. density $\left(\sigma_{t}\right)$, and D. fluorescence (volts). White dots lines show path of VPR towyo locations. 

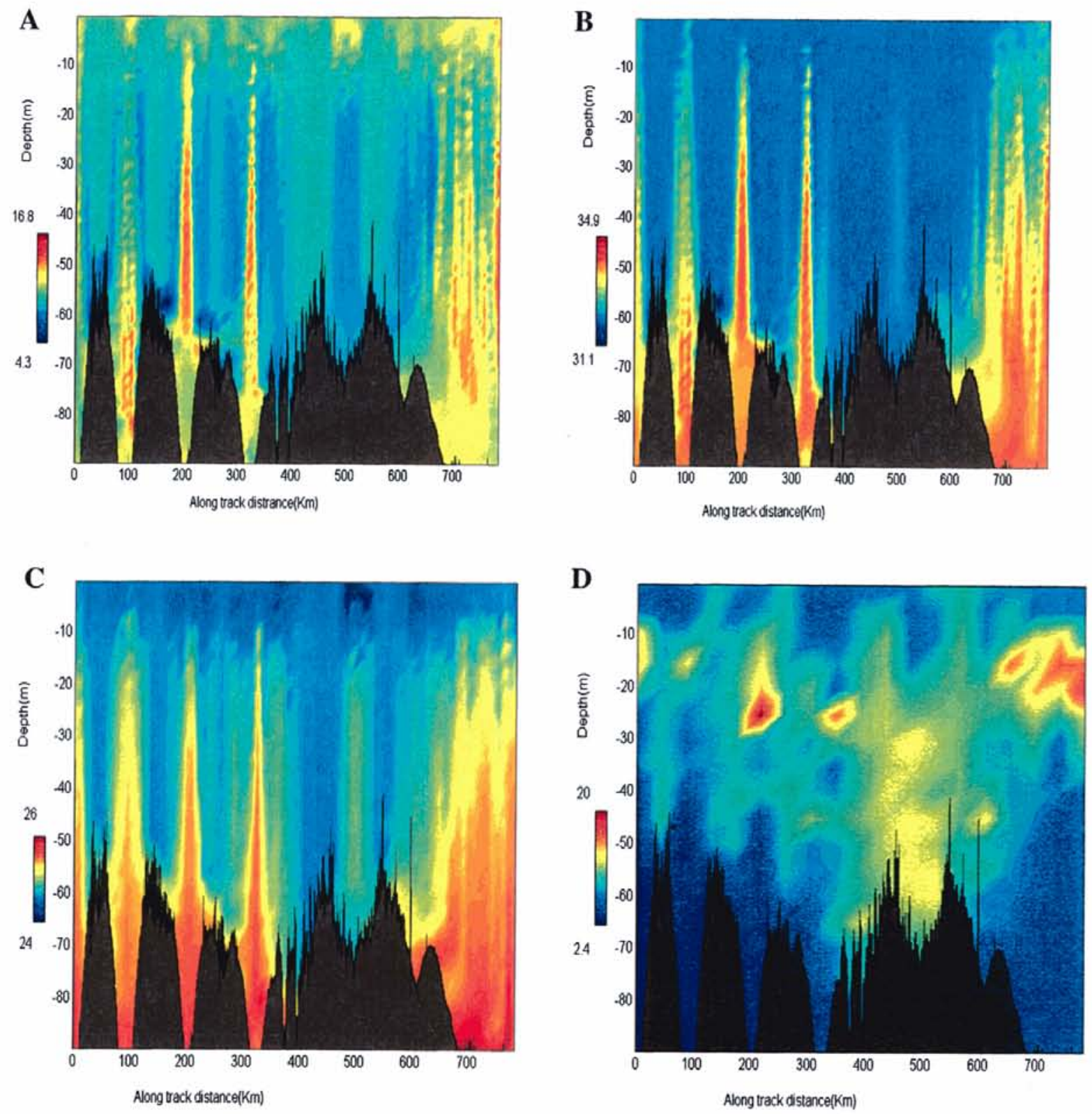

Fig.5 VPR 5-6, A. temperature $\left({ }^{\circ} \mathrm{C}\right)$, B. salinity, C. density $\left(\sigma_{t}\right)$, and D. fluorescence (volts). Abscissa is distance $(\mathrm{km})$ along ship track from start of tow.

T-S Properties and water masses - The hydrographic characteristics determined from the VPR tows revealed four different water masses in the RLR (Fig. 3). VPR5 and 6 
shaped temperature/salinity plots of the warmer season. Vernal warming was obvious in surface water by the warming of low salinity $(<32$, water $)$.

The distributions of temperature, salinity and density from the three deployments VPR 23, VPR 5-6, and VPR7 reveal the hydrographic features for the RLR (Figs. 4-7). The cold water column below $10 \mathrm{~m}$ or $20 \mathrm{~m}$ was evident in temperature plots (Figs. 4-7).

In the VPR2_3 survey, the distribution of temperature and salinity (Fig. 4) together with the T-S plot (Fig. 3) reveal Slope Water in the seaward lower water column ( $>50 \mathrm{~m}$ ), a surface mixed layer, and a tongue of cold pool water between these regions extending from the bottom upwards and seaward sandwiched between the warm-salty Slope Water below and the warmer-fresher surface mixed layer above. The "cold band" or "cold pool" is a particular phenomenon important to outer shelf of Georges Bank and the MidAtlantic Bight during spring, summer and early fall. It stretches from the Gulf of Maine along the outer edge of Georges Bank and then southwest to Cape Hatteras (Flagg, 1987). The warm, higher-salinity Slope Water was observed throughout much of the water column $(>15 \mathrm{~m})$ at the southern end (bottom depth $>60 \mathrm{~m}$ ) of the last two transects. In the northern "mixed area" (bottom depth $<60 \mathrm{~m}$ ) on the crest of the Bank and inside the tidal mixing front, the water had uniform temperature, salinity, and density. Density was highly correlated with salinity (correlation coefficient 0.9290 ) while but not so well with temperature (correlation coefficient 0.5362 ) indicating that density at this time was more dependent on salinity. Salinity generally increases with depth and to seaward throughout the region (Figs. 4-5). This is in keeping with the observation in the T-S diagram that much of the water in this region is a mixture of slope and shelf water masses. 
contained four water masses: shelf water $\left(7.5-11.5^{\circ} \mathrm{C}, 31.6-32.5\right)$, slope water $\left(11-15^{\circ} \mathrm{C}\right.$, 34.3-34.7), shelf-slope mixing zone $\left(7-13^{\circ} \mathrm{C}, 32.5-34.3\right)$ and Georges Bank water (8$\left.10^{\circ} \mathrm{C}, 31.76-31.96\right)$. Slope water tends to be warmer than shelf water because of its proximity to the Gulf Stream, and also tends to be more saline (Flagg, 1987). The "cold band" or "cold pool" is a particular phenomenon important to outer shelf of Georges Bank and the Mid-Atlantic Bight during spring, summer and early fall. It stretches from the Gulf of Maine along the outer edge of Georges Bank and then southwest to Cape Hatteras (Flagg, 1987). The warm, higher-salinity Slope Water was observed throughout much of the water column $(>15 \mathrm{~m})$ at the southern end (bottom depth $>60 \mathrm{~m}$ ) of the last two transects. In the northern "mixed area" (bottom depth $<60 \mathrm{~m}$ ) on the crest of the Bank and inside the tidal mixing front, the water had uniform temperature, salinity, and density. Density was highly correlated with salinity (correlation coefficient 0.9290 ) while density was not so much related to temperature (correlation coefficient 0.5362 ) indicating that density at this time was more dependent on salinity.

Stratification of the water column occurs over the shelf and the top layer of slope water during the spring-summer and is usually established by early June. From the T-S plot, it is evident that a line of mixing occurs from the shelf to the slope (from green to black). Most of the water fell on this line. The intermediate points between the shelf and slope indicate it is a mixture of the two types. The Georges Bank water is typified by much narrower limits (temperature center: 8.96; salinity center: 31.86 ). The shelf water was mainly from the western edge of the study area where the water was fresher (salinity is less than 32.5). The temperature varied from 7.5 to 11.5 because of the establishment of vernal stratification following heating and the subsequent development of surface water. As for hydrography in VPR 2-3, most water parcels belong to the Georges Bank water and shelf water. As for hydrography in VPR 7, the distribution of temperature and salinity resembled the northern portion in VPR 2,3,5,6 and did not show substantial variation over much of the water column (Fig. 3). From these T-S plots it can be seen that the linear T-S relationship typical of winter (Flagg, 1987) was replaced by the V- 

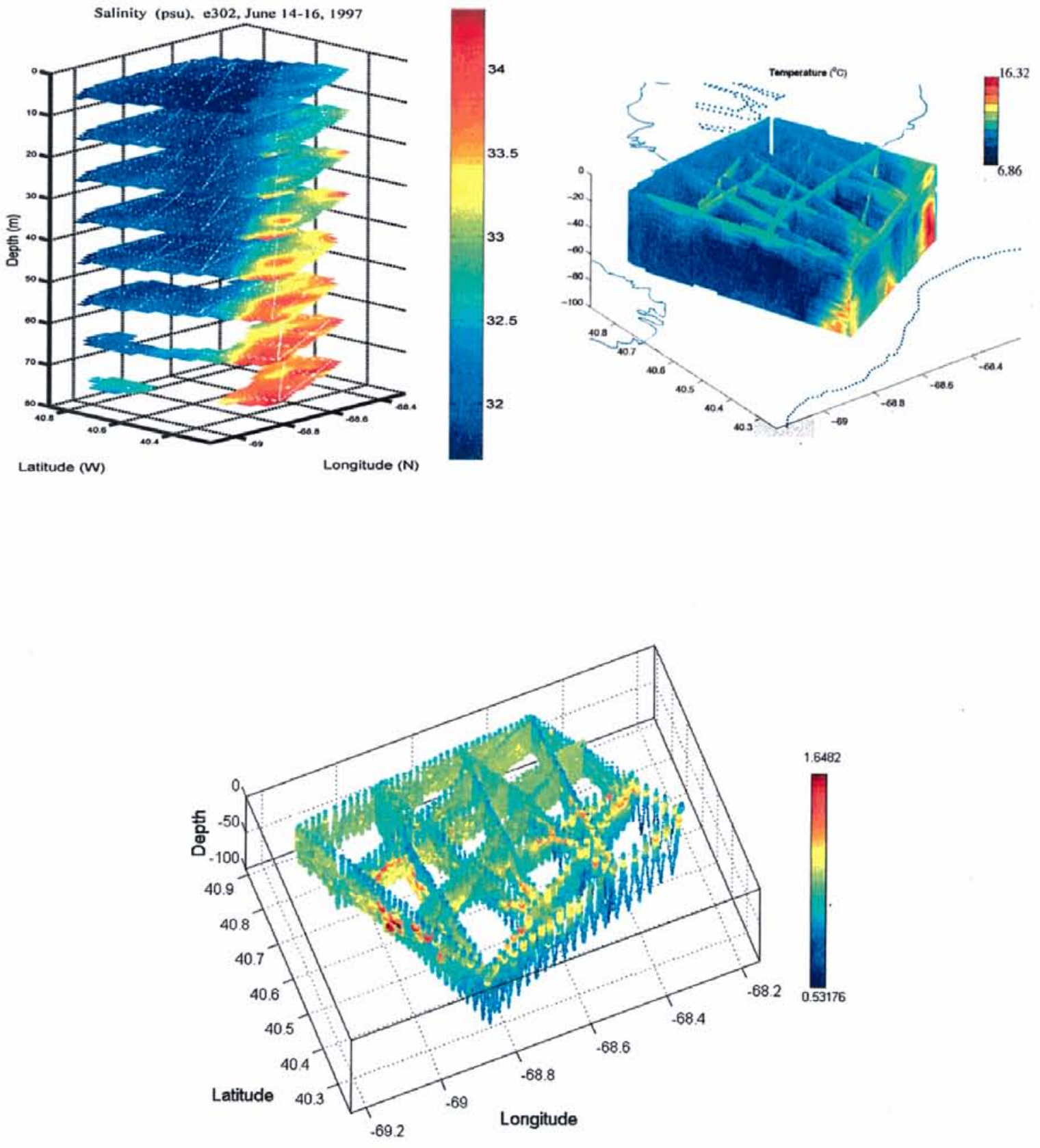

Fig. 5 (cont) VPR5-6, 3D plots: kriged stack plot of salinity (upper left), curtain plot of temperature (upper right), and color dot plot of $\log _{10}$ (fluorescence) (above). 2D kriging was done on 10-m depth intervals of VPR data. Gridding for the curtain plot was done using an inverse distance method (Ashjian and Davis, 1997, see Methods). 

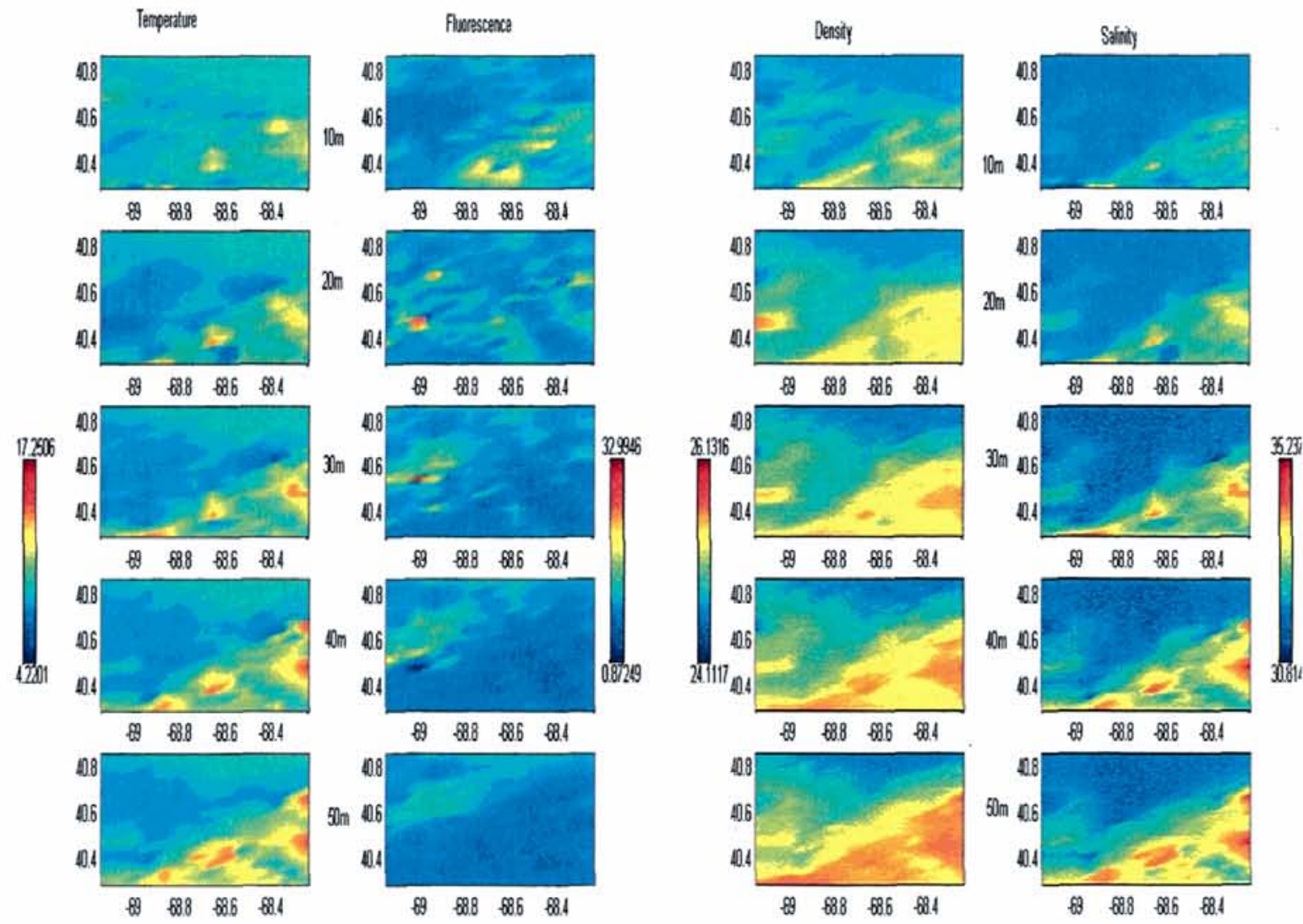

Fig. 6. VPR5-6, 3D-kriged distributions of temperature, fluorescence, density, and salinity. Slices at $10 \mathrm{~m}$ depth layers are shown.

In VPR 5-6, the higher temperatures (greater than 13) and salinities (greater than 34.3) observed in the south sections (Fig 1,2,3,5) were clearly due to the influx of slope water as judged from T-S plot (Fig. 3). The southern portion of the grid contained warmer, high salinity water at depth, cold pool water at mid-depths, and mixed layer water at the surface (Figs. 3-6). In contrast, the northern portion of the grid contained colder, fresher water of more uniform temperature and salinity characteristics. Density was highly correlated with salinity (correlation coefficient equal to 0.9231 ) but not as highly related to temperature (correlation coefficient equal to 0.5490 ), again indicating that density was more dependent on salinity. 
A

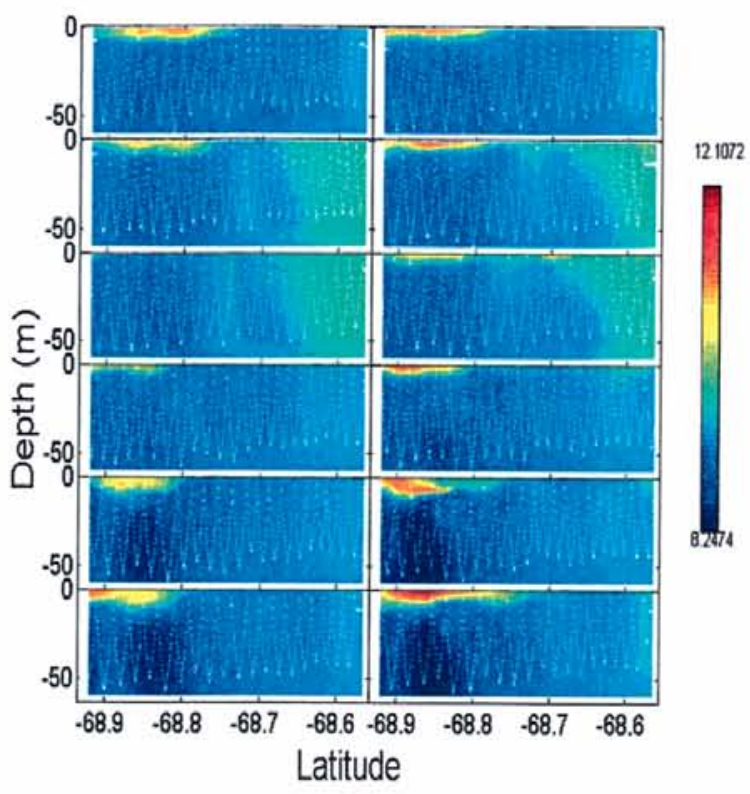

C

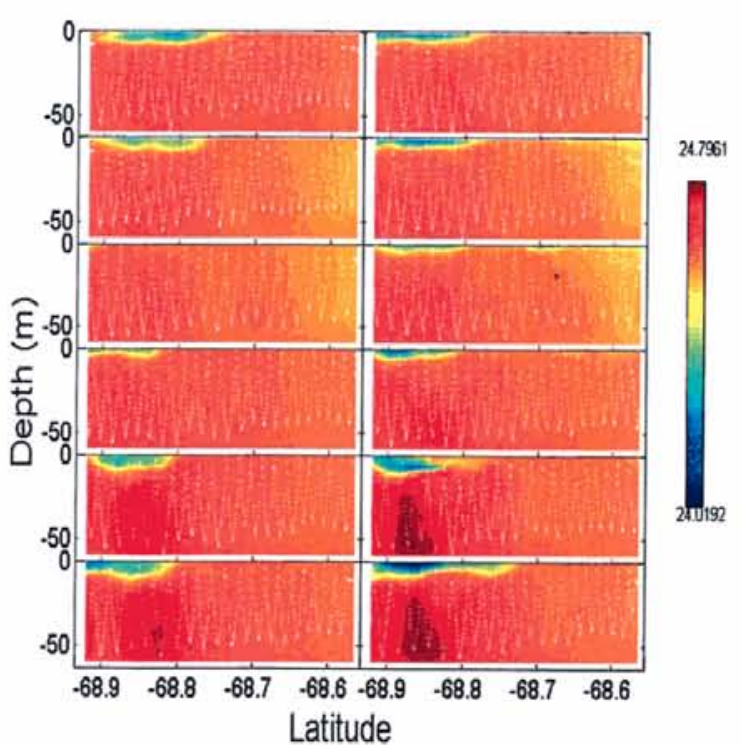

B

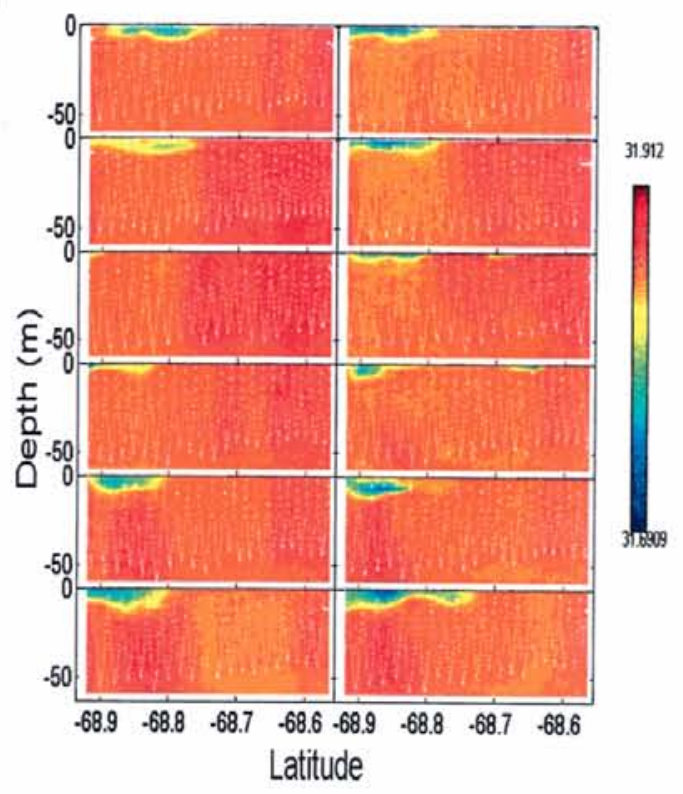

D

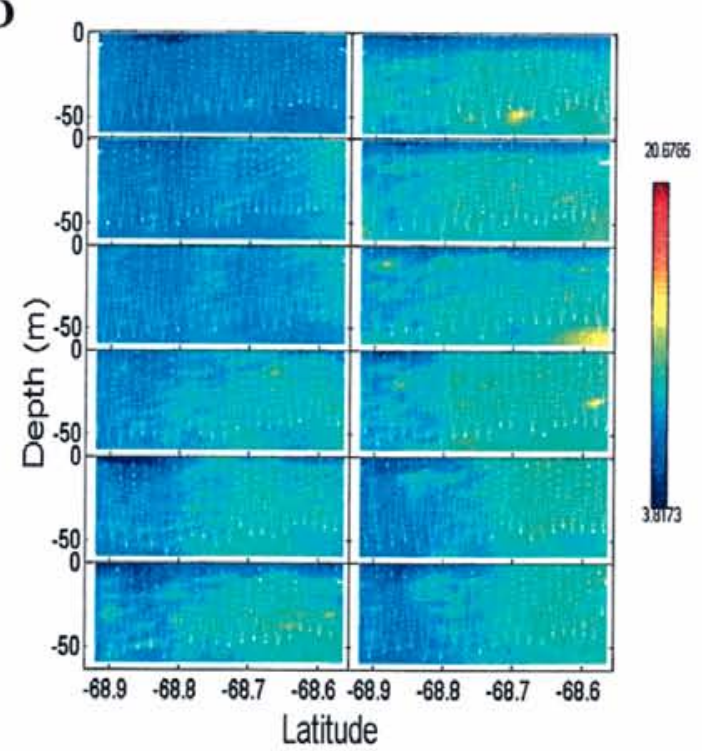

Fig.7. VPR 7, twelve E-W sections for: A. temperature $\left({ }^{\circ} \mathrm{C}\right)$, B. salinity, C. density ( $\left.\sigma \mathrm{t}\right)$, and D. fluorescence (volts). While lines show towyo path where data collected.There are 12 sections in each Panel. Each section was for $2 \mathrm{~h}$. The left column corresponding to the first tidal cycle. The right column corresponding to another tidal cycle. 
The hydrography of VPR7 revealed a distinct shallow surface plume on the W end of the transect (Fig. 7). This plume was characterized by high temperature and low salinity, density, and fluorescence. By contrast, below this plume, at the end of each tidal cycle (bottom panels), was water of low temperature and high salinity and density. In general, the water on the eastern side, nearer the "well-mixed area", was warmer and denser.

In the VPR2-3 sections, a distinct subsurface fluorescence maximum was observed (Fig. 4). This maximum appeared coincident with the upper cold pool water, thermocline, and in the warm fresh surface water to the south (Fig. 4). Subsurface fluorescence maximum also was observed in VPR5-6, including a patch of high fluorescence at mid-depth in the western portion of the grid and large subsurface patch over the slope water to the south (Figs. 5-6). The fluorescence was moderately high and uniform throughout the water column in the northern portion of the RLR (Fig. 5). In VPR7, fluorescence was higher on the eastern side of the transect in the "mixed area", and surface fluorescence was low (Fig. 7).

\subsection{Satellite SST imagery}

The AVHRR SST data revealed the presence of two large warm-core Gulf Stream rings south of Georges Bank during the study period, with one ring located directly south of the RLR and in a position to detrain water from the bank (Fig. 8). A closer look at the southern boundary of the RLR reveals an apparent southern and southwestern movement of water out of this area (Fig. 9). 

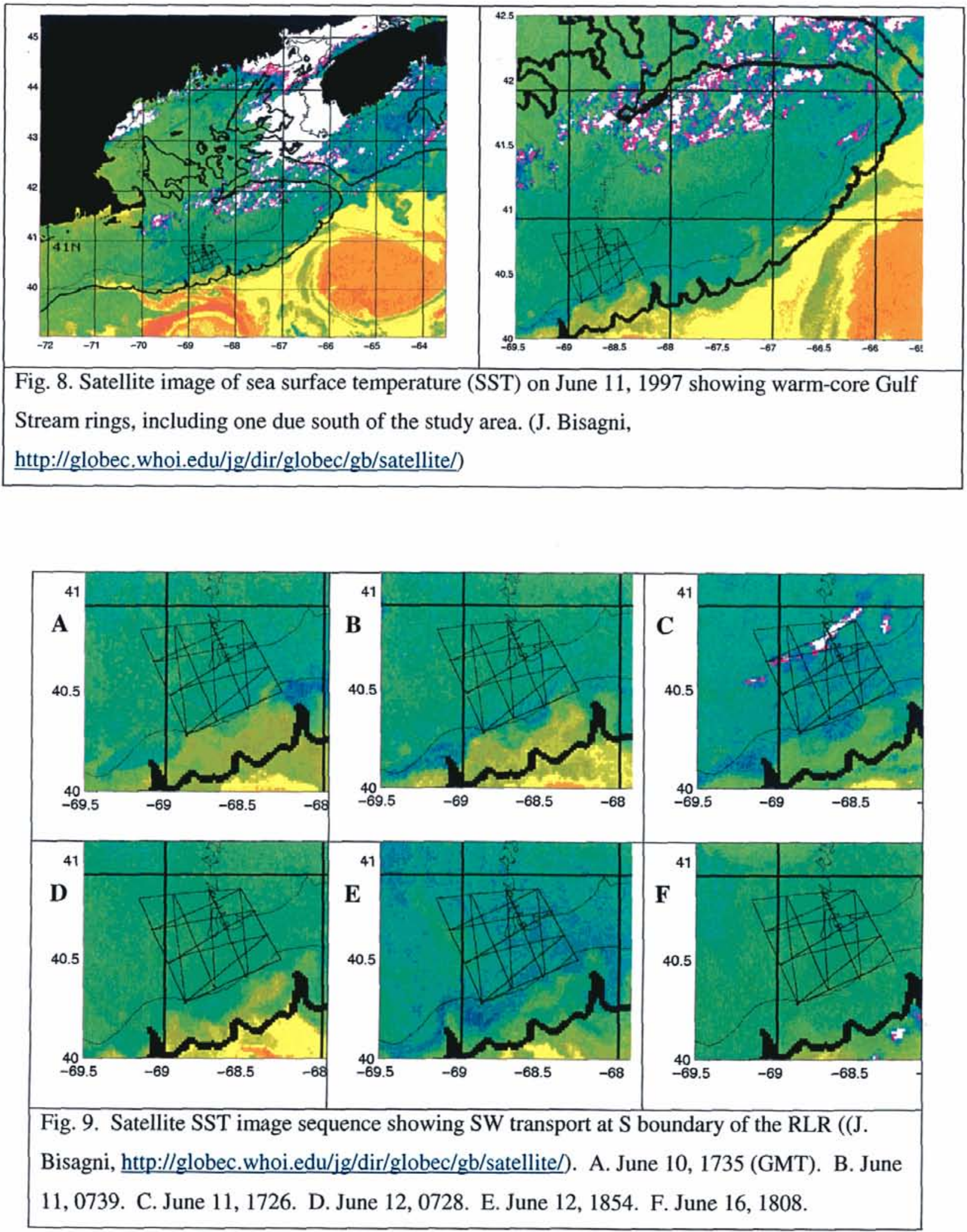


\subsection{Flow field: GPS-Model Drifters and ADCP}

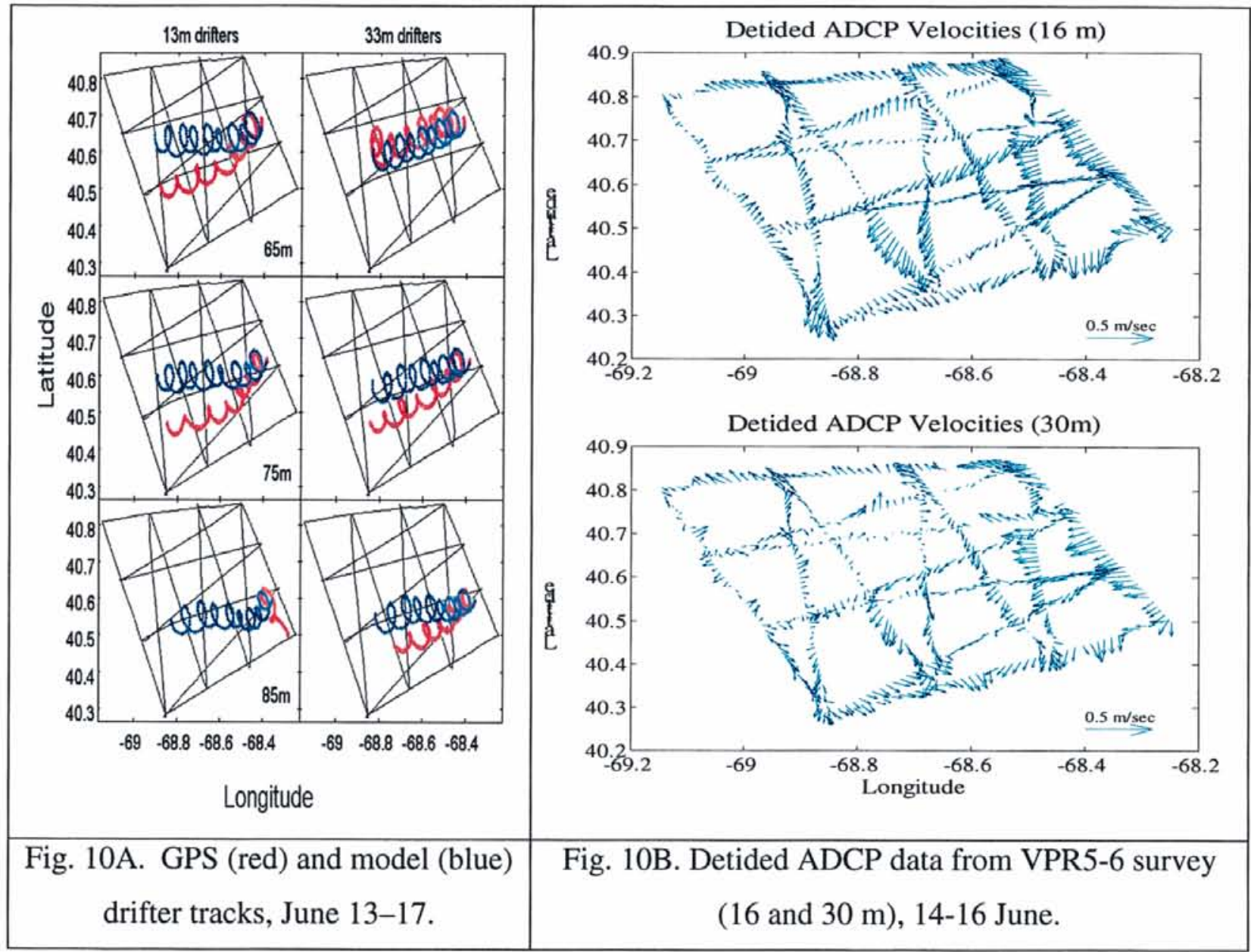

The tidal and subtidal flow through the RLR was observed in the tracks of the GPS drifters launched on the eastern side of the study area along the VPR2-3 transect line (Fig. 10A). These drifters moved in an elliptical motion due to the tide and with a general southwestward subtidal movement roughly parallel to the isobaths. The model drifters, transported by the flow field of the Quoddy model (Lynch et al., 1996) also moved to the southwest and separated from the real drifters at about $5 \mathrm{~km} /$ day except for the deep depth that was released at the $65 \mathrm{~m}$ isobath. Drifters with shallow or deep drogues both moved to the SW at $10.3-12.7 \mathrm{~km} /$ day. The exception was the deep drifters released at $65 \mathrm{~m}$ isobath, which moved at $7.1 \mathrm{~km} /$ day (Fig. 10A). 
The detided ADCP data from the shipboard survey also revealed a southwestward residual flow along the eastern boundary of the RLR at both 16 and $30 \mathrm{~m}$ depth (Fig. 10B). This SW flow was present throughout the southern half of the RLR, except along the southern boundary of the RLR, where the flow was to the south, agreeing with the inferences from the SST imagery. Flow along the northern boundary of the RLR was northward. Flow along the western boundary of the RLR was eastward, and this eastward flow penetrated into the western interior of the RLR at mid-latitude until the velocities became very weak (Fig. 10B).

\subsection{Diel migration}
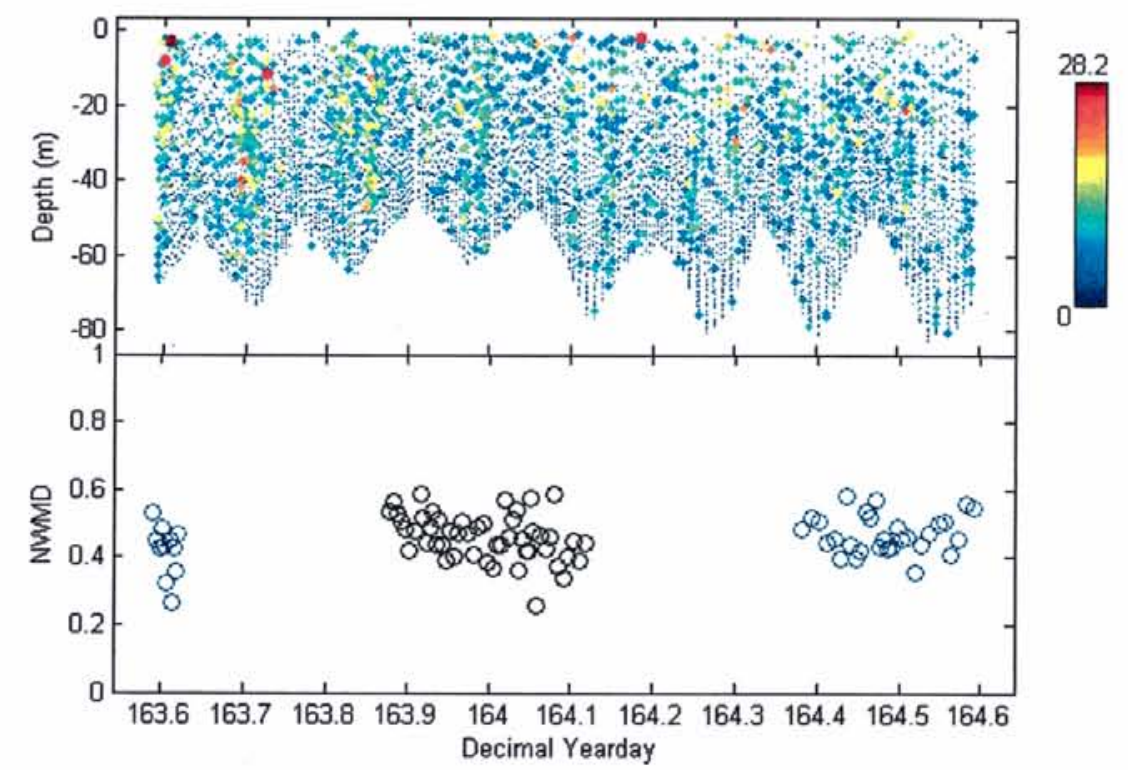

Fig.11A. Copepod vertical distribution (\#/liter, top panel) and normalized weighted mean depth (NWMD) (bottom panel:at night(black circle) and during the day(blue circle)) versus time for VPR4.Blue dots in upper panel show locations where VPR data were collected. 
In order to investigate potential changes in vertical distributions of plankton due to vertical migration, data from VPR4, a 24 hour survey around three drifters, were analyzed as discussed in the Methods section. Copepods had no apparent vertical pattern and were distributed throughout the water column both day and night (Fig.11A). Medusae appeared to be primarily abundant in the lower half of the water column but were present in the upper water column during the initial daytime and nighttime periods (Fig. 11B). A lack of vertical migration for both taxa was found in the temporal patterns of normalized weighted mean depths (Fig. 11). The NWMD for both taxa was not significantly different for the towyos made during the day and night periods, confirming there was no significant diel migration for both species during that period.

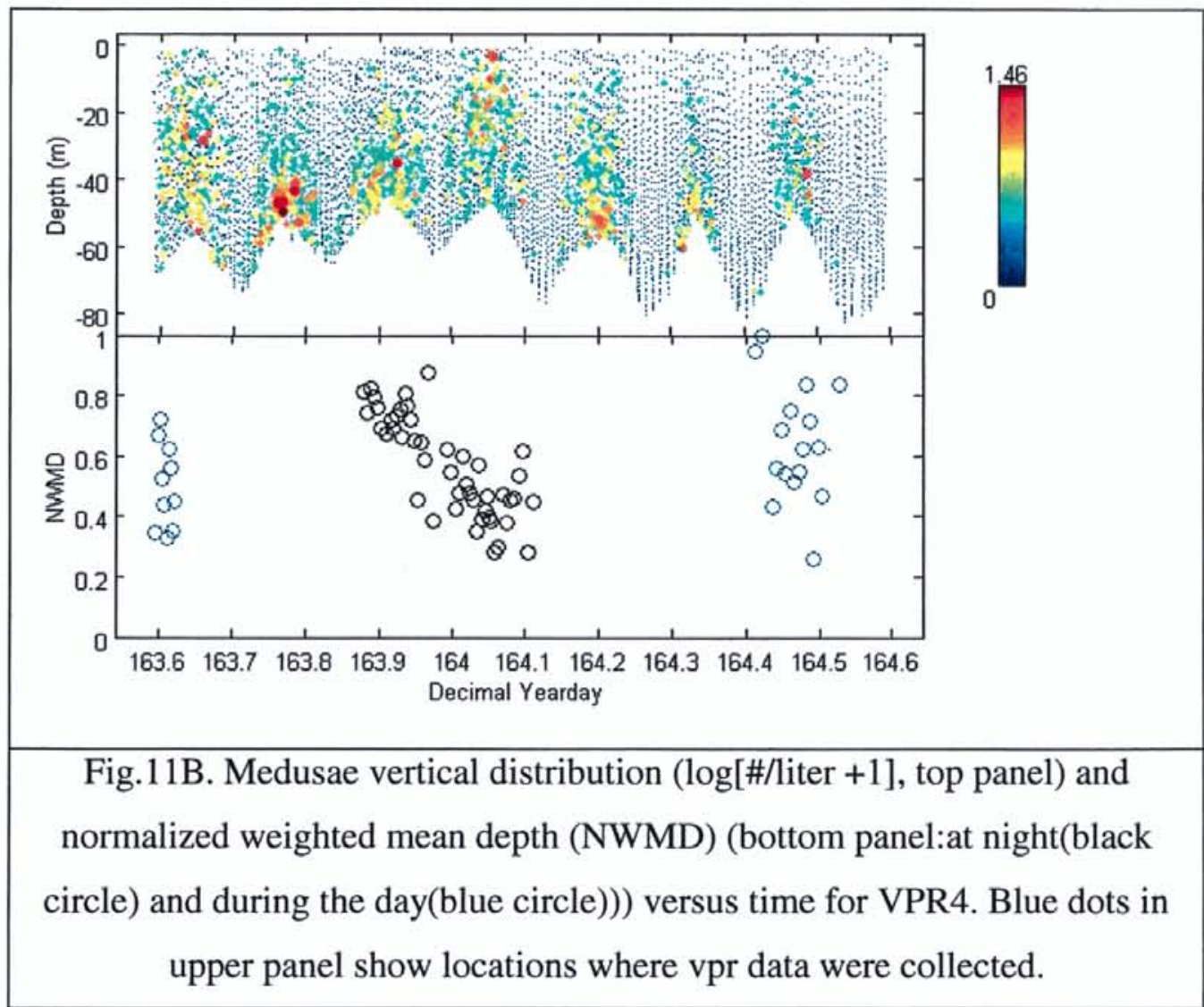




\subsection{Distributional patterns of plankton taxa}

\subsubsection{General abundance levels}

Table 1.A Total individuals of each taxa

\begin{tabular}{|c|c|c|c|c|c|}
\hline & copepod & C. socialis & diatom rod & marinesnow & medusae \\
\hline VPR2-3 & 9088 & 18365 & 11848 & 678 & 1792 \\
\hline VPR4 & 9770 & 15308 & 8294 & 1063 & 1892 \\
\hline VPR5-6 & 16935 & 16581 & 15120 & 1017 & 3282 \\
\hline VPR7 & 10390 & 507 & 22080 & 339 & 2662 \\
\hline Total & 46183 & 50761 & 57342 & 3097 & 9628 \\
\hline
\end{tabular}

Table 1.B Abundance (number per liter) of plankton observed during 5-s time bins. (VPR56). 1=copepod, $2=C$. socialis, $3=$ diatom rod, $4=$ marinesnow, $5=$ medusae

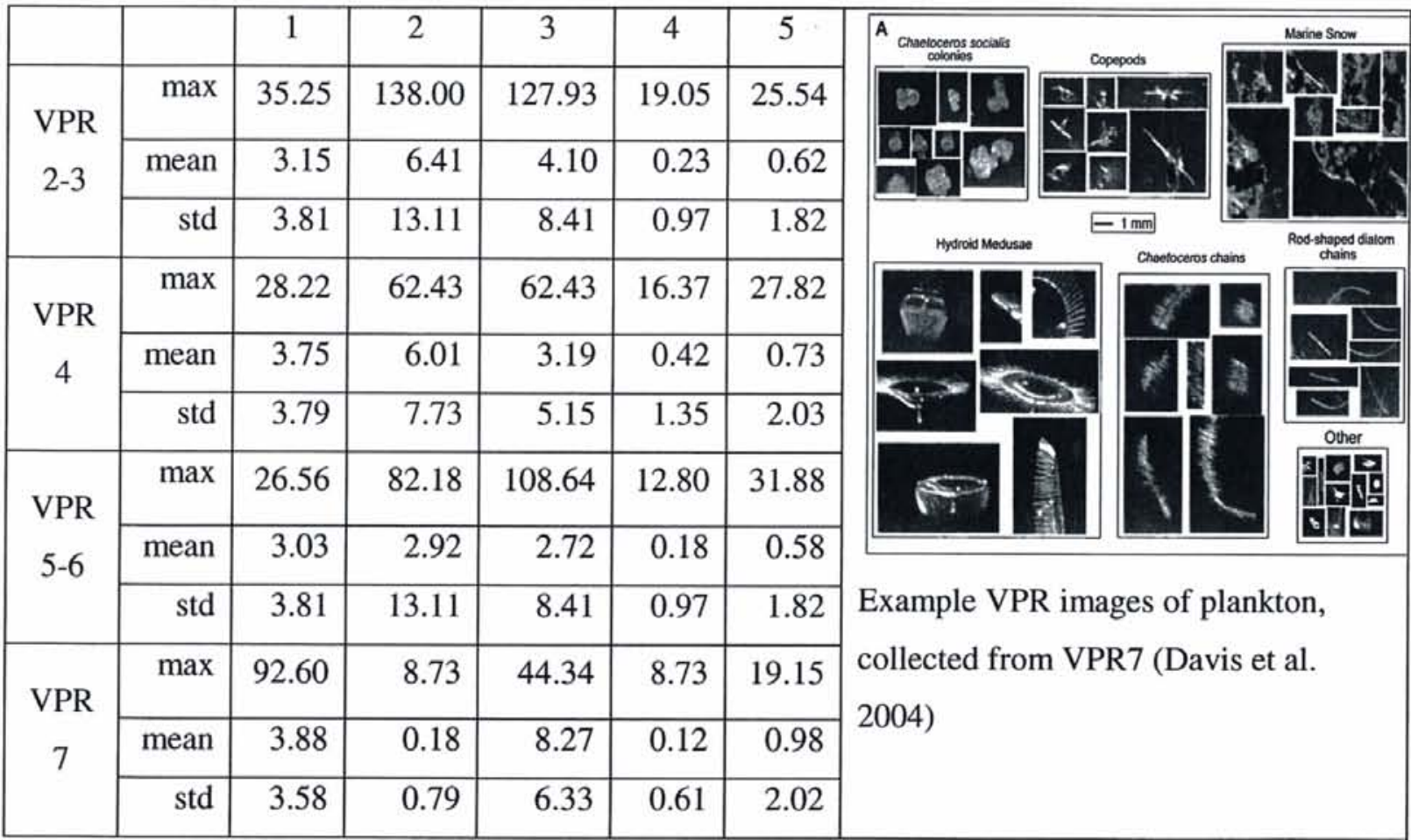

Copepod, medusa, C.socialis, diatom rod and marine snow were identified for this cruise. The total in-focus images were shown in table 1.A. Diatom rod was the most abundant among all taxa. For reference, VPR images of the 5 taxa studied also are presented in the 
Table 1.B. Chaetoceros socialis has a characteristic texture and globular shape that is readily identified by the automatic identification system (Sieracki et al., 1998; Scott, 1996). Accuracies of the automatic identifications are given in Davis et al. (2004). Phytoplankton was more abundant and more variable than zooplankton and marine snow. The diatom colonies, $C$. socialis, were the dominant taxon observed in VPR2-3 and VPR4, and were co-dominants with copepods in VPR5-6, in terms of mean abundance. This group forms very dense patches with maximum abundances per 5-s of 138 colonies/liter. The rod-shaped chains of diatoms also were very patchy, with a maximum concentration of $128 /$ liter. Copepods were abundant everywhere, with mean concentrations ranging from 3.03-3.88/ liter. The marine snow and medusae the least abundant taxa in all tows, except VPR7, where mean $C$. socialis abundance was lower.

\subsubsection{The distribution of copepods}

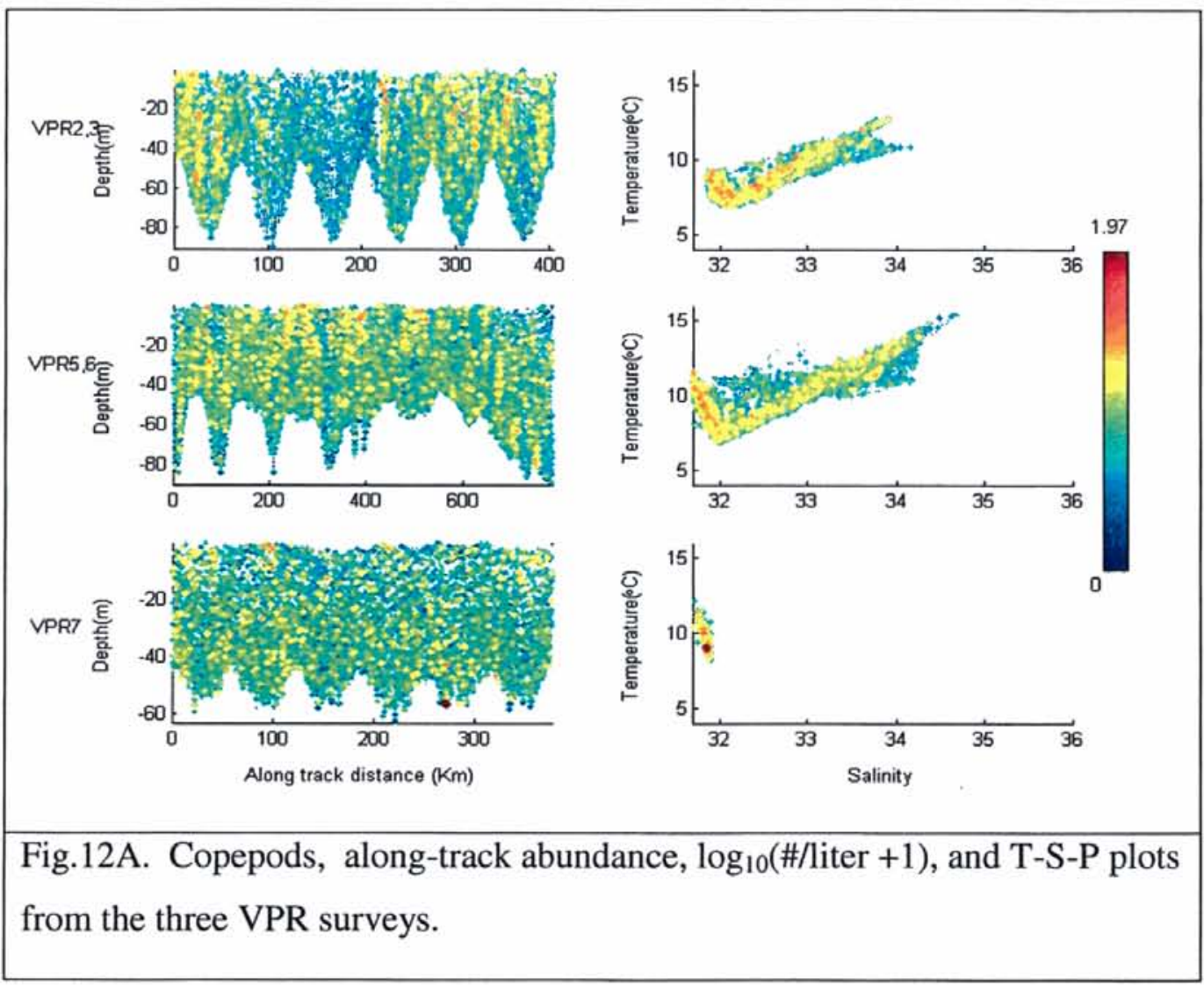


Copepods were broadly distributed both vertically and horizontally (Fig. 12). Although the automatic classification could not distinguish genera or species of copepods, visual examination showed that the copepods imaged by the VPR comprised primarily of ${ }^{\circ} \mathrm{a}$ mixture of Calanus and Pseudocalanus. Lower abundance was observed in sections 4 to 6 in VPR 2-3 (Fig. 12B) apparently due to the tidal advection of lower concentrations of animals from the west. In VPR 5-6, copepods as a group had no apparent pattern or preference to a particular water mass type (Fig. 12A), despite strong hydrographic heterogeneity in the RLR (Figs. 5, 6, also see Factor Analysis section). Over the 24-h repeated E-W transect inVPR7, no obvious patterns in copepod vertical or horizontal distributions were found. The copepods were spread throughout this water mass, which had a very narrow $\mathrm{T}-\mathrm{S}$ range.

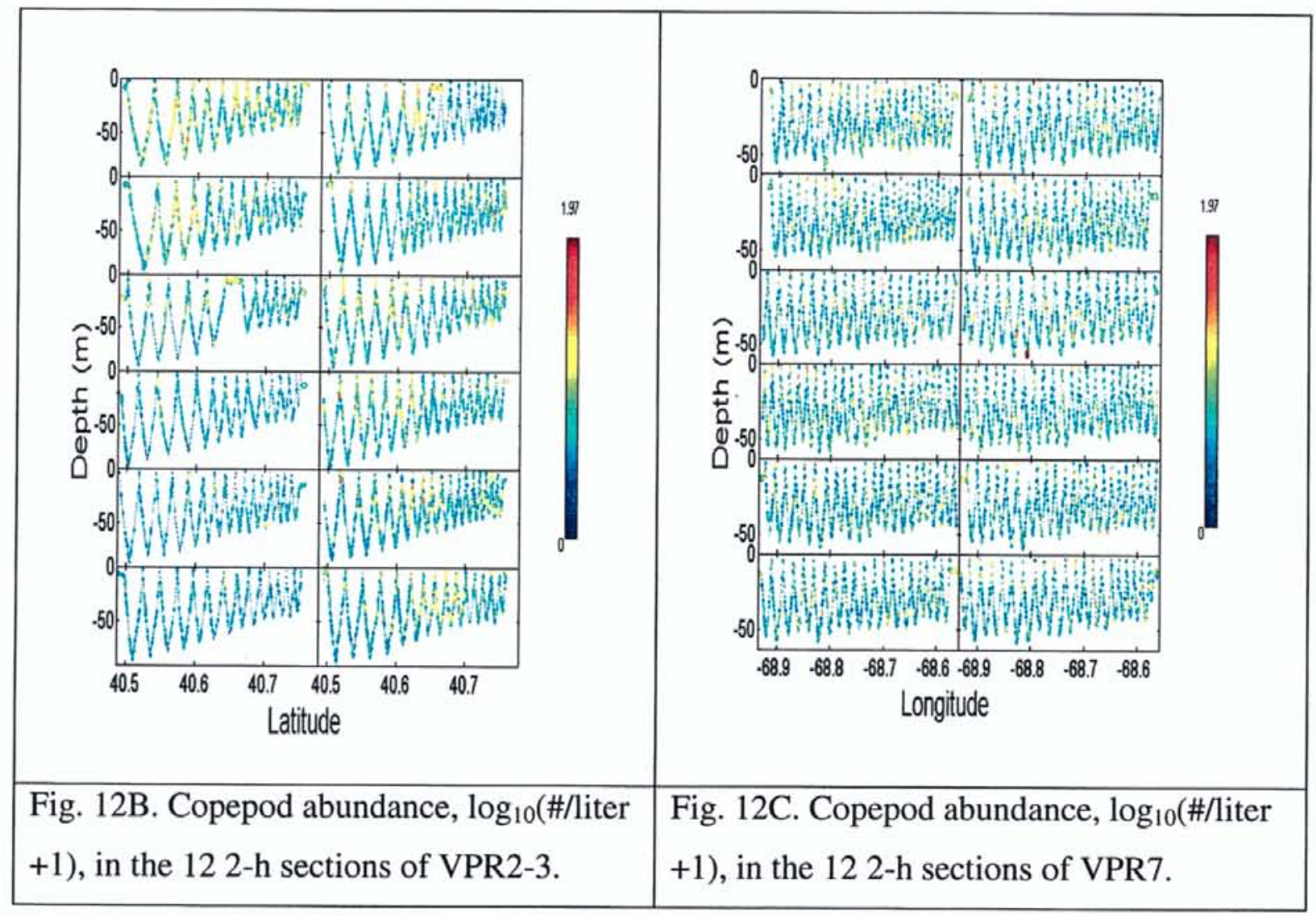




\subsubsection{The distribution of Chaetoceros socialis}

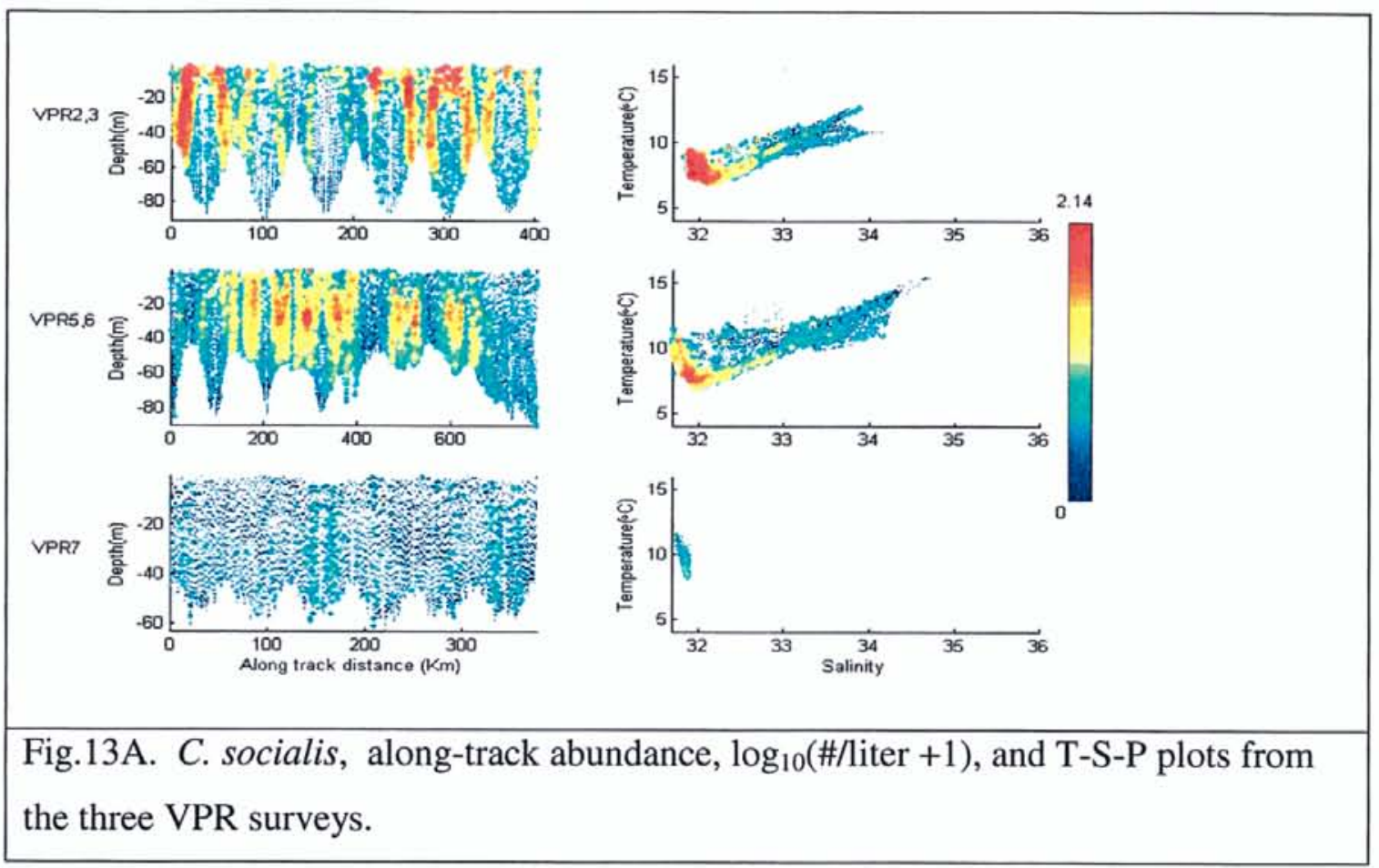

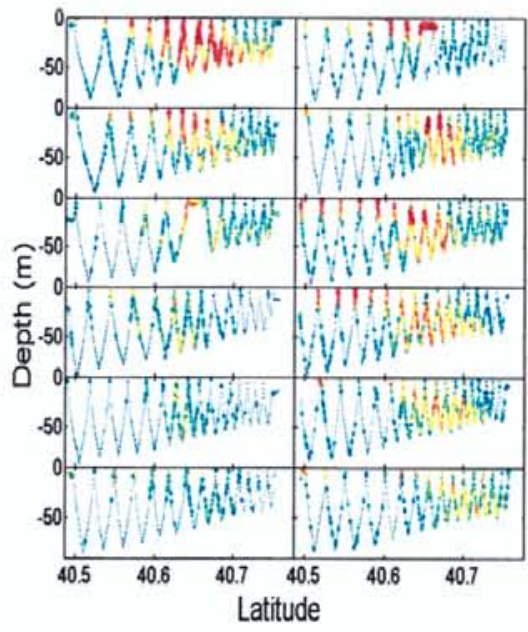

B

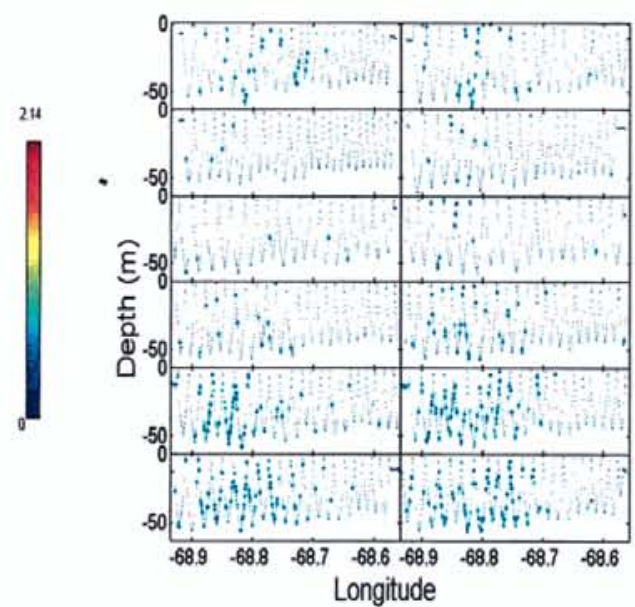

C

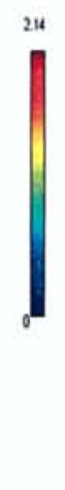

VPR7

Fig.13B. C. socialis abundance, $\log _{10}(\# /$ liter +1$)$, in 2-h sections for VPR $2-3$ and VPR7. 


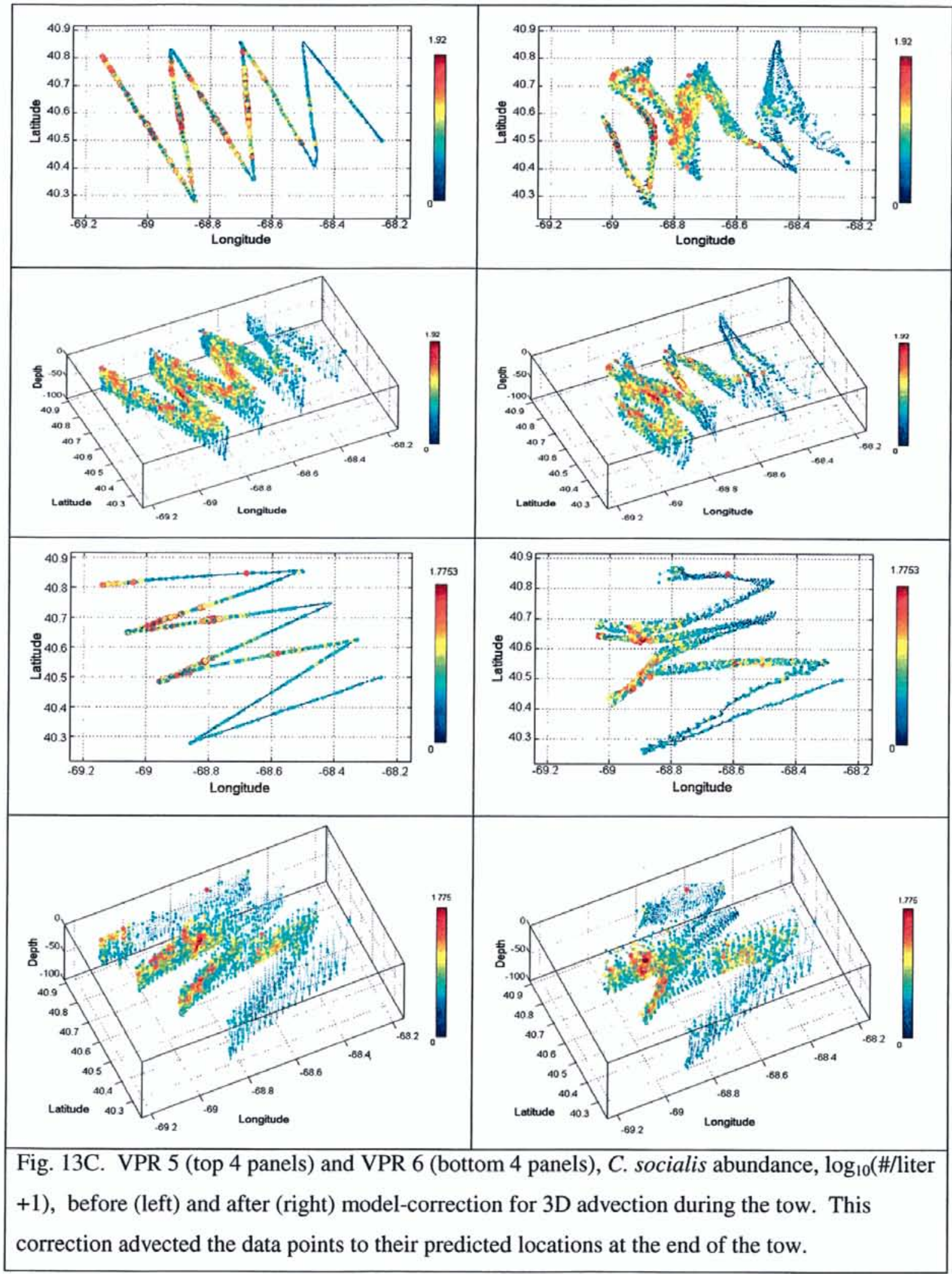


Chaetoceros socialis was the most abundant taxon observed. From VPR 2-3, C. socialis colonies were abundant in the middle of the transect, from the base of the mixed area at the northern edge, where the water is fresher and colder, and then shoaling seaward. At southern end of the transect, the water column contains a surface mixed layer, the cold pool, and warm salty water under the cold pool. $C$. socialis was found in the mixed layer and down into the cold pool/warm water interface, with low abundance in the warm salty water at depth (Fig. 13). At the northern end of the transects, from the distribution plots (Fig. 13C), the abundance was low in well mixed Georges Bank water. There were thick bands of $C$. socialis in the water column associated with cold pool water overlaying the Slope-Shelf front (Fig. 13B). C. socialis were not abundant in the upper 10-12 m of the water column shoreward of the cold pool, nor below this pool.

Data for $C$. socialis from VPR5-6 revealed a large patch of colonies in the western portion of the RLR at mid-depth (Fig. 13A, C). The patch was coherent as seen in the both the original data and the model-dealiased plot (Fig. 13C). This patch also was found in the western portion of the VPR7 survey at the northern extent of the tidal excursion (Fig. 13B, right panel).

\subsubsection{The distribution of rod-shaped diatom chains}

Unlike other plankton, diatom rods were most abundant in fresher to medium-salty water (salinity from 31.6 to 33). In the stratified region, they were much less abundant below 25m depth in VPR2-3 and VPR5-6, whereas in the well-mixed region they were spread throughout the water column. Highest concentrations were found in the high temperature upper water column (Fig.14) and on the crest of the bank (VPR 7). The rodshaped diatoms were abundant surface mixed layer in VPR 5 and 6 in the east and south but had much lower abundance in the deeper water and in the western portion of the RLR where the $C$. socialis was located. High abundance could be seen in the well-mixed area 
north of the tidal mixing front. Diatom rods had no contribution to the highest florescence observed in western section.

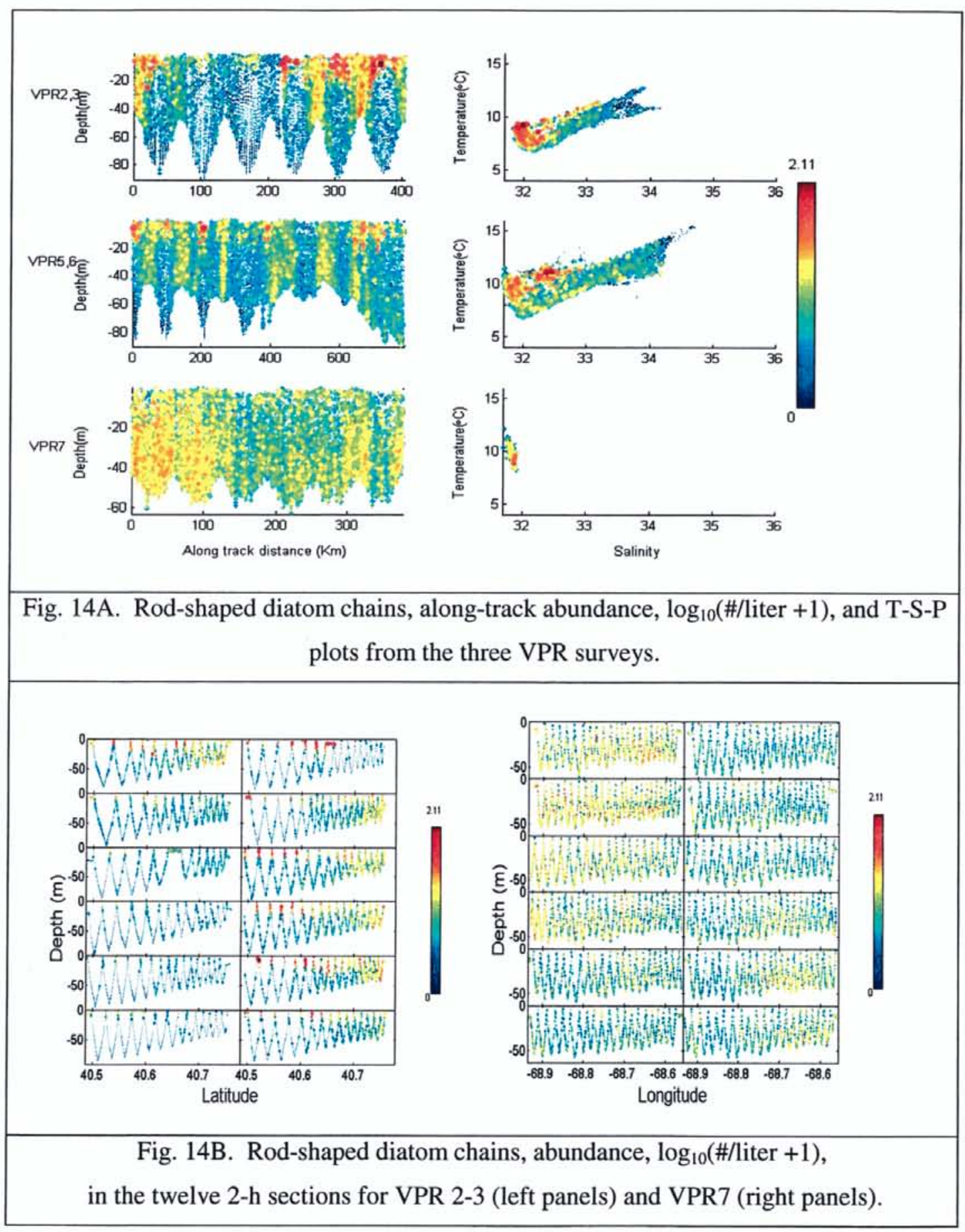




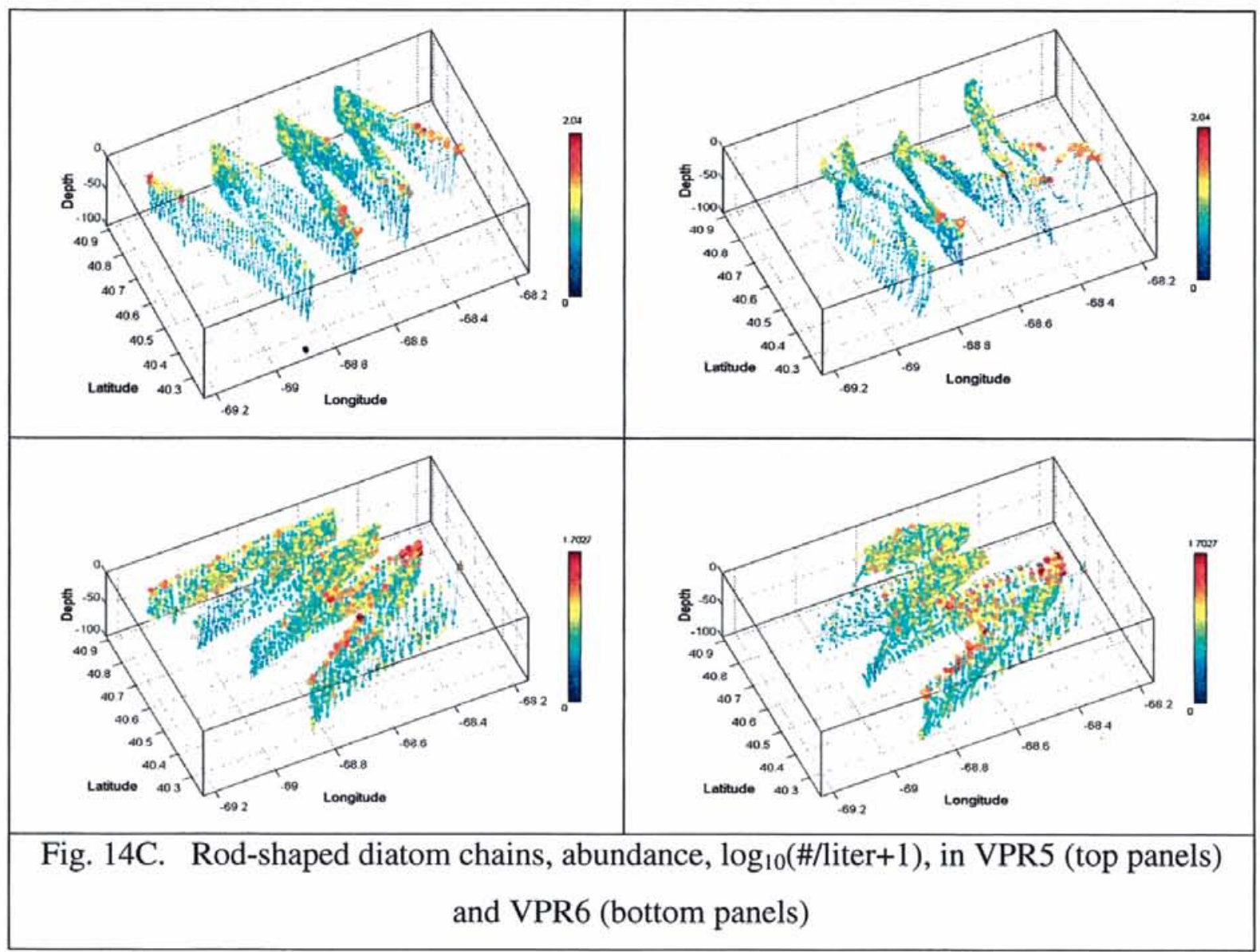

\subsubsection{The distribution of medusae}

Although hydroids had previously been reported suspended in the water on Georges Bank (Bigelow, 1926), they had not been considered important organisms in the pelagic community until recently (Madin et al., 1996). In VPR2-3, high concentrations of medusa were observed at the bottom of the well-mixed water column at the northern end of the transects (Fig. 15A,B). According to the T-S plots, most of them lived in a colder and fresher water (temperature is less than $10^{\circ} \mathrm{c}$, salinity is less than 33) (Fig. 15A). 


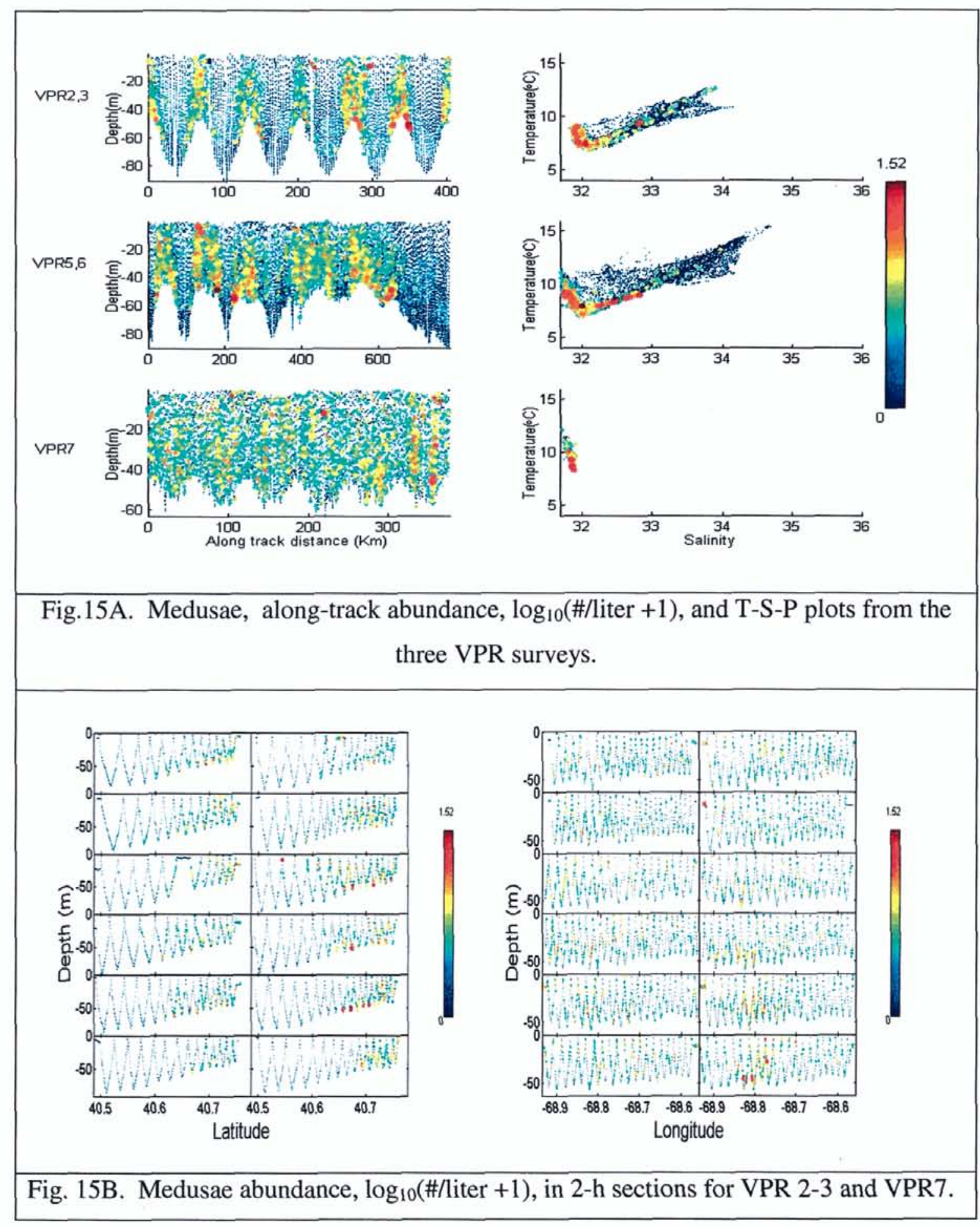




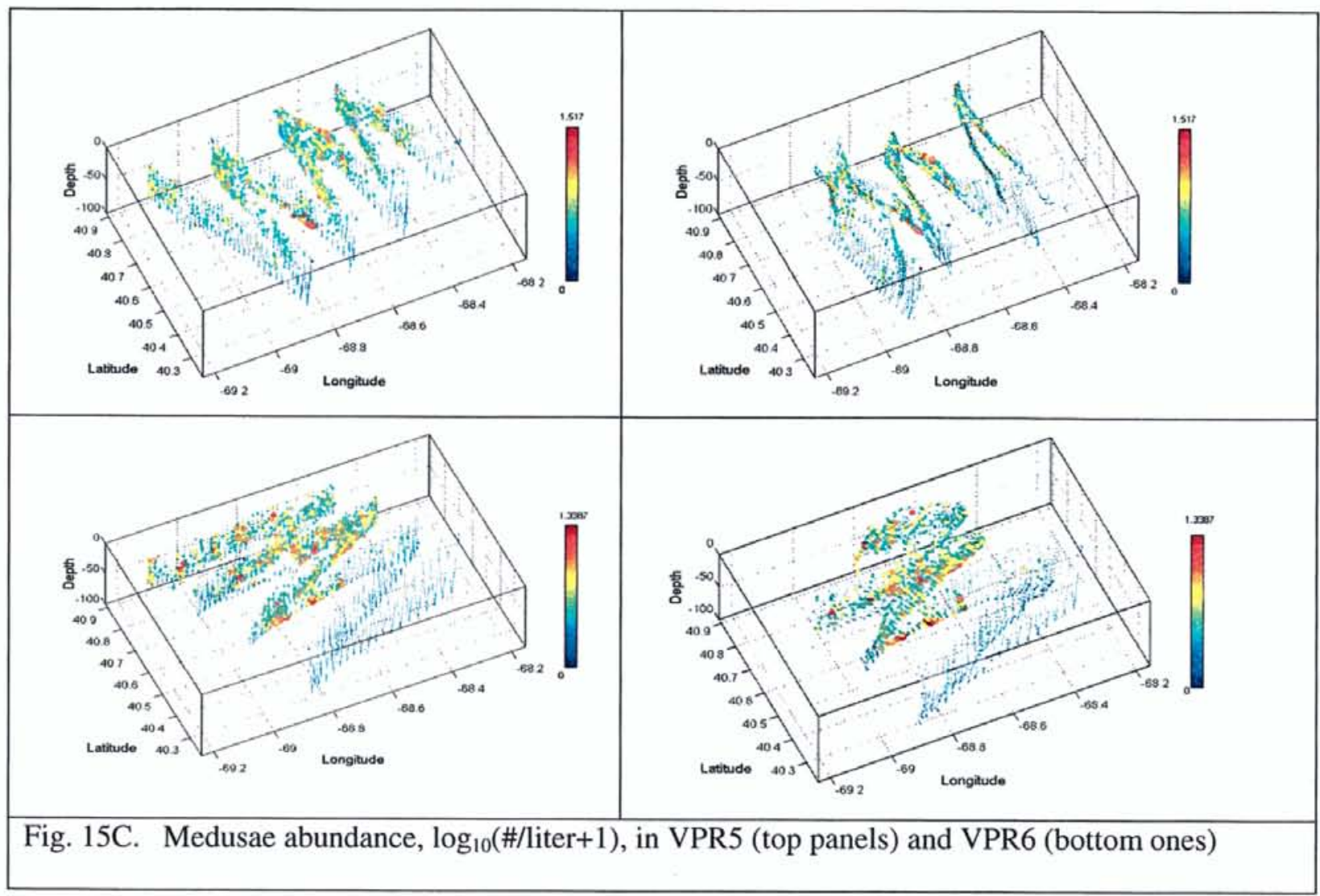

Some colonies also were found to the south of the southern tidal mixing front. VPR5-6 data revealed that the abundance of medusae was highest in the northern half of the RLR (Fig. 15C). Generally the hydroid medusae abundance decreased away from the mixed area to the south and medusae were variously distributed through to the west through the VPR7 transects.

\subsubsection{The distribution of marine snow}

Marine snow particles are millimeter- to centimeter-size aggregates of smaller particles, including phytoplankton cells, zooplankton fecal material and other microorganisms as well as inorganic particles (Gram et al., 2002). They can form in a number of ways including decaying mucous matter from colonial algae and larvacean 

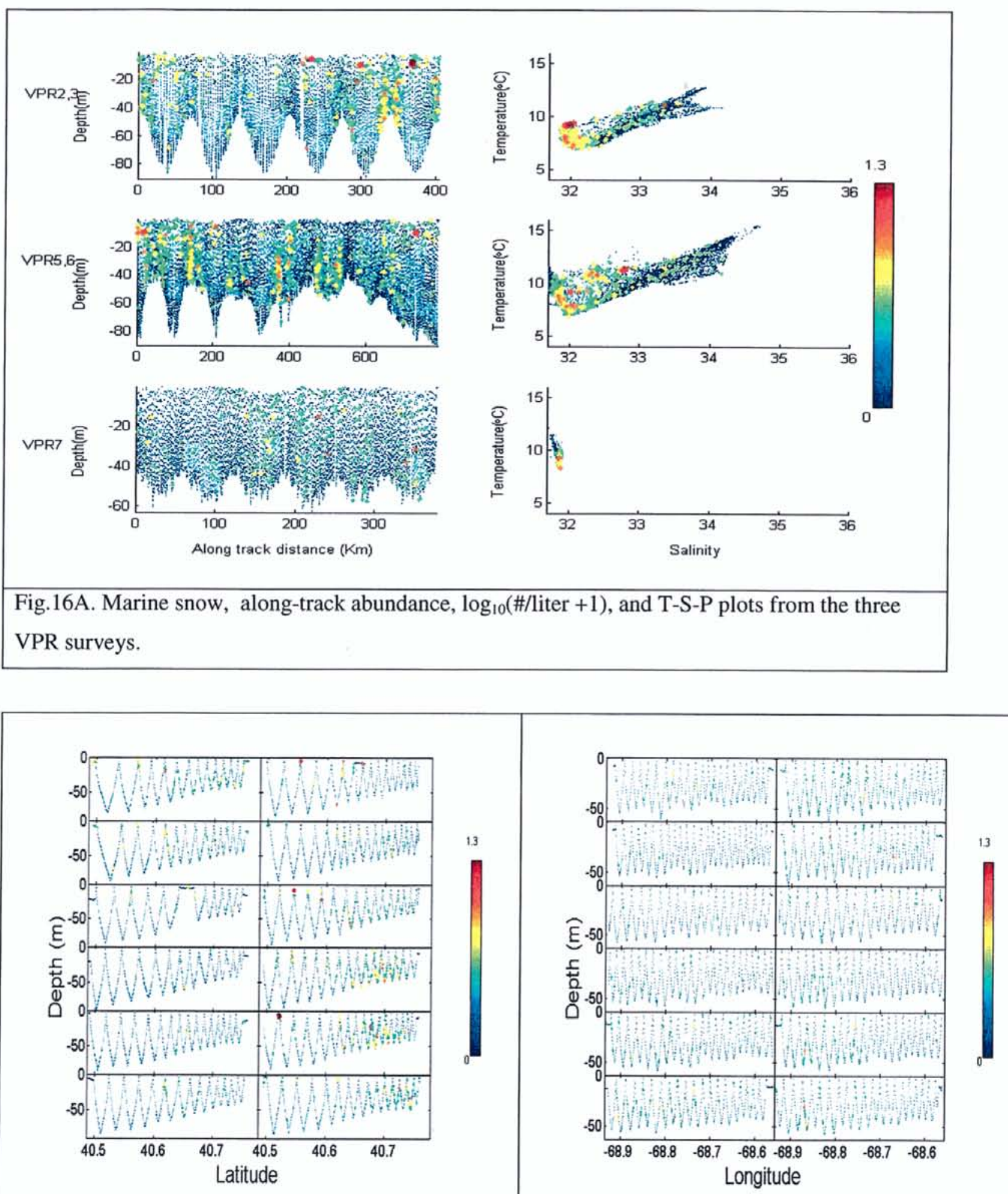

Fig. 16 B. Marine Snow abundance, $\log _{10}(\# /$ liter+1), in VPR2-3 (left panel) and VPR6 (right panel) 


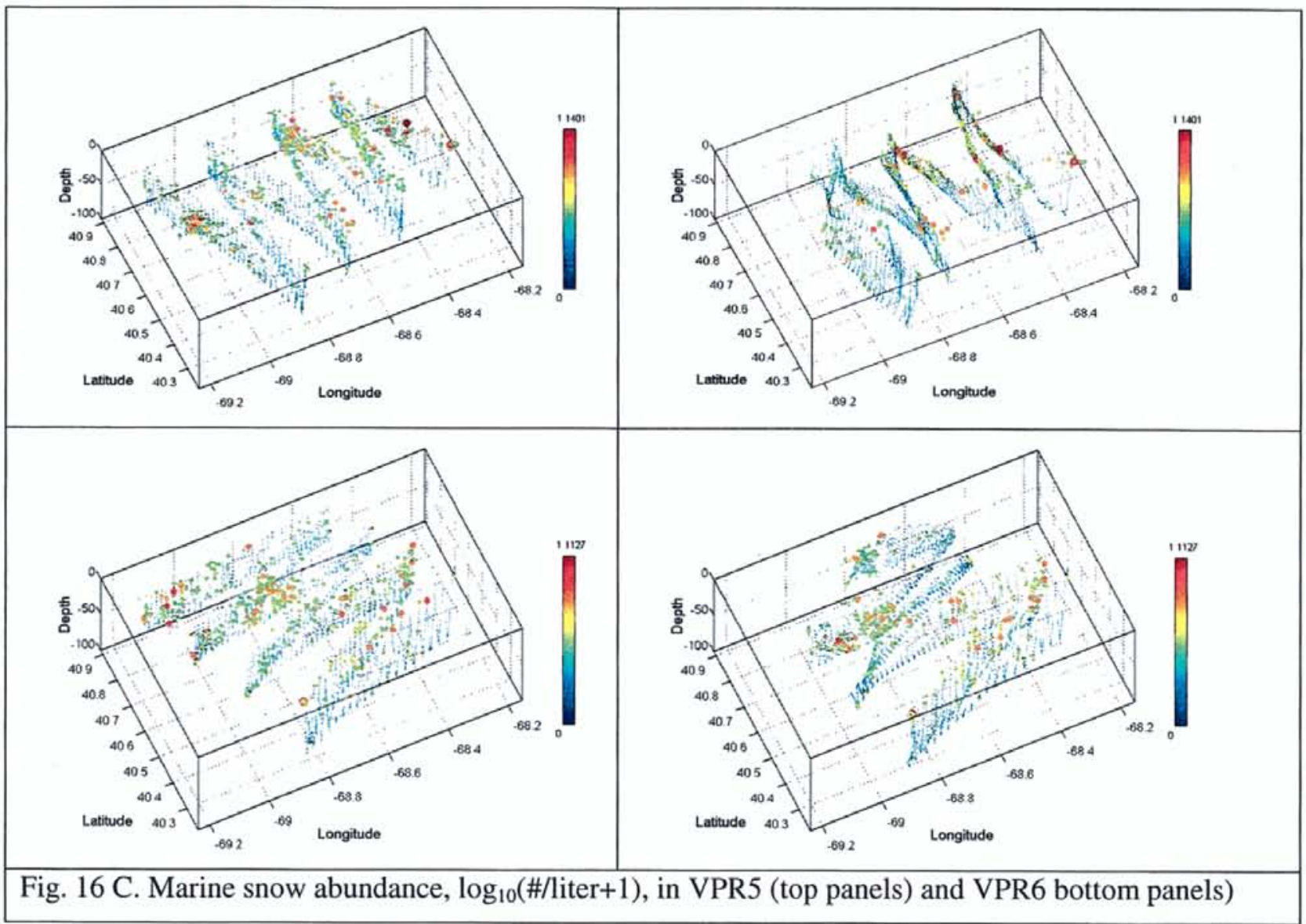

houses. High abundance was observed all through the column in shallow water of the mixed area (Fig. 16). This observation is consistent with other species such as diatom rods. In VPR 2-3, they were most plentiful in cooler and less saline waters. In VPR 5-6, we can not only see high abundance in cold and fresh water but also in high temperature and salty water (Fig. 16A). From VPR 5 and 6, the marine snow was found in the northeastern portion of the RLR and in the vicinity of the $C$. socialis patch as well (Fig. 16C).

\subsection{Fluxes of plankton taxa through the retention/loss region}




\subsubsection{Flux of C. socialis into the RLR through the eastern boundary}

The reversals in eastward current velocity (from the ship's ADCP) through the first six 2$\mathrm{h}$ sections in VPR 2-3 reflect the flow during one 12-h tidal cycle (Fig. 17A). The current initially flows westward (Fig. 17A., blue area in upper left panel), turns eastward, and reverses again to the west by the $8^{\text {th }}$ hour (Fig. 17A., blue area in upper right panel). Maximum velocity was $\pm 0.5 \mathrm{~m} / \mathrm{s}$. The transport of $C$. socialis through this section was controlled largely by the tidal flow, with a strong initial flux to the west followed by an eastward flux, and then a westward flux (Fig.17 B). Net flux through this vertical section over the tidal cycle was obtained by summing the fluxes from the six 2-h sections (Fig.18).
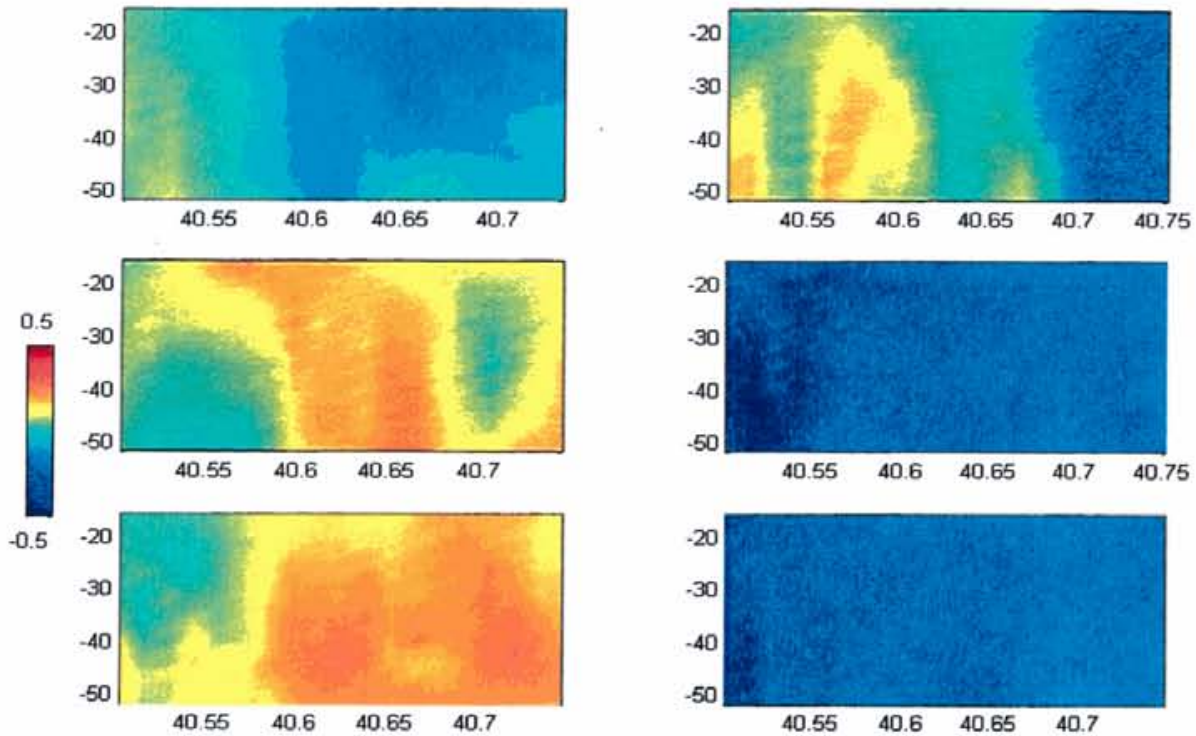

Fig. 17. A. VPR2-3, A. Eastward ADCP current, and B. eastward flux of C. socialis (in $1000 \mathrm{~s}$ of colonies $\mathrm{m}^{-2} \mathrm{~s}^{-1}$ ). The first tidal cycle is shown, six 2-hour sections. (The temporal sequence of panels is from top to bottom and then left to right). 

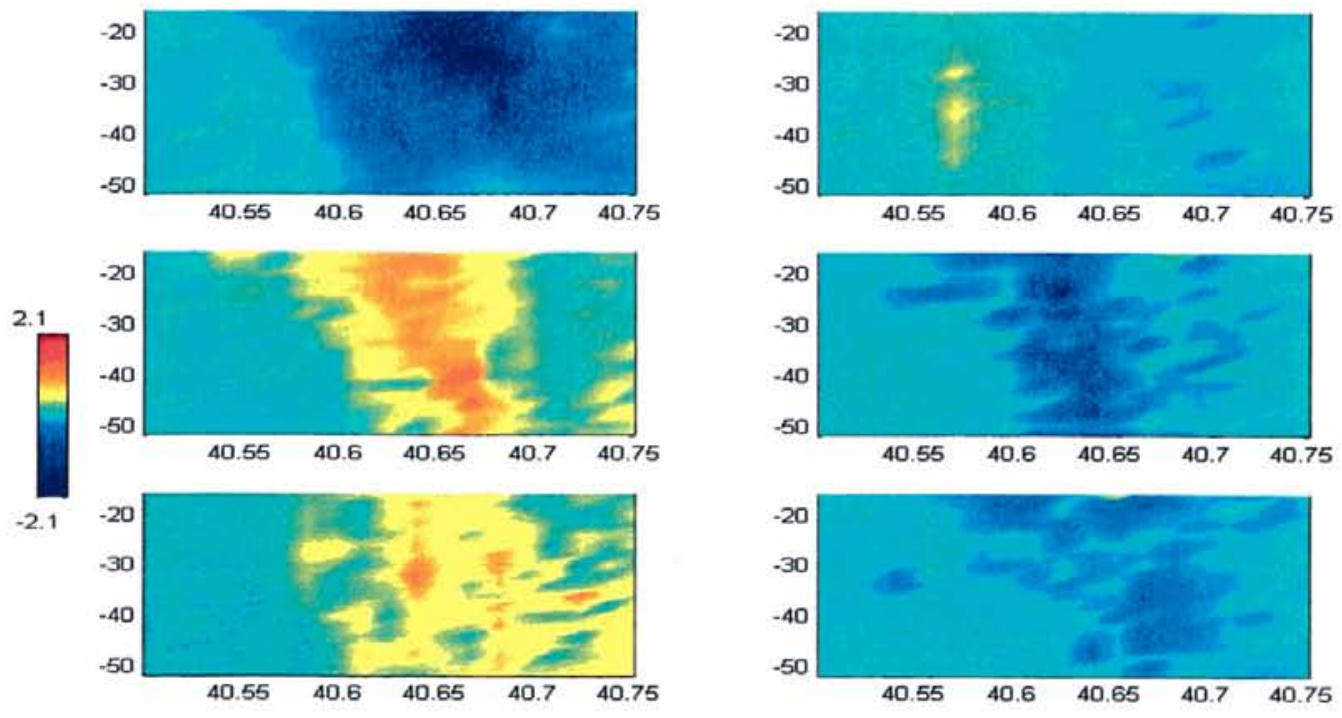

Fig. 17.B. VPR2-3, eastward flux of C. socialis (in 1000s of colonies $\mathrm{m}^{-2} \mathrm{~s}^{-1}$ ). The first tidal cycle is shown, six 2-hour sections. (The temporal sequence of panels is from top to bottom and then left to right).

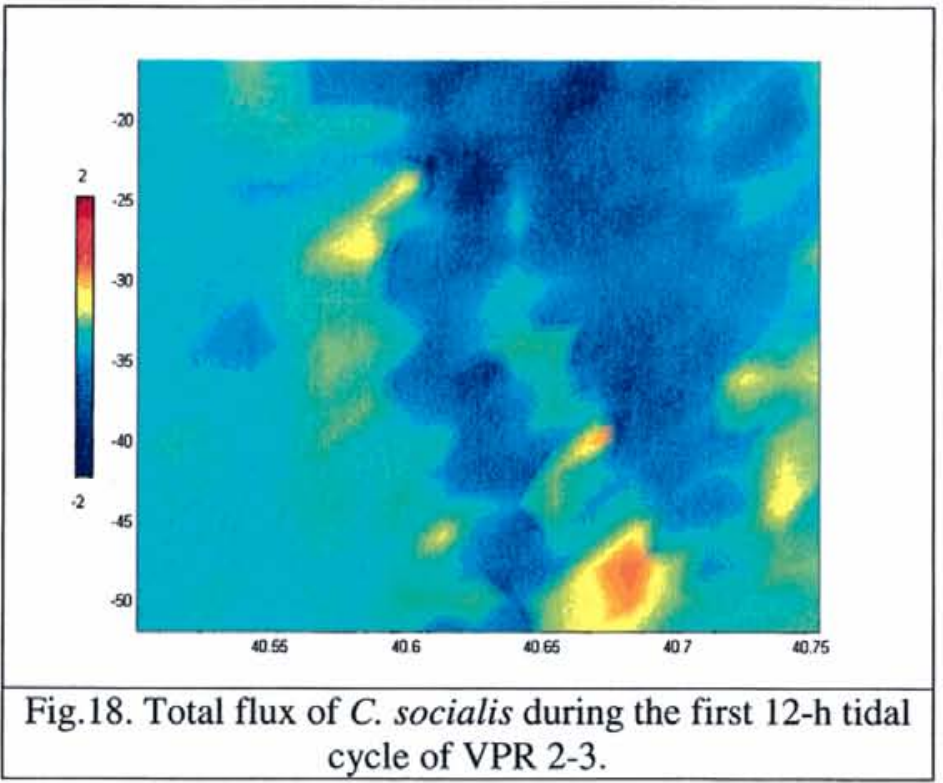


The spatially-averaged flux through this section was 100 colonies $\mathrm{m}^{-2} \mathrm{~s}^{-1}$. The close association of the $C$. socialis patch with seawater density and its movement with the tidal flow indicated that physical factors were controlling the distribution of this species over these time and space scales.

\subsubsection{Fluxes of taxa within the RLR}

The flux of each taxon within the Retention and Loss Region from the detided ADCP and VPR 5-6 abundance data revealed net westward and southward fluxes of all taxa (Table 2).

Table 2. The mean flux of plankton taxa in the RLR from the VPR 5-6 survey. Unit:1000 numbers* $\mathrm{m}^{-2} \mathrm{~s}^{-1}$

\begin{tabular}{|l|c|c|}
\hline & Eastward flux & Northward flux \\
\hline Copepods & -0.0385 & -0.0770 \\
\hline C. socialis & -0.0028 & -0.0729 \\
\hline Diatom rod & -0.0566 & -0.0254 \\
\hline Medusae & -0.0113 & -0.0053 \\
\hline Marine snow & -0.0056 & -0.0023 \\
\hline
\end{tabular}

The spatial distributions of the fluxes are presented in Figure 19. This flux was computed as the product of detided ADCP velocities ( $u$ and $v$ ) and VPR plankton abundances after kriging the data to the same uniform grid. 

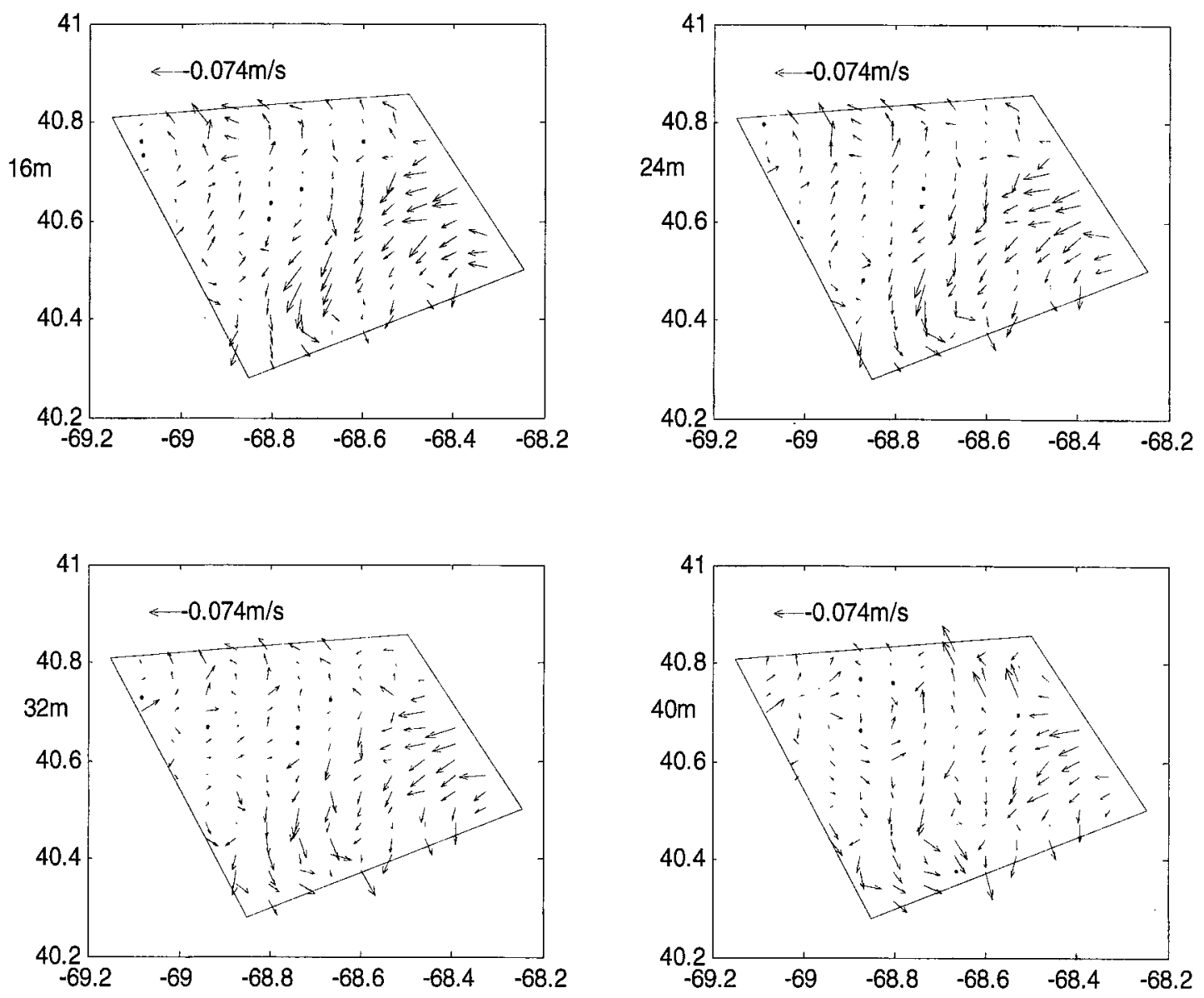

Fig 19A. Velocity vectors for kriged detided ADCP currents in VPR 5-6 at four different depths.

Kriged velocities-The general pattern of the kriged flow field matched that of the unkriged data (cf. Figs. 10B, 19A), with westward currents entering the eastern boundary of the RLR and flowing south and southwest and eastward flow along the western boundary with stagnant flow in the west-central portion of the RLR. 

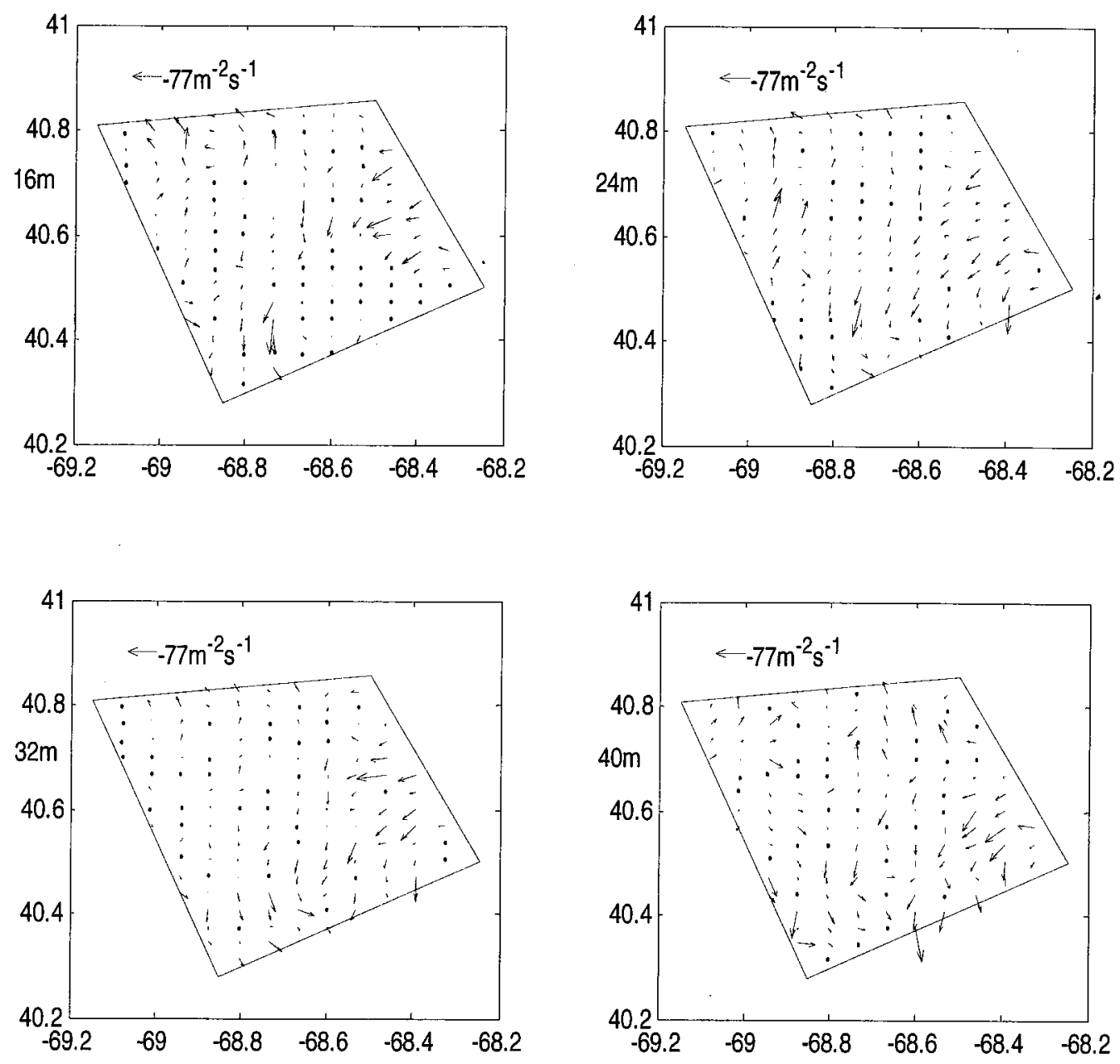

Fig 19B. Flux of copepods

Copepod flux - The flux of copepods mirrored the flow field, since this group was broadly distributed throughout the RLR with no apparent spatial pattern (Figs. 12, 19B). There was a southwestward flux in the eastern portion of the RLR and a southward flux out of the RLR to the south at depth. The flux was northward at the NW corner of the RLR at the surface and near zero in the western central portion of the RLR. 

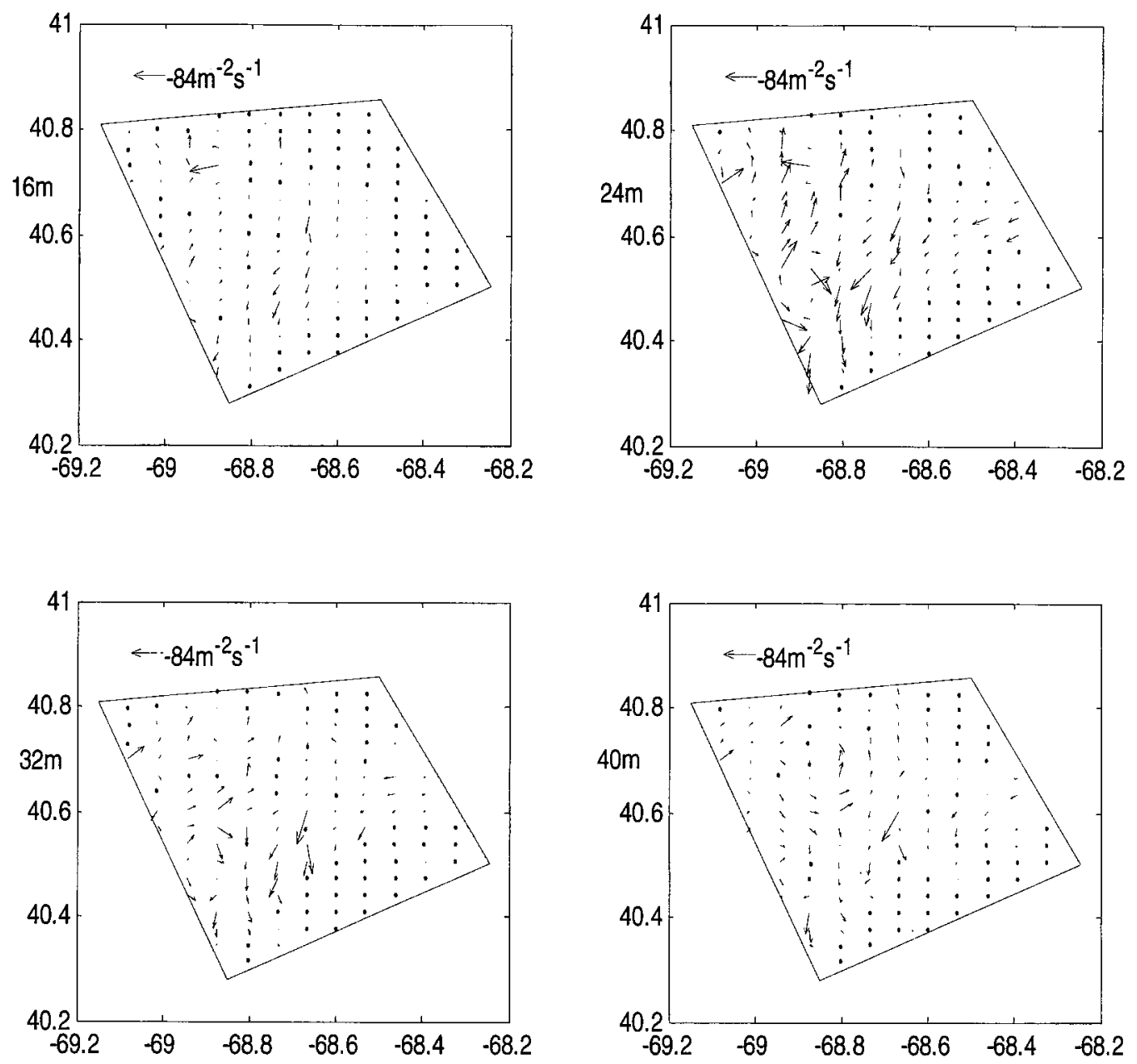

Fig 19C. Flux of C. socialis

Chaetoceros socalis flux-The flux of $C$. socialis was concentrated in the central portion of the RLR at mid-depth, where the main patch was located (Fig. 19C). The flux was confused with no dominant direction, owing to the weak currents in the region of the main $C$. socialis patch (Figs. 19A,C, 13C,). There was no apparent flux across any of the RLR boundaries (Fig. 19C). 

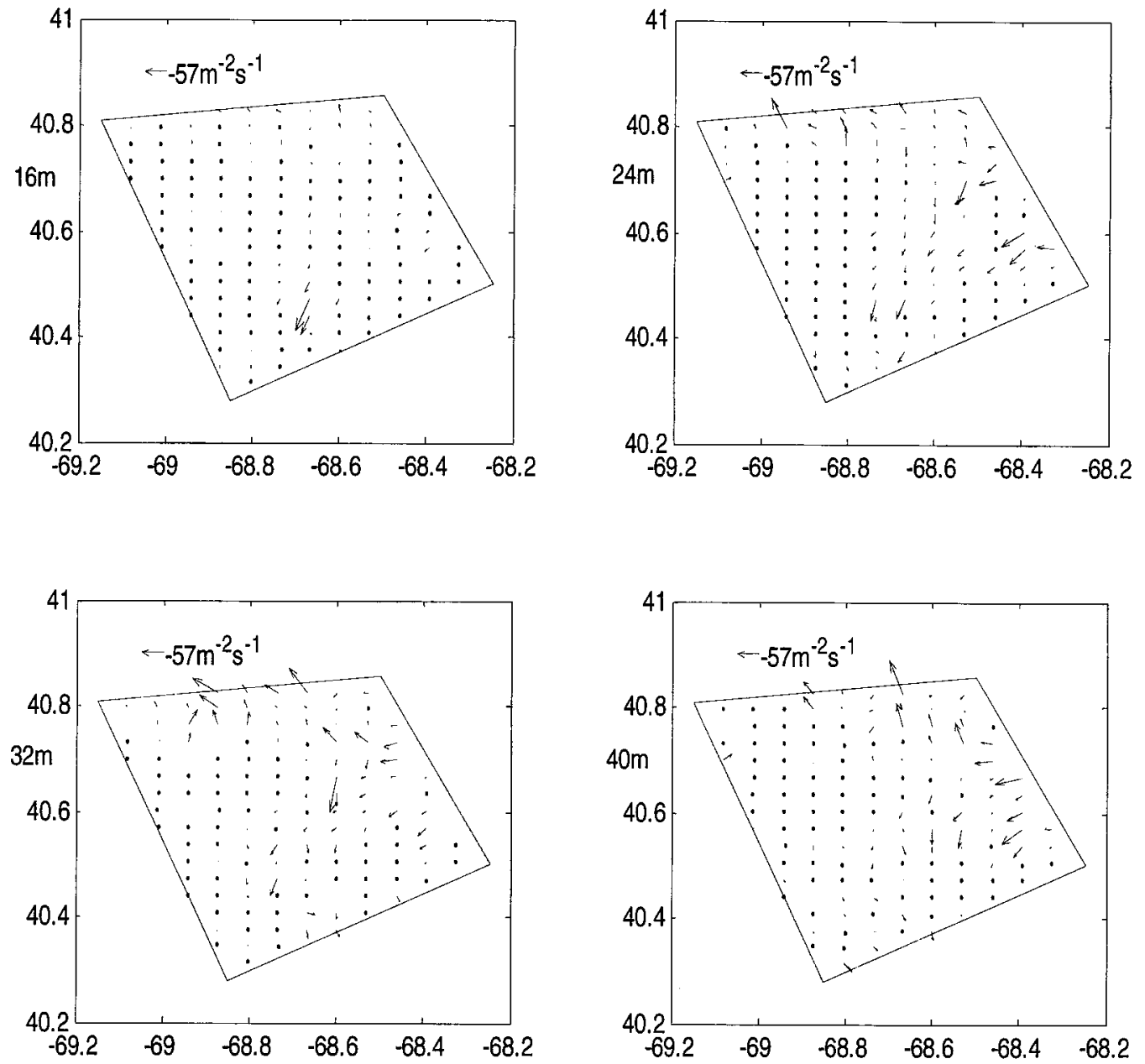

Fig. 19D. Flux of diatom rods

Diatom rod flux-The flux of diatom rods in the surface layer $(16 \mathrm{~m})$ was weak everywhere except one point in the SW corner of the RLR (Fig. 19D). Most of the flux occurred in the deeper layers, with westward flux along the eastern side of the RLR and a northwestward flux along the northern boundary of the RLR. 

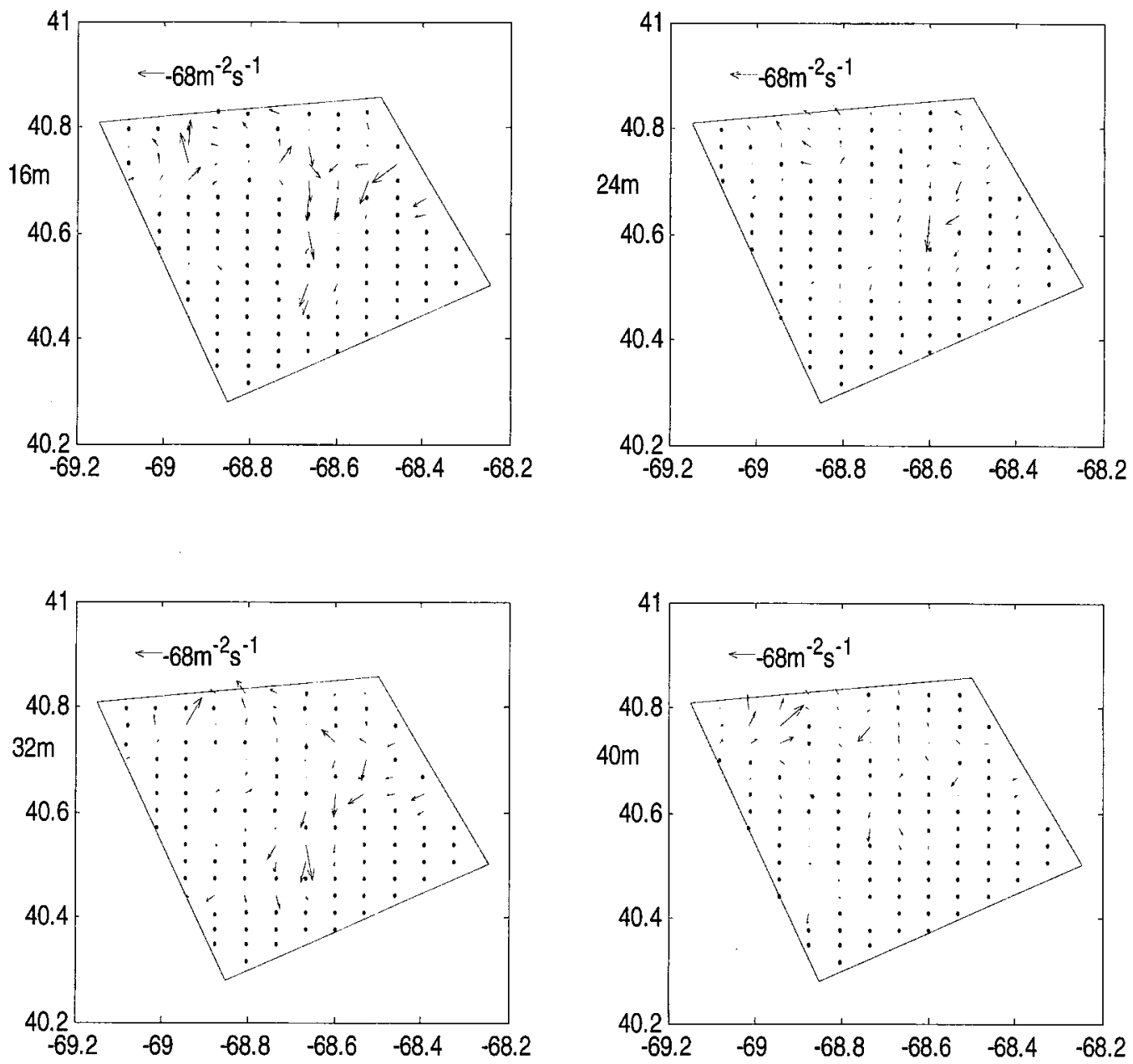

Figure 19E. Flux of medusa

Medusae flux - The flux of medusae was largely in NE half of the RLR with a band of SW flux extending through the RLR (Fig. 19E). The larger flux in the NE reflected the higher abundance of this species in the shallow well-mixed region of the bank. A northeastward flux of medusae was observed in the NW corner of the RLR. 

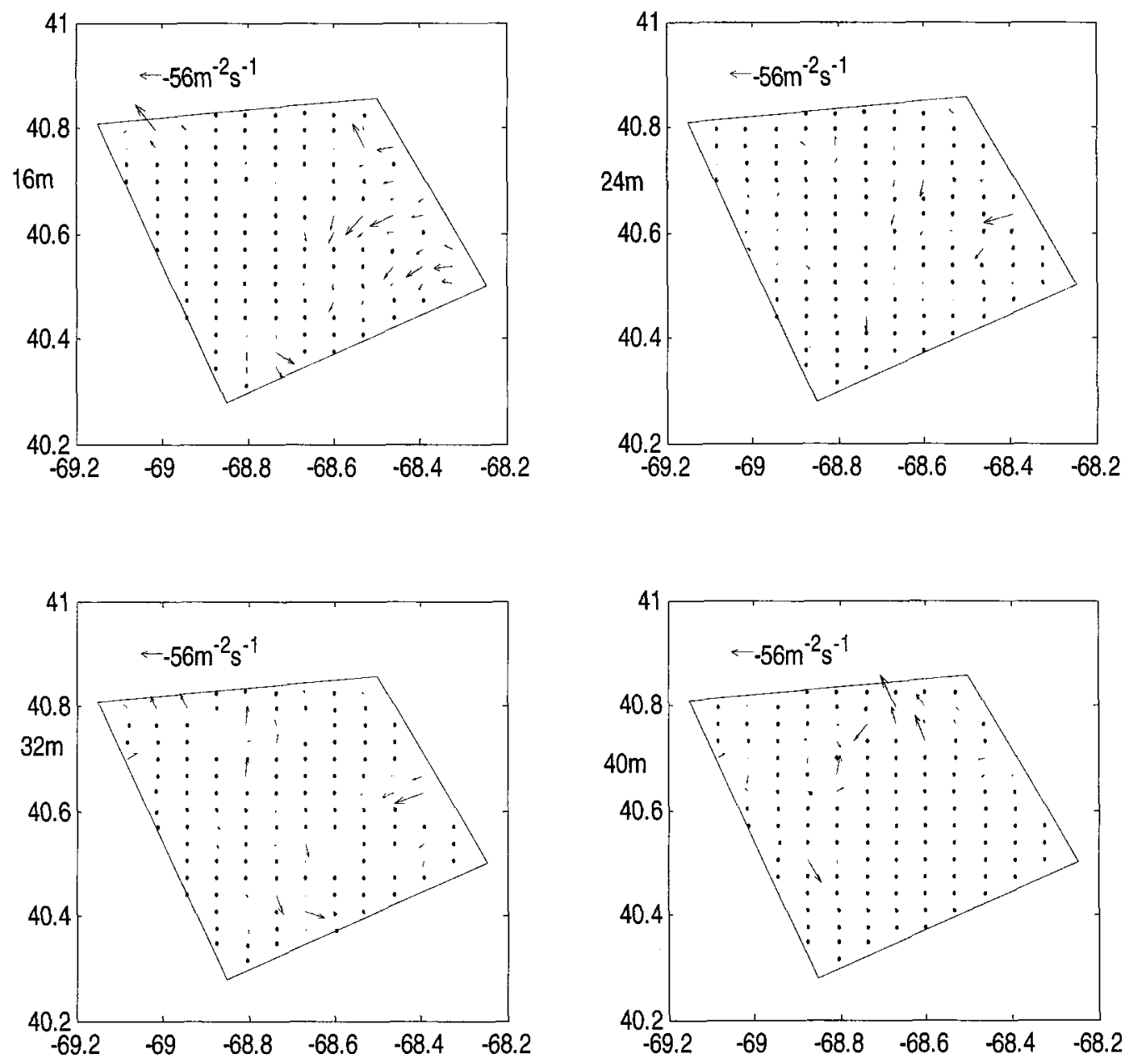

Fig. 19F. Flux of marine snow.

Marine snow flux - The flux of marine snow was largely to the SW in the SE portion of the RLR, with some northward flux in the NE part of the grid (Fig. 19F). Higher flux in the surface in this region is reflective of the relatively high concentration of marine snow at this location. 


\subsection{Model predicted retention/loss of C. socialis}

Transport of the $C$. socialis through the RLR, estimated from the 20d runs of the Lagrangian tracking model, revealed a SW movement and loss to the south and west out of the RLR for all VPR tows (Fig. 20). The exception was the NE corner, in the wellmixed area, where the particles were transported to the north and retained on the bank. (Note: most particles left the model domain during this period and thus are not shown).

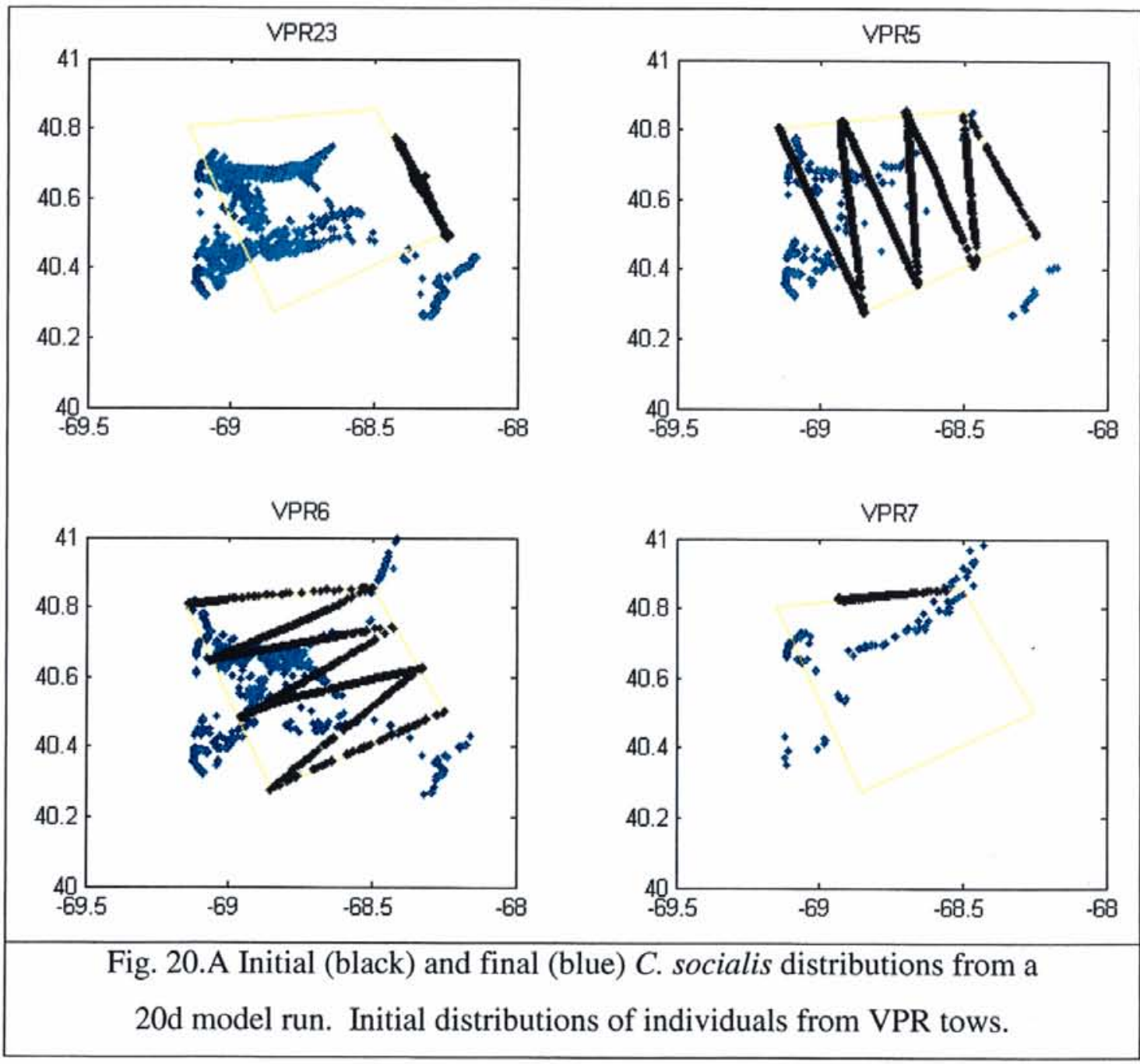




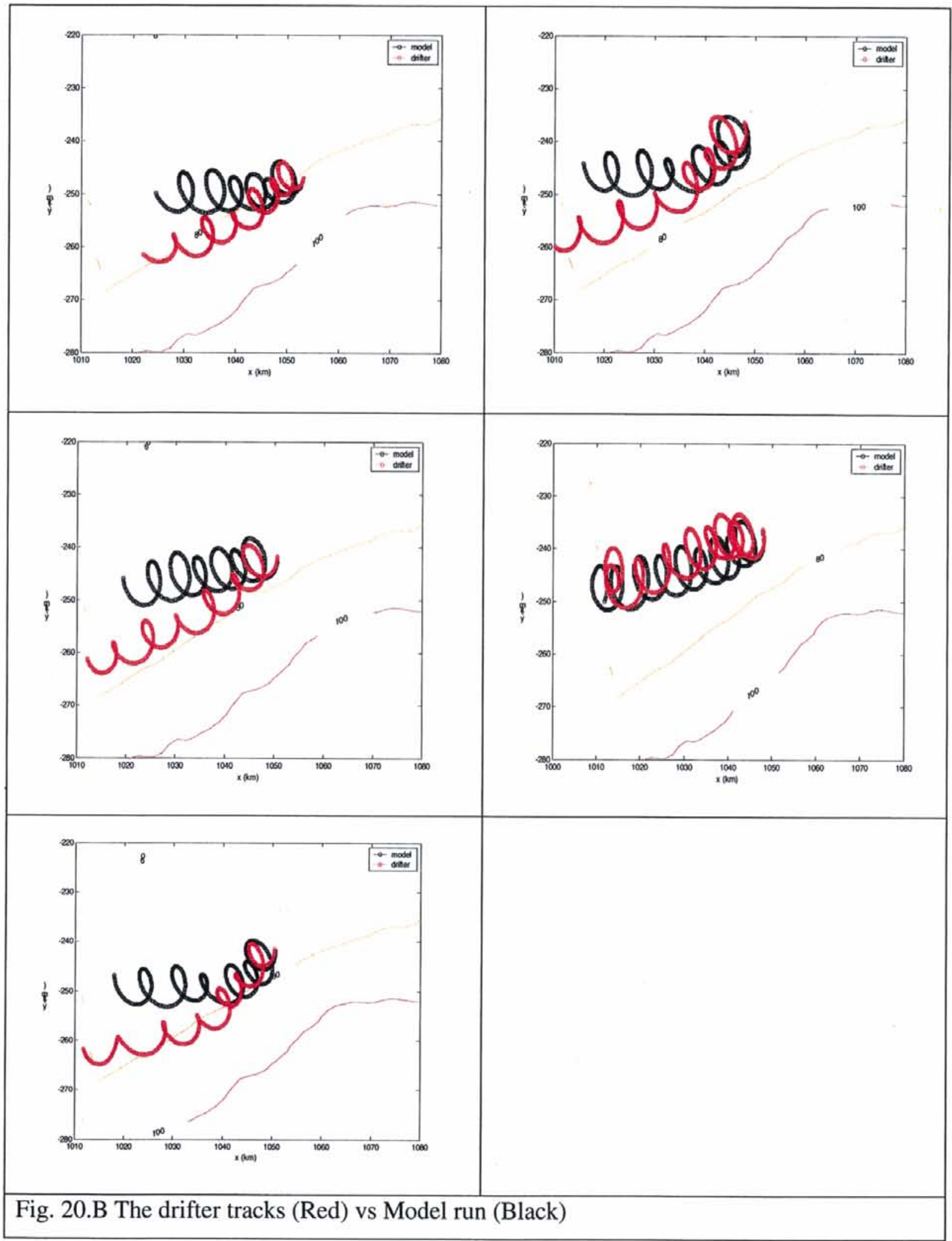


After 20 days, most $C$. socialis were lost from the RLR through the south and west boundaries (Table 3). The individual $C$. socialis colonies observed in the four VPR tows moved out of the RLR to the west after twenty days (Table 3, Fig. 20). Loss through the southern boundary was less important, except for VPR 2-3 whose southernmost particles were lost to the south. A very small percentage of the particles went northward and recirculated around the bank even in the far north sections, VPR 7 (Table 3). As for those particles retained in the box area, they were primarily flowing southwestward at the end of the model run. In all, the RLR was not retaining particles on the bank. This result was also consistent with satellite-tracked drifters deployed during this June cruise, as these drifters were observed to be advected southwestward (Fig. 10A). From drifter tracks and model tracks (Fig. $20 \mathrm{~B}$ ), the interpolation errors by the model were not significant.

\begin{tabular}{|l|c|l|l|l|l|l|}
\hline \multicolumn{7}{|c|}{ Table 3. Model-estimated retention and loss of C. socialis } \\
\hline & Northward & Southward & Westward & In the box & Retention & Loss \\
\hline VPR 2-3 & 0 & 0.2902 & 0.4730 & 0.2368 & 0 & 0.7632 \\
\hline VPR 5 & 0.0002 & 0.0017 & 0.9441 & 0.0541 & 0.0002 & 0.9458 \\
\hline VPR 6 & 0.0441 & 0.0129 & 0.8289 & 0.1141 & 0.0441 & 0.8418 \\
\hline VPR 7 & 0.0631 & 0 & 0.7337 & 0.2032 & 0.0631 & 0.7337 \\
\hline
\end{tabular}

\subsection{Power spectra of dominant variables.}

Power spectra computed to examine scales of variability in the hydrographic and plankton data, revealed several peaks in variation (Fig. 21). The average time interval of the towyo in VPR 7 was 5.4 minutes. The spectrum of pressure was utilized as the reference. The pressure, temperature, salinity, density and fluorescence shared almost the same dominant peaks (Fig. 21), which demonstrated the four variables were associated with the towyo intervals. 

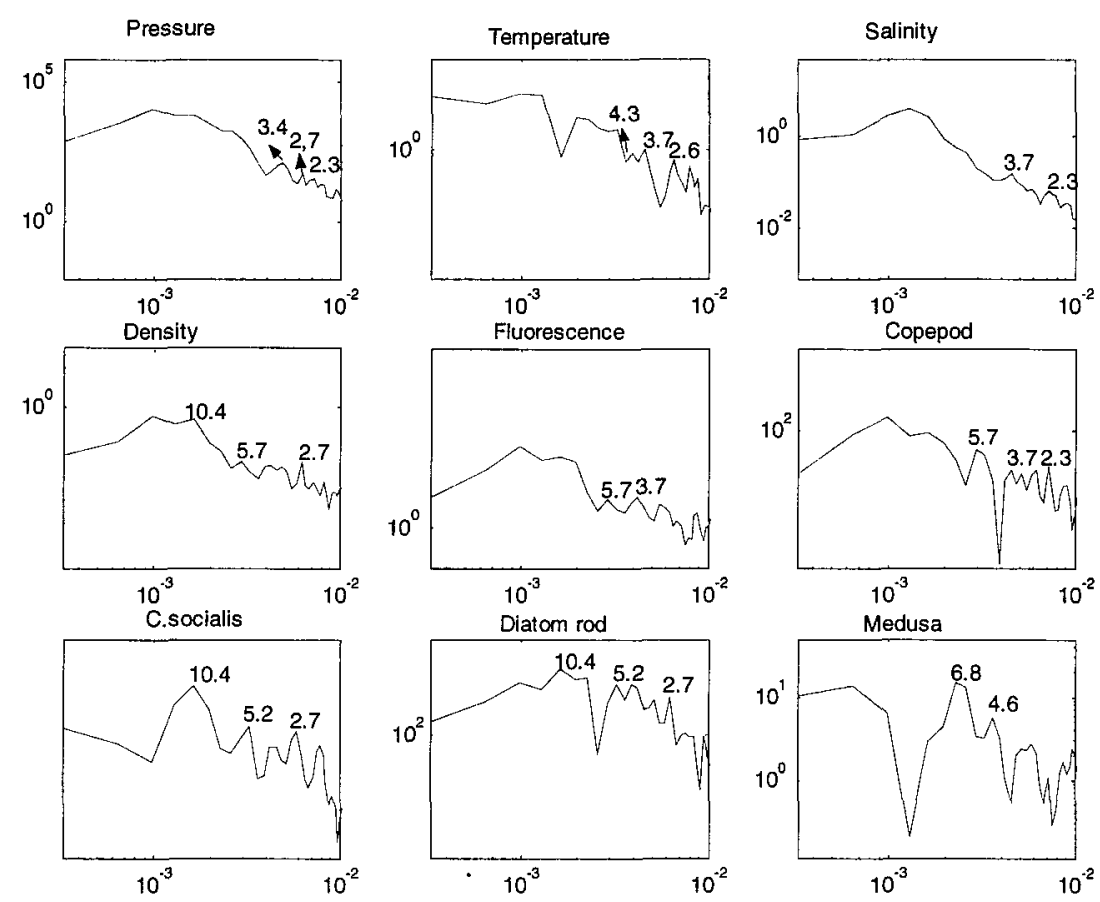

Fig. 21A. Power spectra for pressure, temperature, salinity, density, fluorescence and copepod,C.Socialis, diatom rod and medusa abundances for the first two hours' section in VPR 7. $\mathrm{X}$ axis is frequency, $Y$ axis is energy density. Period (in minutes) of dominant peaks are noted on each panel.

The physical features (temperature, salinity and density) had lower energy density than the biological features (fluorescence and plankton taxa). The higher energy density in fluorescence and plankton taxa indicates the biology was more variable than hydrography, i.e., vertical structure had more influence on plankton abundance and fluorescence than on seawater density. 

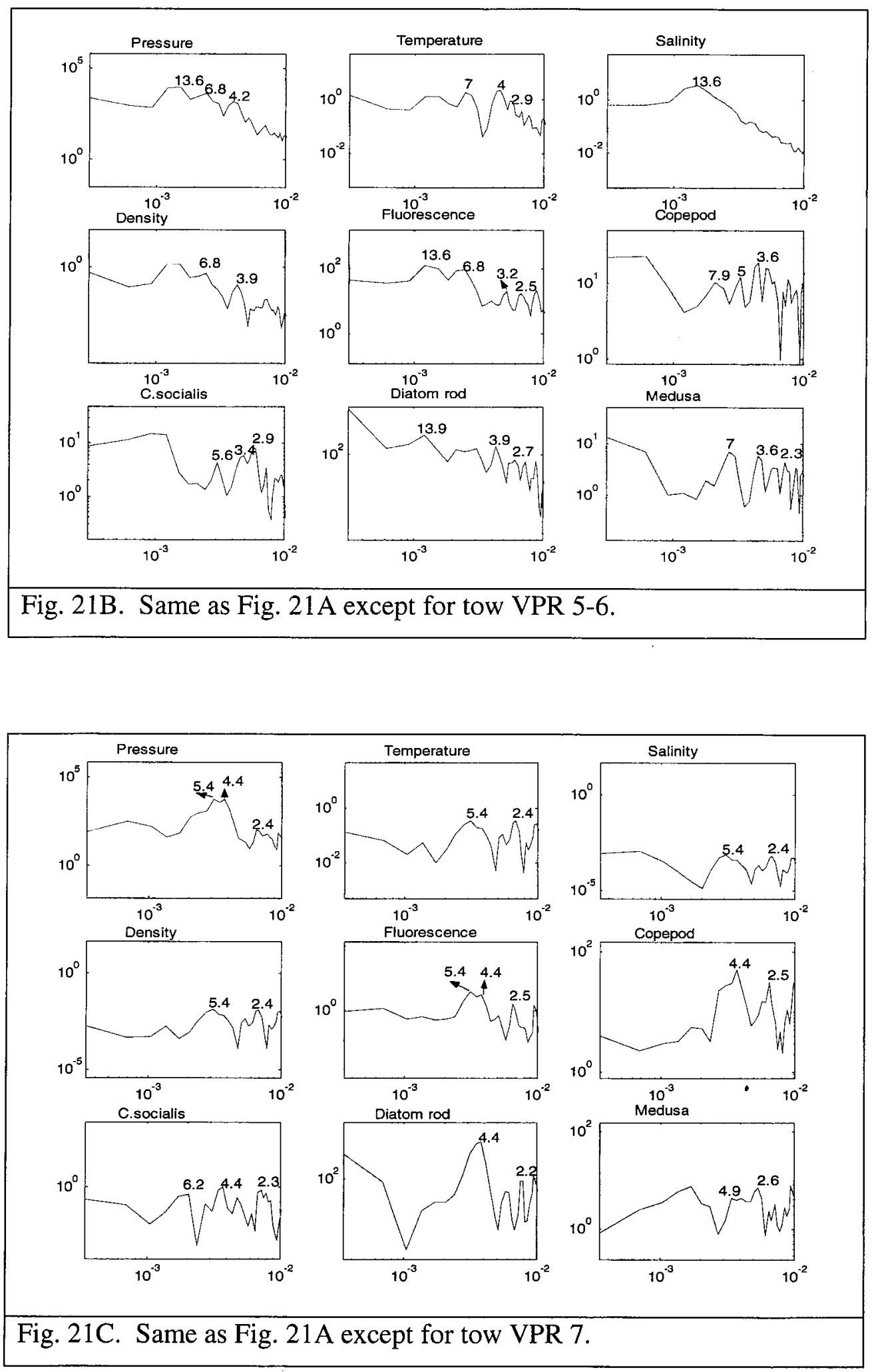


\subsection{Factor analysis}

In VPR 2-3, the first three principal components explained up to $82 \%$ of the total variability in the eight variables: temperature, salinity, density, fluorescence, light attenuation, copepods, $C$. socialis, and diatom rods (Table 4). Other modes accounted for the remaining $18 \%$ of the total variability. The factor-loading matrix (Table 5 ) gives the correlation coefficients between the variables and the factors, and thus indicates the potential contribution of each variable to the corresponding factor. According to Kaiser's criterion, we would retain 3 factors. The first factor is marked by high loadings on salinity (negative), density (negative), fluorescence (positive) and light attenuation (positive). This factor indicates that fluorescence is highly related to light attenuation, implying that the particles suspended in that region are mostly composed of phytoplankton, while density is dominated by salinity. It also indicates that most of phytoplankton resides in fresher upper layers (shallower than $50 \mathrm{~m}$ ) (Fig. 4). The second factor is marked by high loadings on copepod (negative) abundance and smaller loadings on diatom rod abundance (negative). No association between copepods and temperature, salinity, or density were observed, indicating that the distribution of copepods was decoupled from the hydrography in VPR 2-3. Copepods were abundant throughout the whole water column in these VPR 2-3 sections. The third factor is marked by high loadings on temperature (negative), salinity (negative), and $C$. socialis (positive). The patch of $C$. socialis was observed in the cold and fresh water, but not in the high temperature, high salinity water (Figs. 4, 13B).

In VPR 5-6, four factors were used, with the fourth eigenvalue close to 1 (Tables 6, 7). The first four factors contribute $80.14 \%$ of total variance. The first factor is again marked by high loadings on salinity and density, indicating the dominant effect of salinity on density. Temperature is not associated with salinity since the higher surface temperature was caused by radiant heat input via vernal warming. The second factor is marked by high loadings on temperature (positive), C. socialis (negative) and diatom rod (positive), 
which implies abundance of both phytoplankton taxa was controlled by temperature. But the diatom rod distribution is not associated with $C$. socialis, from the distributional plots and the correlation coefficient (-0.0514). Diatom rods are present in temperatures above $6^{\circ} \mathrm{C}$, while $C$. socialis resides in colder water $\left(<5^{\circ} \mathrm{C}\right)$ (Figs. 13, 14). The third factor is marked by high loadings on florescence (positive) and light attenuation (positive). Neither is associated with hydrography, as observed in VPR 2-3. Fluorescence was not limited to colder water, with high levels extending throughout most of the water column (Fig. 5). The correlation coefficient for florescence and light attenuation is high (0.7094). The fourth factor is due to copepod abundance, which was decoupled from hydrography, as seen from the uniform distribution (Fig. 12). Based on the correlation coefficient matrix for hydrography and plankton abundance, there was no significant relationship between copepods and hydrography as apparent in their distributions (Figs.4-7, 12).

Likewise there was not a significant relation between copepods and fluorescence (correlation coefficient 0.001 ).

\begin{tabular}{|c|c|c|}
\hline \multicolumn{3}{|c|}{$\begin{array}{r}\text { Table 4. Eigenvalues from the principle } \\
\text { component analysis for VPR 2-3 }\end{array}$} \\
\hline Eigenvalue & $\begin{array}{c}\text { Total } \\
\text { variance }\end{array}$ & $\begin{array}{c}\text { Cumulative } \\
\text { variance }\end{array}$ \\
\hline 4.1670 & 0.5209 & 0.5209 \\
\hline 1.2071 & 0.1509 & 0.6718 \\
\hline 1.1579 & 0.1447 & 0.8165 \\
\hline 0.7202 & 0.0900 & 0.9065 \\
\hline 0.4227 & 0.0528 & 0.9594 \\
\hline 0.2373 & 0.0297 & 0.9890 \\
\hline 0.0877 & 0.0110 & 1.0000 \\
\hline 0.0002 & 0.0000 & 1.0000 \\
\hline
\end{tabular}




\begin{tabular}{|c|c|c|c|}
\hline & Factor 1 & Factor 2 & Factor 3 \\
\hline Temperature & 0 & 0 & 0.9223 \\
\hline Salinity & -0.7118 & 0 & 0.6662 \\
\hline Density & $\begin{array}{l}-0.8713 \\
\end{array}$ & 0 & 0 \\
\hline Florescence & 0.8927 & 0 & 0 \\
\hline Light attenuation & 0.9425 & 0 & 0 \\
\hline Copepod & 0 & -0.8196 & 0 \\
\hline C. socialis & 0 & 0 & -0.6842 \\
\hline Diatom rod & 0 & -0.6424 & 0 \\
\hline
\end{tabular}

\begin{tabular}{|c|c|c|}
\hline \multicolumn{3}{|c|}{$\begin{array}{r}\text { Table 6. Eigenvalues from the principle } \\
\text { component analysis for VPR 5-6 }\end{array}$} \\
\hline Eigenvalue & $\begin{array}{c}\text { Total } \\
\text { variance }\end{array}$ & $\begin{array}{c}\text { Cumulative } \\
\text { variance }\end{array}$ \\
\hline 2.3316 & 0.2914 & 0.2914 \\
\hline 1.7514 & 0.2189 & 0.5104 \\
\hline 1.3541 & 0.1693 & 0.6796 \\
\hline 0.9742 & 0.1218 & 0.8014 \\
\hline 0.7222 & 0.0903 & 0.8917 \\
\hline 0.6133 & 0.0767 & 0.9683 \\
\hline 0.2530 & 0.0316 & 1.0000 \\
\hline 0.0002 & 0.0000 & 1.0000 \\
\hline
\end{tabular}




\begin{tabular}{|l|c|c|c|c|}
\hline $\begin{array}{c}\text { Table 7. Factor loading matrix for VPR 5-6(any factor loading } \\
\text { whose absolute value smaller than 0.5 was set to zero.) }\end{array}$ \\
\hline & Factor 1 & Factor 2 & Factor 3 & Factor 4 \\
\hline Temperature & 0 & 0.8675 & 0 & 0 \\
\hline Salinity & -0.9629 & 0 & 0 & 0 \\
\hline Density & -0.9299 & 0 & 0 & 0 \\
\hline Florescence & 0 & 0 & -0.9214 & 0 \\
\hline Light attenuation & 0 & 0 & -0.8378 & 0 \\
\hline Copepod & 0 & 0 & 0 & -0.9913 \\
\hline C. socialis & 0 & -0.7067 & 0 & 0 \\
\hline Diatom rod & 0 & 0.6161 & 0 & 0 \\
\hline
\end{tabular}

\begin{tabular}{|c|c|c|}
\hline \multicolumn{3}{|c|}{$\begin{array}{r}\text { Table } \\
\text { component analysis for VPR 7 }\end{array}$} \\
\hline Eigenvalue & $\begin{array}{c}\text { Total } \\
\text { variance }\end{array}$ & $\begin{array}{c}\text { Cumulative } \\
\text { variance }\end{array}$ \\
\hline 2.8701 & 0.3588 & 0.3588 \\
\hline 1.2518 & 0.1565 & 0.5152 \\
\hline 1.0000 & 0.1250 & 0.6402 \\
\hline 0.9721 & 0.1215 & 0.7617 \\
\hline 0.7865 & 0.0983 & 0.8601 \\
\hline 0.6189 & 0.0774 & 0.9374 \\
\hline 0.5006 & 0.0626 & 1.0000 \\
\hline 0 & 0 & 1.0000 \\
\hline
\end{tabular}




\begin{tabular}{|l|c|c|c|c|}
\hline \multicolumn{5}{|c|}{$\begin{array}{l}\text { Table 9. Factor loading matrix for VPR 5-6(any factor loading } \\
\text { whose absolute value smaller than 0.5 was set to zero.) }\end{array}$} \\
\hline & Factor 1 & Factor 2 & Factor 3 & Factor 4 \\
\hline Temperature & 0.9443 & 0 & 0 & 0 \\
\hline Salinity & 0.6639 & 0 & 0 & 0 \\
\hline Density & -0.9019 & 0 & 0 & 0 \\
\hline Florescence & 0 & 0.7076 & 0 & 0 \\
\hline Light attenuation & 0.7112 & 0 & 0 & 0 \\
\hline Copepod & 0 & 0 & 0.9959 & 0 \\
\hline C. socialis & 0 & 0 & 0 & 0.9861 \\
\hline Diatom rod & 0 & -0.7528 & 0 & 0 \\
\hline
\end{tabular}

In VPR 7, the first four factors contributed $76.17 \%$ of total variance (Tables 8,9$)$. The first factor is marked by high loadings on temperature, salinity, density, and light attenuation. Temperature is highly associated with density because of the stronglystratified warm surface plume (Fig. 7A, Table 9). The second factor is marked by loadings on the fluorescence (positive) and diatom rods (negative), which implies other phytoplankton with high abundance instead of diatom rods contribute to fluorescence. The third and fourth modes were dominated by copepods and C. socialis, respectively.

\begin{tabular}{l} 
Table 10.A Correlation coefficients between 1: temperature, 2:salinity, 3:density, \\
4:fluorescence, 5:light attenuation, 6:copepod, 7:C.socialis, 8:diatom rod, 9:marine snow and \\
10:medusa for VPR 2-3 \\
\hline
\end{tabular}




\begin{tabular}{|c|c|c|c|c|c|c|c|c|c|c|}
\hline \multicolumn{11}{|c|}{ Table 10.B Correlation coefficients for VPR 5-6 } \\
\hline & 1 & 2 & 3 & 4 & 5 & 6 & 7 & 8 & 9 & 10 \\
\hline 1 & 1.00 & 0.83 & 0.55 & -0.45 & -0.36 & -0.05 & -0.41 & -0.02 & -0.05 & -0.2 \\
\hline 2 & & 1.00 & 0.92 & -0.49 & -0.59 & -0.11 & -0.32 & -0.24 & -0.07 & -0.23 \\
\hline 3 & & & 1.00 & -0.43 & -0.63 & -0.13 & -0.20 & -0.34 & -0.08 & -0.21 \\
\hline 4 & & & & 1.00 & 0.71 & 0.02 & 0.18 & 0.14 & 0.09 & 0.08 \\
\hline 5 & & & & & 1.00 & 0 & 0.09 & 0.31 & 0.15 & 0.11 \\
\hline 6 & & & & & & 1.00 & 0.07 & 0.05 & -0.01 & 0.04 \\
\hline 7 & & & & & & & 1.00 & -0.09 & 0.05 & 0.09 \\
\hline 8 & & & & & & & & 1.00 & 0.08 & 0.07 \\
\hline 9 & & & & & & & & & 1.00 & 0 \\
\hline 10 & & & & & & & & & & 1.00 \\
\hline \multicolumn{11}{|c|}{ Table 10.C Correlation coefficients for VPR 7} \\
\hline & 1 & 2 & 3 & 4 & 5 & 6 & 7 & 8 & 9 & 10 \\
\hline 1 & 1.00 & -0.15 & -0.98 & 0.06 & 0.06 & 0.05 & -0.19 & 0.07 & -0.09 & -0.14 \\
\hline 2 & & 1.00 & 0.33 & 0.21 & -0.05 & -0.07 & 0 & 0.06 & 0.01 & -0.05 \\
\hline 3 & & & 1.00 & -0.01 & -0.07 & -0.06 & 0.17 & -0.05 & 0.09 & 0.13 \\
\hline 4 & & & & 1.00 & 0 & -0.03 & -0.09 & -0.06 & 0. & -0.08 \\
\hline 5 & & & & & 1.00 & 0.01 & -0.02 & 0.02 & -0.01 & -0.02 \\
\hline 6 & & & & & & 1.00 & 0.01 & 0.04 & 0 & 0.04 \\
\hline 7 & & & & & & & 1.00 & -0.12 & 0.06 & 0.07 \\
\hline 8 & & & & & & & & 1.00 & -0.05 & -0.01 \\
\hline 9 & & & & & & & & & 1.00 & 0.05 \\
\hline 10 & & & & & & & & & & 1.00 \\
\hline
\end{tabular}

\section{Discussion}

\subsection{New Technology}

The high-resolution analysis of the plankton and physics in the RLR was made possible by the use of new sampling technology. With the development of the Video Plankton Recorder (Davis et al., 1992), some of the taxon-specific questions related to how the distribution of plankton and particles correlate with physical variables on scales from millimeters to kilometers can be addressed (Davis et al., 2004). Such high resolution biological/physical sampling can lead to new insights into the underlying processes controlling plankton distributions in the sea. Plankton data collected with nets often have broad confidence intervals with little detailed information on horizontal and vertical distribution. The VPR is designed to sample non-invasively the micro-distribution and 
environment of individual plankton over relatively large spatial scales. Fragile forms such as gelatinous zooplankton, colonial phytoplankton (e.g., Chaetoceros socialis), and marine snow are sampled optically in their natural state without damage, thus providing information not obtainable by conventional sampling equipment such nets, bottles and pumps. Traditional sampling also requires the tedious and time-consuming task of plankton sample identification analysis.

The resulting high-resolution data can be examined using multivariate analysis such as principle component analysis and power spectrum analysis (Mariano et al., 1996; Ashjian et al., 2001). High-resolution sampling can provide a better estimate of the underlying statistics of the plankton and their association with environmental variables. The VPR system is providing insights into the planktonic environment through rapid sampling as well as providing time series of $2 \mathrm{D}$ and $3 \mathrm{D}$ snapshots of the dynamical pelagic environment.

\subsection{Plankton Distributions}

The different plankton taxa observed each had characteristic patterns in relation to the hydrography, with the exception of copepods which were everywhere abundant. As for C. socialis, previous studies of the distributional pattern of this species were limited due to the difficulty in sampling this delicate organism (Sieracki et al., 1998; Gallager et al., 1996). Plankton nets can easily become clogged with the mucilaginous material from these colonies in regions of high abundance. The colonies are easily fragmented when sampled through the spigot of a Nisken or GoFlo bottle and totally destroyed by net and pump sampling (Davis et al., 1996, 2004). The non-invasive sampling of the VPR proved essential in obtaining accurate estimates of population abundance for this important diatom species. From the present study and other VPR cruises since 1993, $C$. socialis has been found to occur in great abundance along thermocline and southern pycnocline (Davis et al., 1996; Gallager et al., 1996, 2004; Sieracki et al., 1998). C. 
socialis is seldom found in Georges Bank Water per se, while there is a significant abundance in the heterogeneous shelf-slope mixing region. A possible reason might be higher nutrients brought in with the Slope Water. Like other phytoplankton, C. socialis growth may be nutrient-limited above the thermocline, so that growth in the nutrient-rich, interface water may be enhanced.

Marine snow is also easily destroyed in conventional sampling methods (Davis et al., 1996). But marine snow scatters light well, and thus we could quantify the distributional patterns using the VPR. Marine snow was most abundant in the lower half of the water especially in the northern sections. This pattern is similar to the distributional pattern of phytoplankton species in the well-mixed region and we might infer that the marine snow in the studied region was produced in part by phytoplankton decomposition (Herren et al, 2004; Norrbin et al., 1996). During VPR 4, marine snow biomass was much less at night than during the day (computed but not shown here). Late in the morning, marine snow concentrations were about threefold higher than during the night. The plausible mechanism might be that some part of marine snow was decomposed by microbes or had been consumed by zooplankton (Dilling, 2004; Herren, 2004; Newell, 2005). Marine snow plays an important role in ocean carbon cycling and food web structure (Ransom, 1998).

The association of rod-shaped diatoms with the well-mixed area, and with the surface layer over the outer shelf, indicates two different taxonomic components to this group. It is likely that the diatom rod observed comprised different species in these two areas. Marine snow was plentiful in both these regions as well and these diatoms may have contributed to their formation. The observed northward recirculation within the wellmixed region may serve to retain the diatom rods growing on the crest of the bank.

The medusae also were more abundant in the shallower regions of the bank as has been previously found (Bigelow, 1926; Madin et al., 1996). The association of these 
organisms with the Georges Bank water reveals their origin in the well-mixed area. These medusae and their polyp counterparts are thought to be important predators of copepods and larval fish on the bank. Their location in the shallow regions of the bank serves to reduce their advective loss from the region.

\subsection{Diel Vertical Migration}

Diel vertical migration (DVM) by zooplankton is a universal feature in the world ocean, as well as being common in freshwater environments (Kouassia , 2001; Hays, 2003). No diel migration was observed for either copepods or medusa during VPR4 (the 24 hour Lagrangian survey around the drifter). The weighted mean depth of copepod abundance remained at an approximately constant distance off the bottom, following the shape of the bottom topography. Their abundance was essentially the same during both day and night. This non-migratory result was similar with prior studies in this region (Ashjian el al., 2001; Hays, 1995), while it was different from many other DVM studies such as that in a Gulf Stream meander crest (Mariano et al,1996). DVM in zooplankton is usually assumed to be a way of balancing predation risk and growth, factors which both tend to increase towards the surface (Fiksen et al., 1998; Dale, 1999). For copepods exposed to visual predators, diel migration is generally expressed by an alternation between foraging in the upper, food-rich layers by night, and avoiding predators by migrating to depth during day. This relationship is a function of predator abundance (Bollens et al., 1989; Martin,1996) and food availability (Gliwicz et al., 1988). It is known that Calanus finmarchicus do not typically migrate vertically during their spring growth phase, but rather stay at the surface both day and night. Other copepods may behave similarly in this region. The lack of DVM may be indicative of abundant food throughout the water column or a lack of significant abundance of predators. The observed lack of DVM, enabled us to use passive (non-migrating) particles in the Lagrangian modeling study of plankton transport through the RLR. 


\subsection{Water masses and plankton}

This study provides a high resolution, 3-dimensional view of the mosaic of water types in the RLR. The complexity of the mosaic is due, in part, to interactions among the four distinct hydrographic regimes that converge in the south west corner of Georges Bank: (i) the well-mixed Georges Bank water; (ii) the Mid-Atlantic Bight shelf; (iii) the slope; and (iv) water overlying the continental shelf and slope. The Georges bank water is distinguished by its homogeneity vertically and horizontally (Flagg, 1987). In the RLR, temperature is centered in $8.96{ }^{\circ} \mathrm{C}$, and salinity is centered at 31.86 with variance less than 0.12. In the shallow, central region of Georges Bank, strong tidal currents keep the water column well mixed year round (Flagg, 1987). The boundary between well mixed bank water and the stratified region is referred to as the tidal mixing front (Mountain, 1996). This front is seen in the temperature, salinity, and density plots to be located close to the $60 \mathrm{~m}$ isobath (Figs. 4, 5, 7).

In the well-mixed bank water, chlorophyll values are relatively uniform throughout the water column except for a high abundance patch in western corner. In the stratified region, a near surface maximum in chlorophyll was associated with the density stratification, while very low fluorescence was found elsewhere in the water column. In general, fluorescence was greater in the well-mixed region than in the stratified water on the southern flank of the bank. The florescence peak in the mid-western sections was coincident with the large patch of $C$. socialis, and is likely due to this patch, since concentrations of $C$. socialis in this patch were so high ( 83 colonies/liter). The high fluorescence found in the offshore surface waters might be due to the influence of the warm core ring located south of the bank during this time. Ryan (2001) found that a similar Gulf Stream warm core ring influenced chlorophyll distributions along the southern flank of Georges Bank between the 60-m isobath and the shelf-break front during May through mid-June. This Gulf Stream ring caused an intrusion of salty 
nutrient-rich water onto the shelf, enhancing phytoplankton growth and causing higher fluorescence in this region (Ryan, 2001).

The aim of the factor analysis was to investigate the correlation between hydrographic features and plankton abundances. In VPR 2-3, the first 3 factors accounted for $80.14 \%$ of the total variance, while in VPR 5-6 and VPR 7 the first 4 factors contributed $81.25 \%$ and $76.17 \%$, respectively. The difference in the factor analysis result for the three tows implies that the water masses were not quite the same, although they are close proximity to each other. The north-south sections of VPR 2-3 formed the eastern, in-flow boundary of the RLR and the water entering through this section is expected to be most similar to that in the RLR itself. The east-west, north-south, zigzag grid of VPR 5-6 sampled the interior of the RLR, while the east-west transect of VPR 7 sampled the northern boundary of the RLR. For VPR5-6, the first principal component was characterized by a highly positive correlation between salinity and density, whereas temperature influenced density only in VPR 7.

Copepod abundance constituted a unique factor in VPR 5-6 and VPR 7. In VPR 2-3, copepods combined with diatom rods constituted a second important factor. Copepods were decoupled from the hydrographic features as this numerous zooplankton taxon was distributed throughout the RLR and was independent of water mass. C. socialis was constrained to a narrow hydrographic environment except for the lower concentrations in VPR 7. This species was negatively related to temperature, reflecting their affinity for colder water, especially in the cold pool per se. Unlike $C$. socialis, the diatom rods were associated with slightly warmer water. Interestingly, diatom rods had no correlation with florescence and appeared to have an inverse relationship with florescence in VPR 7. This result is in contrast with the apparently similar $3 \mathrm{D}$ spatial distribution of this taxon and fluorescence, with uniformly moderate concentrations in the northern region and higher levels in the offshore surface waters. Likewise, $C$. socialis had no influence on fluorescence, despite the close association between fluorescence and the dense patch of 
this species in the mid-western portion of the RLR. The lack of correlation between these two large diatom taxa and fluorescence could indicate that other phytoplankton species, too small to be observed with the VPR, were responsible for the high fluorescence values. Alternatively, the correlation could have been low due to the separation of the two phytoplankton taxa in the analysis. In VPR 5-6, light attenuation was highly correlated with fluorescence which does suggest that some small particles (other phytoplankton) may contribute to the fluorescence. High fluorescence observed in the upper water at the southern end of the transects could have been due to diatom rods, while the high fluorescence at mid-depths in the mid-western RLR may have been due to the $\mathrm{C}$. socialis patch. But these patterns were not found in the factor analysis for some unknown reason.

\subsection{Spectral Analysis}

The power spectral density curves revealed little useful information other than showing that the biology was more variable than the physics. The dominant peaks in the spectra were caused by the VPR undulating vertically through a stratified water column. The higher variation in the biological variables is expected since these variables are nonconservative and are influenced by exponential growth and death factors. A further analysis of the spectral components as a function of 3D space is the subject of future research.

\subsection{Retention-loss}

Georges Bank is well known as a highly productive marine area with large commercial fish yields (Backus, 1987). The retentive nature of the clockwise bank circulation is thought to be responsible for maintaining high zooplankton stocks and larval fish survival (e.g., Davis, 1984; Lough and Bolz, 1989, GLOBEC, 1992). This clockwise recirculation is due to a combination of tidal rectification, wind-forcing, and density driven geostrophic flow around the roughly ellipsoidal bathymetry (Butman et al., 1987). 
Although it occurs year around, the clockwise circulation pattern is thought to strengthen markedly with the onset of vernal stratification, yielding strong around-bank flow. During winter and early spring, most of the water is not retained on the bank and instead flows off the bank to the southwest through the so-called retention-loss region (RLR). With the progression of spring the water in the RLR is thought to increasingly flow northward and re-circulate around the bank. This re-circulation serves to retain plankton on the bank.

Flux calculation method have the potential to be misleading when the nondivergent flow is strongly dominant over the divergent flow. Thus the estimate of divergent or convergent flux or the next flux through a section might be significantly in error if the velocities do not balance. If given the whole flow fields through all four sides of the RLR, the flux of water can be calculated to see whether it is balanced. And then the flux of particles for four walls will be more reliable.

The results of this VPR study in the RLR during June 1997 indicate that this region was not retentive to plankton, since the bulk of the flow remained to the southwest, despite the presence of a vernally warmed surface layer. The bulk of the plankton was carried out of this area through the southern and western boundaries of the RLR. The net flux of all the plankton taxa was to the west and south, not to the north. Thus the concept that Georges Bank retains plankton during this time of year needs to be reconsidered. Careful study of the processes controlling plankton distributions and transport within the RLR needs to be done in order to quantify the gyre closure and retention of plankton. Each year and season may well be different and need to be assessed on a case-by-case basis.

\subsection{Significance of results}

This study provides essential information on the processes affecting gains and losses of plankton from the retention-loss region of Georges Bank during late spring/early summer. 
In a larger context, insights and data gained from this study will be used together with information on bank-wide population structure (broad scale cruises) and vital rates in GLOBEC modeling studies of the processes controlling plankton populations on the bank. The overall GLOBEC Georges Bank Program is providing new insights into the dynamics of pelagic marine systems including population dynamics of the dominant zooplankton, larval fish food availability, and potential effects of changing climate forcing on zooplankton population abundance. Information obtained here can be used as part of the larger goal to assess or predict the potential fate of these populations under various global climate change scenarios. 
References:

Ashjian, C. J. and Davis, C. S., 1997. Cruise Report. R/V ENDEAVOR Cruise 302 to Georges Bank. June 9-22, 44 pp.

Ashjian, C. J., Davis, C.S., Gallager, S.M., Alatalo,P., 2001. Distribution of plankton, particles, and hydrographic features across Georges Bank described using the Video Plankton Recorder .Deep Sea Research Part II: Topical Studies in Oceanography, Volume 48, Issues 1-3, Pages 245-282

Backus, R. H., 1987. (ed.) Georges Bank, MIT Press, Cambridge, MA, 593 pp.

Bigelow, H. B. 1926. Plankton of the Offshore Waters of the Gulf of Maine. Bull. Bur. Fish., 40, (Part 2, Document No. 968):1-509.

Bollens, S. M., and Frost, B. W. 1989. Zooplanktivorous fish and variable diel vertical migration in the marine planktonic copepod Calanus pacificus. Limnology and Oceanography, 34: 1072-1083.

Broughton, E. and Lough, R. G., A direct comparison of $1-\mathrm{m}^{2}$ MOCNESS and Video Plankton Recorder zooplankton abundance estimates: possible applications for augmenting net sampling with video systems. (Submitted to Deep Sea Res. II)

Butman, B., Loder, J.W. and Beardsley, R.C., 1987. The seasonal mean circulation: observation and theory. In: Backus, R.H. and Bourne, D.W., Editors. Georges Bank, MIT Press, Cambridge, MA, pp. 125-138

Chen, C., Liu, H., Beardsley, R.C., 2003. An unstructured, finite-volume, threedimensional, primitive equation Oceanography model: application to coastal Oceanography and estuaries. Journal of Atmospheric and Oceanic Technology 20, 159-186.

Chen, C., Beardsley, R., 1998. Tidal mixing and cross-frontal particle exchange over a finite amplitude asymmetric bank: A model study with application to Georges Bank. Journal of Marine Research 56, 1163-1201.

Cura. J., 1987. Phytoplankton. In: Georges Bank. R. H. Backus (ed.), MIT Press. pp. 213-219.

Dale, T., 1999. Distribution and life cycle of Calanus.Limnology and Oceanography, 25, 597-609.

Davis, C.S., Wiebe, P.H., 1985. Macrozooplankton Biomass in a warm-core Gulf Stream Ring:Time series changes in Size structure,Taxonomic composition and vertical distribution. Journal of geophysical research 90,NO.C5, pp.8817-8884.

Davis, C. S. 1987a. Zooplankton Life Cycles. In: Georges Bank. R. H. Backus (ed.), MIT Press. pp. 256-267. 
Davis, C. S. 1987b. Components of the zooplankton production cycle in the temperate ocean. J. Mar. Res., 45, 947-983.

Davis, C. S., Gallager, S. M. , Solow, A. R., 1992a. Microaggregations of oceanic plankton observed by towed video microscopy. Science 257, 230-232.

Davis, C. S., Gallager, S. M., Berman, M. S., Haury, L. R., Strickler, J. R., 1992b. The Video Plankton Recorder (VPR): Design and initial results. Arch. Hydrobiol. Beih., 36, 67-81.

Davis, C. S., Gallager, S. M., Marra, M., Stewart, W. K. 1996. Rapid visualization of plankton abundance and taxonomic composition using the Video Plankton Recorder. Deep Sea Research. II, 43, 1947-1970.

Davis, C. S., Hu, Q. , Gallager, S. M. , Tang, X. , Ashjian, C. A., 2004. Real-time observation of taxa-specific plankton distributions: An optical sampling method. Mar. Ecol. Prog. Ser., 284, 77-96.

Davis, C. S., F. Thwaites, S. M. Gallager, and Q. Hu. 2005. A three-axis fast-tow digital Video Plankton Recorder for rapid surveys of plankton taxa and hydrography. Limnol. Oceanogr., Methods, 3, 59-74.

Davis, J.C., 1986, Statistics and Data Analysis in Geology, 2th Edition. John Wiley and Sons,New York, $646 \mathrm{pp}$.

Dilling, L., Alldredge, A.L., 2000. Fragmentation of marine snow by swimming macrozooplankton: A new process impacting carbon cycling in the sea, Deep Sea Research Part I: Oceanographic Research Papers, Volume 47, Issue 7, Pages 1227-1245

Evans, G. T. 1978. Biological effects of vertical-horizontal interactions, In: Spatial pattern in plankton communities, Plenum Press; New York, NY (USA), p.157179, NATO Conf. Ser., pt.4, v.3.

Fiksen, O., and Carlotti, F. 1998. A model of optimal life history and diel vertical migration in Calanus finmarchicus. Sarsia, 83: 129-147.

Fischer, J., and Visbeck, M. 1993. Seasonal variation of the daily zooplankton migration in the Greenland Sea. Deep-Sea Research I, 40: 1547-1557.

Flagg, C.N., 1987. Hydrographic structure and variability. In: Backus, R.H. and Bourne, D.W., Editors, 1987. Georges Bank, MIT Press, Cambridge, MA, pp. 106-124

Gallager, S. M., Davis, C. S. , Epstein, A. W. , Solow, A. , Beardsley, R. C. , 1996. Highresolution observations of plankton spatial distributions correlated with hydrography in the Great South Channel, Georges Bank. Deep Sea Res. II, 43, 1627-1664.

GLOBEC. 1991a. GLOBEC: Initial Science Plan. Report Number 1. 93 pp.

GLOBEC. 1991b. GLOBEC: Northwest Atlantic Program, GLOBEC Canada/U.S. Meeting on N.W. Atlantic Fisheries and Climate. Report Number 2.93 pp. 
GLOBEC. 1992. GLOBEC: Northwest Atlantic Implementation Plan. Report Number 6. $69 \mathrm{pp}$.

Gliwicz, M. Z., and Pijanowska, J., 1988. Effect of predation and resource depth distribution on vertical migration of zooplankton. Bulletin of Marine Science, 43: 695-709.

Gram, L., Grossart, H. P. , Schlingloff, A., and Kiorboe, T., 2002. Possible quorum sensing in marine snow bacteria: production of acylated homoserine lactones by Roseobacter strains isolated from marine snow. Appl. Environ. Microbiol. 68:4111-4116.

Greene, C. H., Pershing, A. J. , Conversi, A. , Planque, B. , Hannah, C. , Reid, P. C., Jossi, J. , Mountain, D. , Sameoto, D. , Head, E. , Benfield, M. C. , Smith, P. C., Wiebe, P. H., Durbin, T., 2003. Trans-Atlantic responses of Calanus finmarchicus populations to basin-scale forcing associated with the North Atlantic Oscillation. Progress in Oceanography, 58, 301-312.

Hardy, A. C. 1936. Observations on the uneven distribution of oceanic plankton. Discovery Reports, 11, 511-538.

Henrren,C.M., Alldredge, A.L., Case, J.F., 2004. Coastal bioluminescent marine snow: fine structure of bioluminescence distribution, Continental Shelf Research, Volume 24, Issue 3, Pages 413-429

Hays, G. C. 1995. Diel vertical migration behaviour of Calanus hyperboreus at temperate latitudes. Marine Ecology, Progress Series, 127: 301-304.

Hjort, J., 1914. Fluctuations in the great fisheries of northern Europe viewed in the light of biological research. Rapp. P.-V. Reun. Cons. Int. Explor. Mer, 20, 1-228.

Kaiser, H. F. , 1960. The application of electronic computers to factor analysis. Educational and Psychological Measurement, 20

Kouassia, E., 2001.Vertical Migrations and Feeding Rhythms of Acartia clausi and Pseudodiaptomus hessei (Copepoda:Calanoida) in a Tropical Lagoon (Ebrie', Co^ te d'Ivoire),Coastal and Shelf Science, Estuarine, 52, 715-728

Lough, R. G., Bolz, G. R., 1989. The movement of cod and haddock larvae onto the shoals of Georges Bank. J. Fish. Biol., 35 (Supplement A): 71-79.

Lough, R. G., Trites, R. W., 1989. Chaetognaths and oceanography on Georges Bank. J. Mar. Res., 47, 343-369.

Lough, R. G. and Manning, J.P. , 2001. Tidal-front entrainment and retention of fish larvae on the southern flank of Georges Bank,Deep Sea Research Part II: Topical Studies in Oceanography, Volume 48, Issues 1-3, Pages 631-644

Lynch, D. R., Ip, J. T. C., Naimie, C. E. , Werner F. E., 1996. Comprehensive coastal circulation model with application to the Gulf of Maine, Continental Shelf Res., 16: 875-906. 
Lynch, D.R., Naimie, C.E. and Hannah, C.G., 1998. Hindcasting Georges Bank circulation, Part I: detiding. Continental Shelf Research, 18: 607-639.

Lynch, D.R. et al., 2001. Real-time data assimilative modeling on Georges Bank. Oceanography, 14: 65-77.

Mardin,L.P., Bollens, S.M., Horgan, E., Butler, M., Runge, J., Sullivan, B.K., KleinMacPhee, G.K., Durbin, E., Durbin, A.G., Van Keuren, D., Plourde, S., Bucklin, A. and Clarke, M.E., 1996. Voracious planktonic hydroids: unexpected predatory impact on a coastal marine ecosystem. Deep-Sea Research 43, pp. 1823-1830.

Mariano,A.J., Hitchcock, G.L., Ashjian, C.J., Olson, D.B., Rossby, T., Ryan, E. and Smith, S.L., 1996. Principal component analysis of biological and physical variability in a Gulf Stream meander crest. Deep-Sea Research 43, pp. 1531-1565

Mountain, D.G., Taylor, M.H. ,1996. Fluorescence structure in the region of the tidal mixing front on the southern flank of Georges Bank,Deep Sea Research Part II: Topical Studies in Oceanography, Volume 43, Issues 7-8, Pages 1831-1853

Newell, C.R, Pilskaln, C.H., Robinson, S.M., MacDonald B.A., The contribution of marine snow to the particle food supply of the benthic suspension feeder, Mytilus edulis, Journal of Experimental Marine Biology and Ecology, In Press, Corrected Proof, Available online 17 March 2005

Norrbin, M. F., C. S. Davis, and S. M. Gallager. 1996. Differences in fine-scale structure and composition of zooplankton between mixed and stratified regions of Georges Bank. Deep Sea Res. II, 43, 1905-1924.

Ransom, B., Shea, K.F., Burkett, P.J., Bennett, R.H., Baerwald, R. , 1998. Comparison of pelagic and nepheloid layer marine snow: implications for carbon cycling ,Marine Geology, Volume 150, Issues 1-4, Pages 39-50

Reyment, R. and K.G. J“oreskog, 1993, Applied Factor Analysis in the Natural Sciences, Cambridge,University Press, New York, 371 p.

Ryan, J. P., Yoder, J. A., Townsend, D. W.,2001. Influence of a Gulf Stream warm-core ring on water mass and chlorophyll distributions along the southern flank of Georges Bank, Deep Sea Research Part II: Topical Studies in Oceanography, Volume 48, Issues 1-3, Pages 159-178

Sieracki, M., Gifford, D., Gallager, S. M., Davis, C. S., 1998. Observations on a dense patch of the diatom, Chaetoceros socialis, on the southern flank of Georges Bank: Distribution, colony structure and grazing losses. Oceanogr., 11, 30-35.

Zar, J. H., 1974. Biostatistical Analysis. Prentice-Hall Inc., Englewood Cliffs, NJ, pp.105-108

Zheng, L.Y, 1999. A three-dimensional modeling study of estuarine system: An application to Satilla River, Georgia, M. S. Thesis. Athens, Georgia, University of Georgia. 